\title{
Developmental Rate and Behavior of Early Life Stages of Bighead Carp and Silver Carp
}

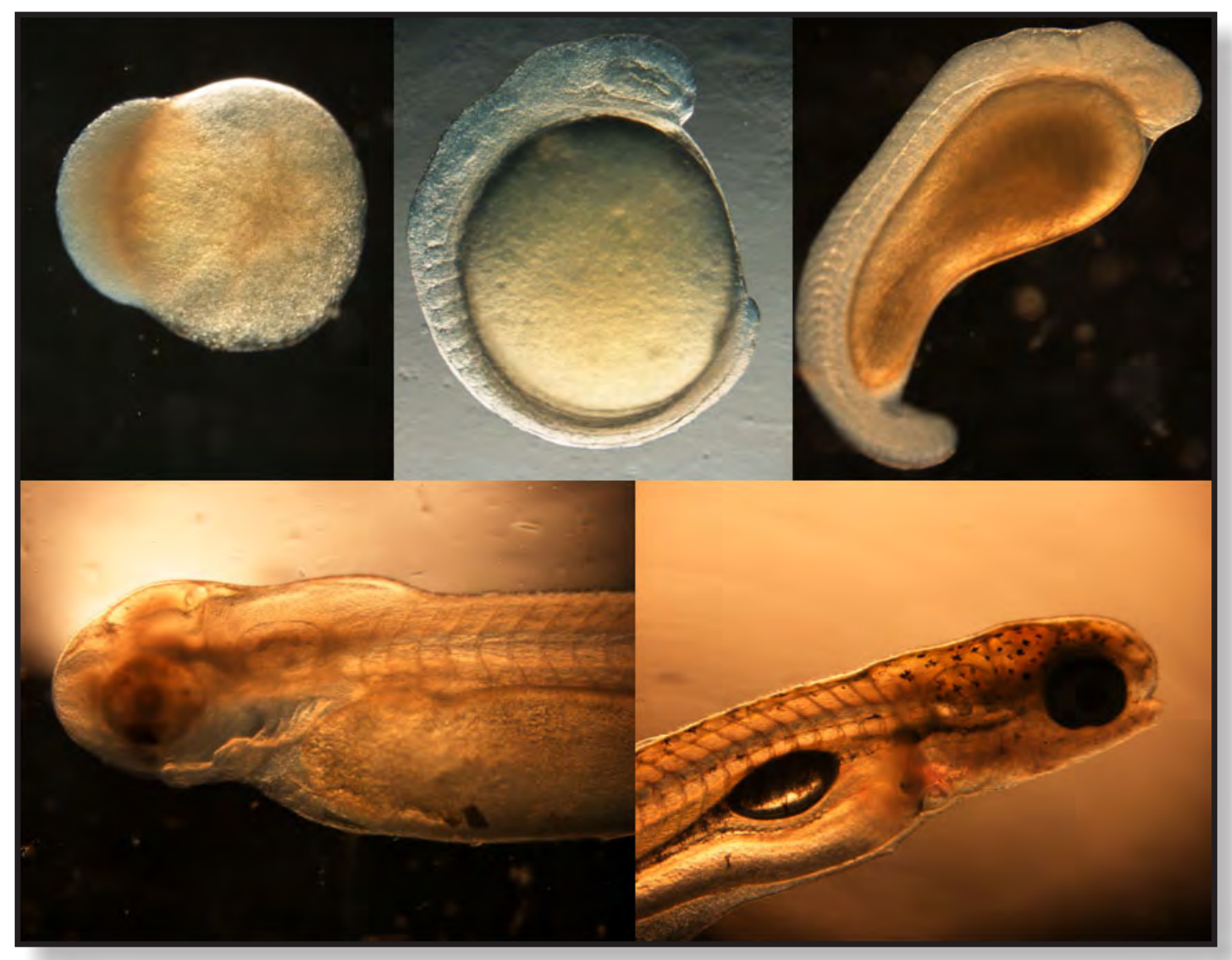

Scientific Investigations Report 2011-5076 
Cover images. Left to right (top) silver carp embryo at morula stage, silver carp embryo at olfactory placode stage, silver carp embryo at otolith appearance stage, (bottom) silver carp larvae at gill filament stage, silver carp larvae at one-chamber gas bladder stage. 


\section{Developmental Rate and Behavior of Early Life Stages of Bighead Carp and Silver Carp}

By Duane C. Chapman and Amy E. George

Scientific Investigations Report 2011-5076 


\section{U.S. Department of the Interior \\ KEN SALAZAR, Secretary \\ U.S. Geological Survey \\ Marcia K. McNutt, Director}

U.S. Geological Survey, Reston, Virginia: 2011

For more information on the USGS - the Federal source for science about the Earth, its natural and living resources, natural hazards, and the environment, visit http://www.usgs.gov or call 1-888-ASK-USGS.

For an overview of USGS information products, including maps, imagery, and publications, visit http://www.usgs.gov/pubprod

To order this and other USGS information products, visit http://store.usgs.gov

Any use of trade, product, or firm names is for descriptive purposes only and does not imply endorsement by the U.S. Government.

Although this report is in the public domain, permission must be secured from the individual copyright owners to reproduce any copyrighted materials contained within this report.

Suggested citation:

Chapman, D.C., George, A.E., 2011, Developmental rate and behavior of early life stages of bighead carp and silver carp: U.S. Geological Survey Scientific Investigations Report 2011-5076, 62 p. 


\section{Contents}

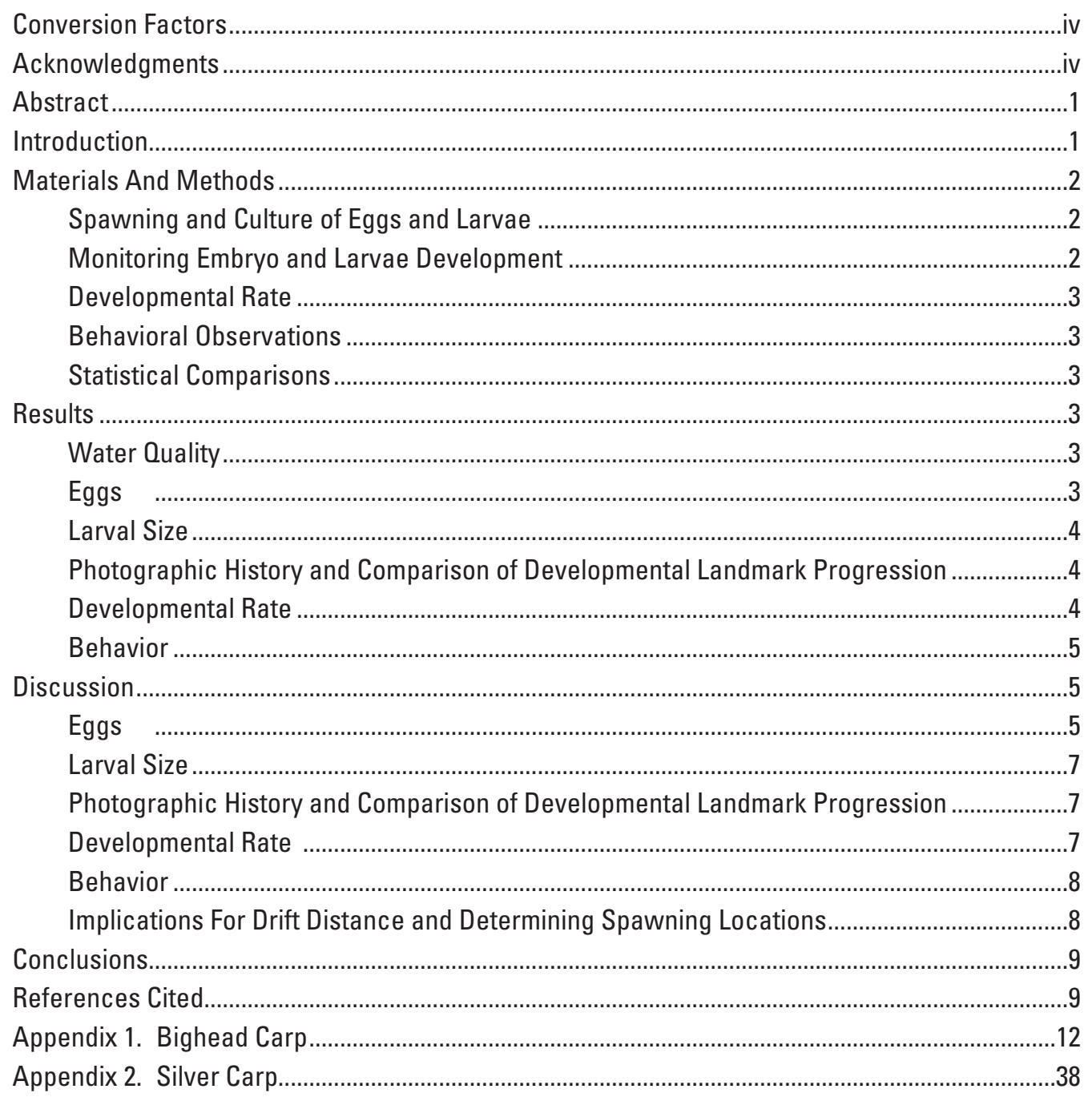

\section{Figures}

1. Size of bighead carp eggs in different temperature treatments with time .......................4

2. Size of silver carp eggs in different temperature treatments with time. ...........................5

4. Cumulative thermal units for embryonic development in silver carp using $11.1^{\circ} \mathrm{C}$ as $T_{\min }$

3. Cumulative thermal units for embryonic development in bighead carp using

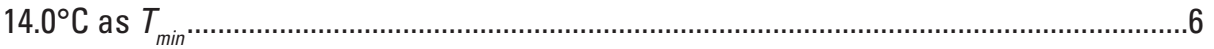

5. Windows Media Video of bighead carp swimming behavior at the hatching stage ........5

6. Windows Media Video of silver carp swimming behavior at the hatching stage ..............5

7. Windows Media Video of bighead carp swimming behavior after gas bladder inflation 


\section{Conversion Factors}

\begin{tabular}{lcl}
\multicolumn{1}{c}{ SI to Inch/Pound } & \multicolumn{1}{c}{ Multiply } & Bo obtain \\
\hline & Length & \\
\hline millimeter $(\mathrm{mm})$ & 0.03973 & inch (in) \\
kilometer $(\mathrm{km})$ & .62137 & mile (mi) \\
\hline & Mass & \\
\hline kilogram $(\mathrm{kg})$ & 2.20462 & pound, avoirdupois (lb) \\
\hline & Volume & fluid ounce (oz)
\end{tabular}

\section{Acknowledgments}

We thank Jeff Beasley, Elizabeth Brothers, Curt Byrd, James Candrl, Aaron Castillo, Andrew Cravens, Joe Helming, Gabe Nichols, Marie Pope, and Becky Welly of the U.S. Geological Survey for assistance with spawning and culture maintenance.

We also thank Joe Deters, Shannon Earhart, and Karthik Masagounder for assistance with spawning and culture maintenance. 


\title{
Developmental Rate and Behavior of Early Life Stages of Bighead Carp and Silver Carp
}

\author{
Duane C. Chapman and Amy E. George
}

\begin{abstract}
The early life stages of Asian carp are well described by Yi and others (1988), but since these descriptions are represented by line drawings based only on live individuals and lacked temperature controls, further information on developmental time and stages is of use to expand understanding of early life stages of these species. Bighead carp and silver carp were cultured under two different temperature treatments to the one-chamber gas bladder stage, and a photographic guide is provided for bighead carp and silver carp embryonic and larval development, including notes about egg morphology and larval swimming behavior. Preliminary information on developmental time and hourly thermal units for each stage is also provided. Both carp species developed faster under warmer conditions. Developmental stages and behaviors are generally consistent with earlier works with the exception that strong vertical swimming immediately after hatching was documented in this report.
\end{abstract}

\section{Introduction}

Bighead carp and silver carp (together, the bigheaded carps) are large cyprinids native to eastern Asia, and are considered undesirable invasive species in North America (Conover and others, 2007). They were brought to the United States in the early 1970s and quickly escaped captivity. Since the 1990s, populations of these fishes in the Mississippi River Basin have expanded exponentially and have become problematic (Kolar and others, 2007). There is now great concern that bigheaded carps will invade the Laurentian Great Lakes and damage those important recreational and commercial fisheries (Conover and others, 2007).

Bigheaded carps are thought to have precise requirements for the survival and recruitment of the eggs and larvae. The eggs of bigheaded carps are laid in turbulent areas and the eggs and larvae develop while drifting downstream. The eggs are slightly negatively buoyant and must be held in suspension by water turbulence or they will settle to the bottom, where they are thought to perish. Kolar and others (2007) summarized the extensive literature on this topic. It is unclear from the literature if the larvae also have similar requirements, but it is clear that in large rivers where these fishes are known to spawn and recruit successfully, there is a long phase of larval drift.

Yi and others (1988; English translation available in Chapman, 2006) developed an excellent guide to the identification of bigheaded carps and of the sequential stages of their development. They divided the early life history of these species (and of grass carp and black carp) into a total of 48 developmental stages, the first 30 encompassing fertilization to hatching, and the rest encompassing the remainder of development until squamation. The study of Yi and others (1988) was performed on eggs and fishes captured from the Yangtze River in the 1960s (publication was delayed by the cultural revolution; Chapman and Wang, 2006). The researchers did not have the capability for photographic microscopy, or for tight control of temperature during development. Contrary to standard North American practices, all drawings and descriptions of different developmental stages were generated from live fishes; no fishes were preserved in that study, as is usual in North America. Some features used by Yi and others (1988) to identify these fishes and their developmental stages are less visible in preserved specimens (Chapman and Wang, 2006).

The first objective of this study was to estimate the combination of temperature and time required for development of bigheaded carp larvae to any given stage. This, along with velocity and a longitudinal dispersal estimate, is required to model the length of a river needed for recruitment of bigheaded carps. The second objective was to develop a photographic life history of bigheaded carps using preserved specimens and some live specimens to complement the line drawings of Yi and others (1988). The third objective was to evaluate the developmental landmarks of Yi and others (1988), which were developed for eggs and fishes collected from the Yangtze River in the 1960s, relative to North American fishes, to ensure that no substantial differences in the progression of those landmarks were observed that might complicate or invalidate work based on the developmental stages of Yi and others (1988). The fourth and final objective was to observe the swimming behavior of the fish at different developmental stages. Swimming stages would not require current to avoid 
sinking to the bottom and, therefore, time required to develop to this stage may be important in defining the minimum river length required for recruitment of bigheaded carps.

\section{Materials And Methods}

\section{Spawning and Culture of Eggs and Larvae}

All water used was Columbia Environmental Research Center well water, which has a hardness of 260-280 milligrams per liter $(\mathrm{mg} / \mathrm{L})$ as calcium carbonate $\left(\mathrm{CaCO}_{3}\right)$ and alkalinity of $230-240 \mathrm{mg} / \mathrm{L}$ as $\mathrm{CaCO}_{3}$. For both experiments, one each with bighead and silver carp, two temperature treatments were used to culture eggs and larvae in the lab. Each temperature treatment consisted of 10 aquaria that were each equipped with a modified MacDonald hatching jar (450-millimeter $(\mathrm{mm})$ tall and $130-\mathrm{mm}$ internal diameter) and a small submersible pump to recirculate water from the aquarium into the hatching jar, and to provide an upwelling current to keep the eggs suspended in the water column within the jar. Jars were equipped with surface screens to avoid any eggs escaping into the aquarium before hatching. In the "warm" treatment, temperature was maintained above ambient through the use of a heated water bath. In the "cold" treatment, temperature was maintained by room temperature. The temperatures chosen for the two temperature treatments reflect conditions that would be common during spawning times of bigheaded carps in North American waters, but do not represent the range of temperature tolerance of the two species, nor all the conditions that could be encountered by wild populations. The optimum temperature for development is also unknown. All aquaria were provided with a slow flow-through of well water. Temperature was monitored continuously with $\mathrm{HOBO}$ temperature loggers (Onset Computer Company, model Pro-v2) recording at 15 -minute intervals.

Adult bighead carp were obtained from Osage Catfisheries on June 11, 2010, and adult silver carp were obtained from the Missouri River on June 28, 2010. Fishes were held at the Columbia Environmental Research Center in 1,500 liter flow-through fiberglass tanks at $24-26^{\circ} \mathrm{C}$. Fish were evaluated for spawning readiness upon arrival (bighead carp) or capture (silver carp). Fish were anesthetized with MS-222, after which males were evaluated for the presence of milt after gently applying pressure to the abdomen and females were evaluated by inserting a catheter into the urogenital pore and collecting egg samples. Eggs were placed into a clearing solution (60 percent ethanol, 30 percent formalin, 10 percent acetic acid) and the location of the germinal vesicle was used to determine if the female would be used for hormone induction.

Two female bighead carps were selected for hormone induction, weighing 7 kilogram $(\mathrm{kg})$ and $8 \mathrm{~kg}$. Females initially received an intramuscular injection of 200 international units per kilogram (IU/kg) Human Chorionic Gonadotropin (HCG) on June 13, 2010. A resolving dose of 4 milligrams per kilogram $(\mathrm{mg} / \mathrm{kg})$ carp pituitary gland was given 6 hours later as an intraperitoneal injection. Three males $(6.5,7$, and $8.75 \mathrm{~kg}$ ) received a $4 \mathrm{mg} / \mathrm{kg}$ intraperitoneal carp pituitary injection 16 hours before the expected ovulation period. Doses and timing were based on Jhingran and Pullin (1985). Eggs were fertilized with a mixture of milt from three males.

Adult silver carp were obtained from the Missouri River on June 28, 2010. One female, weighing $3.75 \mathrm{~kg}$, was selected for hormone induction. The female initially received an intramuscular injection of 600-IU/kg Human Chorionic Gonadotropin (HCG) on June 28, 2010. A resolving dose of $4 \mathrm{mg} / \mathrm{kg}$ carp pituitary gland was given 6 hours later as an intraperitoneal injection. Two males ( 3.75 and $4 \mathrm{~kg}$ ) received a $4 \mathrm{mg} / \mathrm{kg}$ intraperitoneal carp pituitary injection 16 hours before the expected ovulation period, and the eggs were fertilized with a mixture of milt from these two males.

Milt was collected into plastic tubes on the morning of fertilization and stored in beakers on ice until use. Milt quality was evaluated by checking percentage of active sperm and duration of motility. On the morning of the day following initial hormone injection, 30 minutes after the initial release of eggs was observed, eggs were hand-stripped into a bowl and fertilized by the dry method (Piper and others, 1982) for 1 minute, then rinsed and placed into water baths for a 30-minute water-hardening period. Two water baths were used, one "cold" treatment and one "warm" treatment, matching the temperature in the hatching jars where the eggs were stocked.

After 30 minutes, eggs were placed into hatching jars at a density of 50 milliliters, $(\mathrm{mL})$ of eggs per jar, and with 10 jars per temperature treatment. Water flow was adjusted so that eggs were kept in suspension in the water column within the jar, but did not impinge on the screen lids. Because the eggs changed in buoyancy throughout the first 2 hours, it was necessary to frequently adjust the flow rate during that time to avoid impingement of eggs on the surface screen. Waterquality indicators (dissolved oxygen, $\mathrm{pH}$, hardness, conductivity) were measured in the jars before stocking, and again following breakdown of the experiment.

During the hatch, the screens were removed and the fish were allowed to escape the hatching jars into the aquarium. The pumps and hatching jars were then removed, and the fishes were maintained in the aquarium through 12 days post-fertilization ("cold" water treatment of bighead carp) and 8 days post-fertilization (both silver carp treatments and "warm" water treatment of bighead carp).

\section{Monitoring Embryo and Larvae Development}

Before hatching, three to six eggs from each temperature treatment were removed from hatching jars by a suction device at intervals of 15-30 minutes. After hatching, three larvae from each treatment were removed from tanks at $4-8$ hour intervals, using either a dip net or a suction device. Because later stages were longer in duration, the intervals at which evaluations were made increased with time. Samples were 
removed from alternating jars and tanks in sequential order. Eggs and larvae were examined and photographed under a Nikon SMZ 1500 stereoscopic microscope (7.5x-112.5x total magnification) with camera attachment (Nikon DS-Fi1, 5 megapixel), noting developmental stage and any abnormalities. Measurements of live egg membranes and larval fish total length were taken using Nikon Elements software. Because eggs generally are not perfect spheres, the reported egg measurements are the mean of two perpendicular diameters.

When necessary, MS-222 was used to anesthetize eggs and larvae for live photography. After live photography, eggs and larvae were preserved in 10 percent buffered formalin in 25 -mL scintillation vials. Embryos and larvae were staged and photographed again after preservation. When necessary, egg membranes were removed for image clarity.

Timing for developmental stages was based on the recorded time of the first individual of each temperature treatment found at a particular stage. All stages were based on the definitions of Yi and others (1988), and were not counted until the stage could be considered complete (for example, a larva would not be considered in the melanoid eye stage until the eye was completely darkened).

\section{Developmental Rate}

For poikilotherms, the total amount of thermal energy experienced with time is strongly related to speed of early development of embryos and larvae and of sexual maturation of adults (Schmidt-Nielson, 1995). However, there is no standard way to account for this parameter. A wide variety of acronyms, terminology, and methods for calculation have been used. Terms that have been used include T.U. (Temperature Units; Leitritz and Lewis 1976), HTU (Hourly Temperature Units; Piper and others, 1982), ATU (Accumulated Temperature Units; Lattuca and others, 2008), CTU (Celsius Temperature Units; Kynard and Parker, 2005; or Cumulative Temperature Units; Zhu and others, 2006), and degree-days (Guma'a, 1978; Gorbach and Krykhtin, 1981; Hamel and others, 1997). These have individually been defined in various ways using different intervals of time and different temperature scales (Piper and others, 1982). Most often, zero on the temperature scale is used as the base value (Leitritz and Lewis, 1976; Kynard and Parker, 2005; Burrill and others, 2010) but, in some cases, time periods that do not exceed some particular temperature value are excluded (Gorbach and Krykhtin, 1981) or temperature is scaled by counting number degrees over a "thermal minimum" (Guma'a, 1978) or "thermal constant" (Berven, 1982). In these last cases, the cumulative thermal value, assuming constant temperature, is determined by a formula similar to

$$
C T U=t\left(T_{c}-T_{\min }\right)
$$

where

$$
C T U \text { is the cumulative thermal unit, }
$$

\author{
$t$ is the time unit, \\ $T_{c} \quad$ is the temperature of treatment $c$, and \\ $T_{\min } \quad$ is the thermal minimum or thermal constant.
}

Berven (1982) stated that the thermal constant should be the temperature at which development ceases, and Guma'a (1978) implied that the thermal minimum should be the intercept of the regression line and the abscissa in equation relation between growth rate and temperature. In use, however, the goal of temperature scale change is to arrive at a formula whereby the cumulative thermal value is predictive of the developmental stage. This goal was accomplished by first plotting CTU (defined here as summation of hourly mean temperature in Celsius) by the developmental stage, and then iteratively determining the value for $T_{\min }$ in which the $C T U$ value was most similar for all developmental stages.

\section{Behavioral Observations}

Behavioral observations were made throughout the study, with particular attention on the initiation time and different types of swimming behavior. An attempt to determine the proportion of fish that exhibited any specific behavior was not attempted in this study. These were general observations on the behavior of the fish in the aquaria. Video of key behaviors (first swimming, beginning of horizontal swimming) was taken for documentation.

\section{Statistical Comparisons}

A Welch two-sample, two-sided $t$-test was used to evaluate differences in size between fully-hardened eggs cultured at different temperatures. The same test also was used to evaluate the differences in total length between temperature treatments at each stage of larval development.

\section{Results}

\section{Water Quality}

Regardless of temperature treatment, water-quality properties remained within ranges compatible with egg and larvae development (dissolved oxygen, 7.7-8.8 mg/L; $\mathrm{pH}, 8.1-8.2$; hardness, $230-300 \mathrm{mg} / \mathrm{L}$; conductivity, 600-700 microsiemens per centimeter $(\mu \mathrm{S} / \mathrm{cm}))$.

\section{Eggs}

Bighead carp eggs were generally larger than silver carp eggs. There were differences in the sizes between the two temperature treatments; after water hardening, eggs in the "cold" treatment tended to be smaller than in the "warm" water treatment (bighead carp: $5.14 \mathrm{~mm}$ compared to 5.42 
mm, probability $(p)<0.001$; silver carp: $4.12 \mathrm{~mm}$ compared to $4.46 \mathrm{~mm}, p<0.001$; figs. 1, 2). The egg membrane began to swell immediately upon exposure to water, and continued expansion for 3 to 4 hours, regardless of temperature, fertilization, or developmental state. Bighead carp eggs were approximately $1.6 \mathrm{~mm}$ in diameter before fertilization and swelled to a mean size of $5.3 \mathrm{~mm}$ (standard deviation $(\mathrm{SD})=0.58 \mathrm{~mm}$, with a range of $3.6-6.7 \mathrm{~mm}$ ) by 4 hours post fertilization (fig. 1), whereas silver carp eggs were approximately $1.4 \mathrm{~mm}$ in diameter before fertilization, and swelled to a mean diameter of $4.3 \mathrm{~mm}(\mathrm{SD}=0.45 \mathrm{~mm}$, with a range of $3.2-5.4 \mathrm{~mm})$ by 4 hours post fertilization (fig. 2).

\section{Larval Size}

Bighead carp in the hatching stage were significantly larger in the "cold" water treatments (approximately $5.5 \mathrm{~mm}$, $\mathrm{SD}=0.12 \mathrm{~mm})$ than in the "warm" water treatments $(5.8 \mathrm{~mm}$, $\mathrm{SD}=0.12 \mathrm{~mm})(p=0.016)$. At the gas bladder inflation stage, bighead carp were significantly larger in the "cold" water treatment $(8.55 \mathrm{~mm}, \mathrm{SD}=0.13 \mathrm{~mm})$ than in the "warm" water treatments $(7.97 \mathrm{~mm}, \mathrm{SD}=0.61 \mathrm{~mm})(p=0.011)$. Silver carp at the hatching stage in the "cold" water treatment were $5.55 \mathrm{~mm},(\mathrm{SD}=0.28 \mathrm{~mm})$ and $4.6 \mathrm{~mm}(\mathrm{SD}=0.45 \mathrm{~mm})$ in "warm" water treatments $(p=0.0036)$. At the gas bladder inflation stage, silver carp were significantly larger in "cold" water treatments $(8.2 \mathrm{~mm}, \mathrm{SD}=0.37 \mathrm{~mm})$ than in "warm" water treatments $(7.7 \mathrm{~mm}, \mathrm{SD}=0.14 \mathrm{~mm})(p=0.016)$. Sizes of live fish at all larval stages were smaller than reported by Yi and others (1988).

\section{Photographic History and Comparison of Developmental Landmark Progression}

Appendix 1 provides a photographic history, using preserved and live specimens, of the developmental stages of bighead carp as classified by Yi and others (1988). Appendix 2 is a similar history of silver carp. Line drawings from Yi and others (1988) are also provided when available. Landmarks were observed in the same order of progression as described by Yi and others (1988). The only difference noted was the later appearance of eyespots than described by $\mathrm{Yi}$ and others (1988). Eyespots were generally seen by stage 32, though not in hatching or embryonic stages (See appendix 1, figs. 1-31 and 1-32 and appendix 2, figs. 2-31 and 2-32).

\section{Developmental Rate}

In the silver carp test, the "cold" temperature was maintained at $19.6^{\circ} \mathrm{C}(\mathrm{SD}=0.1789)$ and the "warm" temperature was maintained at $22.5^{\circ} \mathrm{C}(\mathrm{SD}=0.10)$. In the bighead carp test, the "cold" temperature was maintained at $20.1^{\circ} \mathrm{C}$ $(\mathrm{SD}=0.39)$ and "warm" temperature was maintained at $22.3^{\circ} \mathrm{C}$ $(\mathrm{SD}=0.15)$. As expected, both species developed more rapidly at warmer temperatures (tables 1-1, 2-1). The best alignment of CTU to developmental stage for embryos between the two

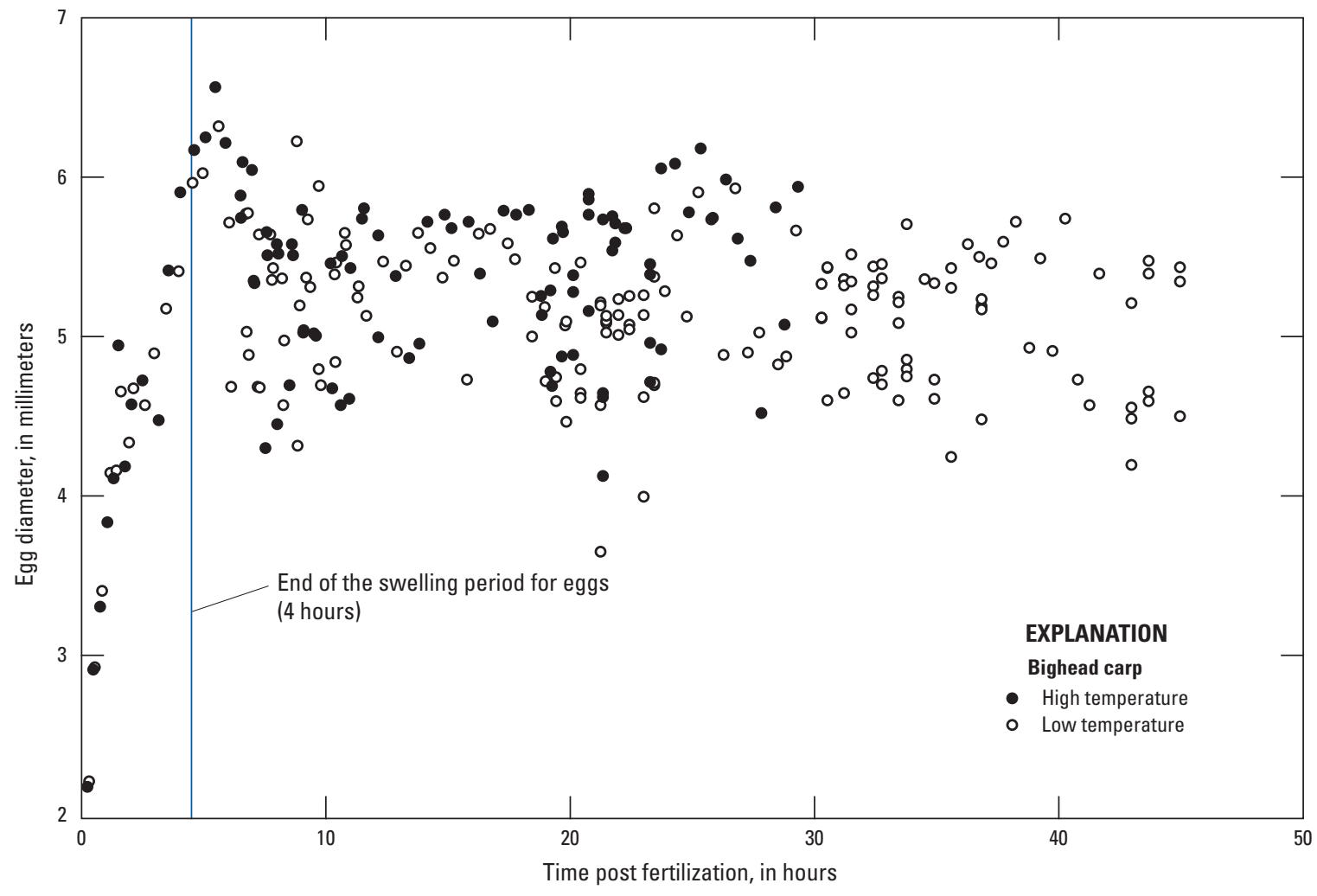

Figure 1. Size of bighead carp eggs in different temperature treatments with time. 


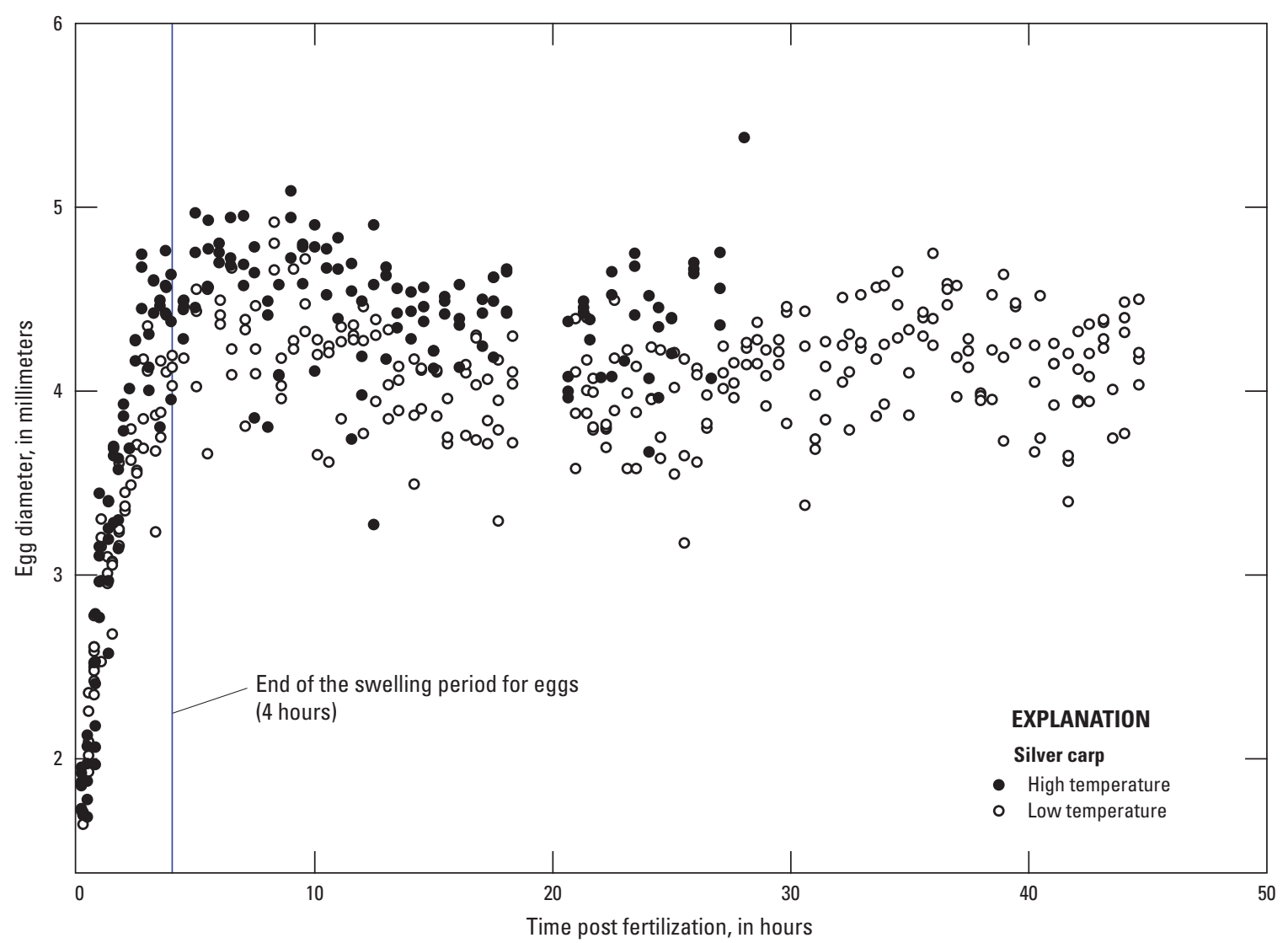

Figure 2. Size of silver carp eggs in different temperature treatments with time.

temperature regimes occurred with a $T_{\min }$ of $14.0^{\circ} \mathrm{C}$ for bighead carp (fig. 3) and $11.1^{\circ} \mathrm{C}$ for silver carp (fig 4).

\section{Behavior}

Bighead carp and silver carp were both more active in the later stages of embryonic development. Embryos in the late stages of development often required anesthesia with MS-222 for live microscope photography.

Both species of carp began swimming strongly immediately after hatching, but this swimming was almost vertical in its nature (fig. 5, Windows Media Video of bighead carp swimming behavior at the hatching stage; fig. 6, Windows Media Video of silver carp swimming behavior at the hatching stage). Larvae in aquaria strongly swam directly toward the surface, sometimes spiraling slightly, followed by a resting phase in which they ceased swimming and drifted headfirst toward the bottom. For both species, regardless of temperature, brief horizontal swimming behavior near the water surface began at stage 36 (melanoid eye) and, by stage 37 (gas bladder emergence), most fish were swimming horizontally most of the time. By stage 38 (gas bladder inflation), fish swam in a normal horizontal pattern at varying depths or rested without swimming. After inflation of the gas bladder, fish could maintain their position in the water column without swimming (fig. 7; Windows Media Video of bighead carp swimming behavior after gas bladder inflation).

\section{Discussion}

\section{Eggs}

For both species and all temperature treatments, the average egg diameter documented in the study is on the low end of the ranges reported by Yi and others (1988) from the Yangtze River. Silver carp eggs were slightly smaller than those reported by Murty and others (1986) and bighead carp eggs were slightly smaller than reported by Chapman and Deters (2009). Egg size is highly variable and dependent on a number of factors, including environmental gradients and maternal effects (Johnston and Leggett, 2002), and the ionic composition of the rearing water (Fuiman and Trojnar, 1980). Rach and others (2010) found that water-hardened silver carp egg size was affected by hardness and that eggs hardened in soft $\left(50 \mathrm{mg} / \mathrm{L}\right.$ as $\left.\mathrm{CaCO}_{3}\right)$ water similar to that of the Yangtze River 


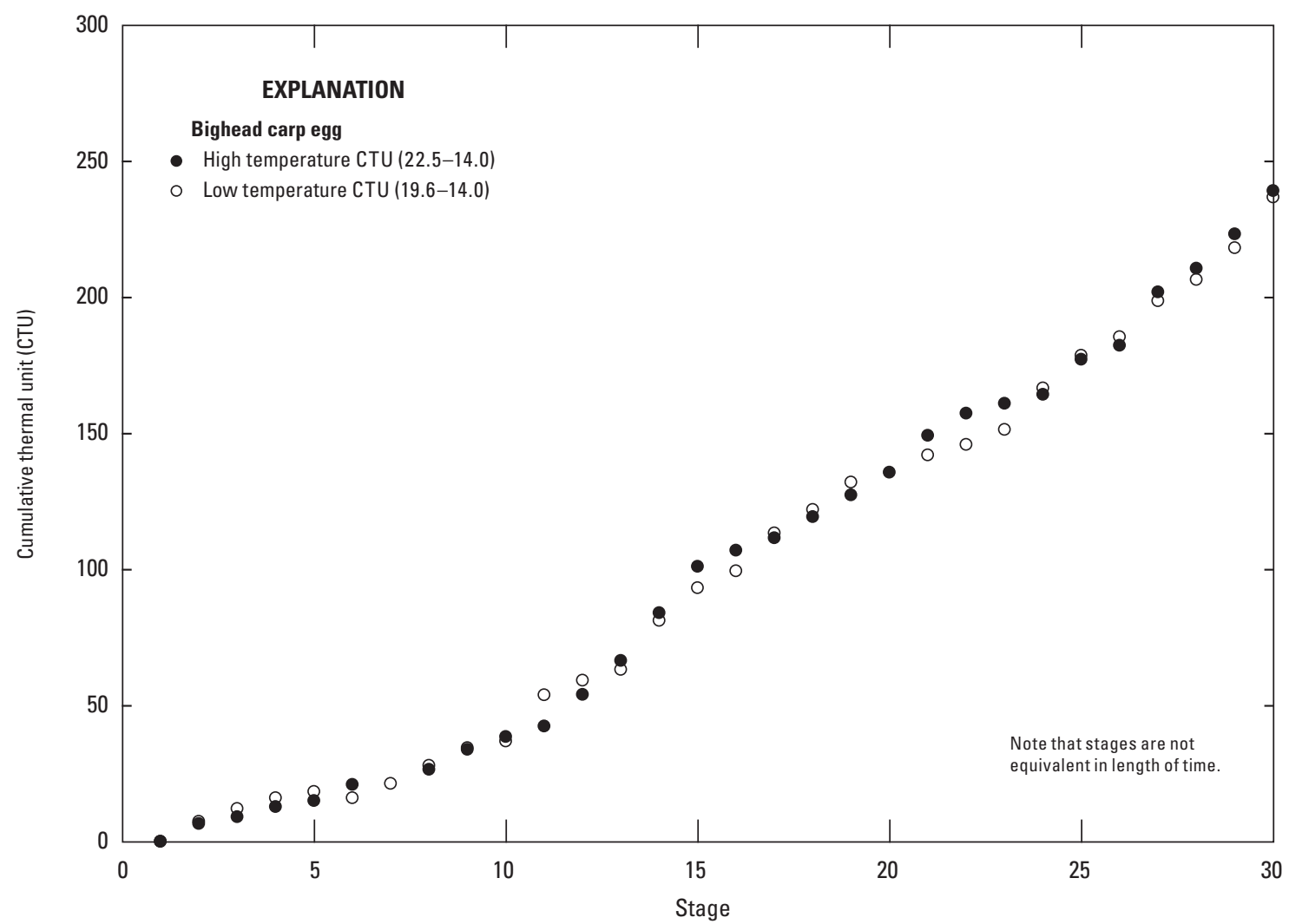

Figure 3. Cumulative thermal units (CTU) for embryonic development in bighead carp using $14.0^{\circ} \mathrm{C}$ as $T_{\text {min }}$.

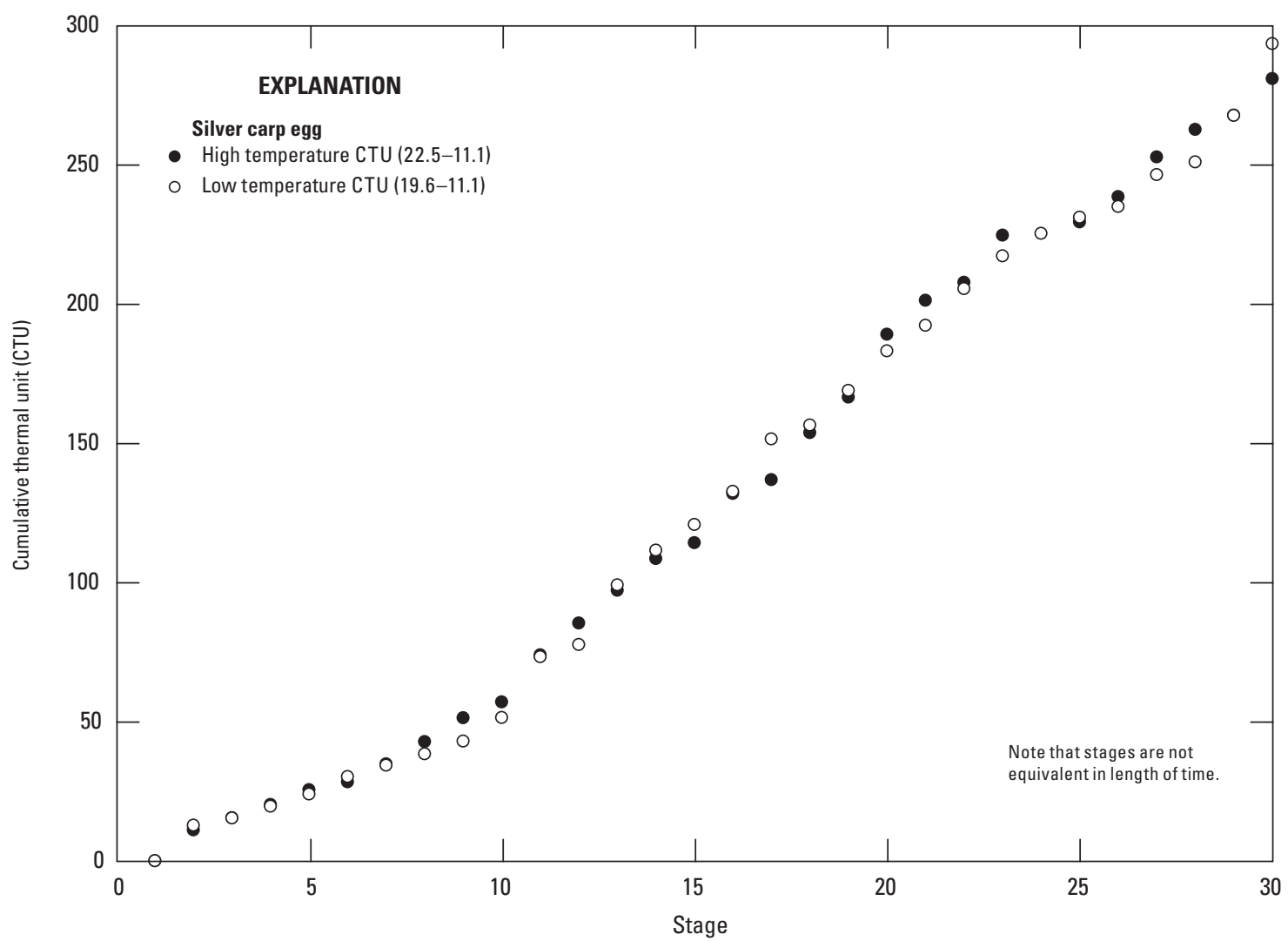

Figure 4. Cumulative thermal units (CTU) for embryonic development in silver carp using $11.1^{\circ} \mathrm{C}$ as $T_{\text {min }}$. 
had 37 percent more eggs per volume than those hardened in waters of hardness similar to this study. Wu and Tan (2000) found no effect of maternal parent size on the size of eggs before water hardening, except in the case of silver carp of less than $6.5 \mathrm{~kg}$, in which case, egg size increased with parent size and with number of previous spawns. The only female silver carp that provided useful gametes in this study was $3.75 \mathrm{~kg}$, which is likely related to the egg size being slightly smaller than reported in other studies.

Water-quality factors, notably water hardness, are known to cause differences in egg diameter (Spade and Bristow, 1999; Gonzal and others, 1987; Rach and others, 2010), and there were minimal differences in the water hardness of the two temperature treatments, though it is unclear whether the difference $(262 \mathrm{mg} / \mathrm{L}$ "cold" temperature for bighead carp, and $230 \mathrm{mg} / \mathrm{L}$ "warm" temperature for silver carp) was large enough to affect egg diameter. In another study, Chapman and Deters (2009) did not find significant difference in the size of bighead carp eggs incubated at a wider range of water hardness. Temperature can also affect egg size (Daoulas and Economou, 1986; Miller and others, 1995), although most cases suggest that larger eggs occur in colder water. There appears to be no connection between egg size and size of larvae at hatching. The variation in egg diameter at temperature may be because the temperature of "warm" treatments is closer to the optimal incubation temperature, though more data on egg diameter at multiple temperature regimes is required to test the relationship between temperature and egg diameter of bigheaded carp eggs.

Information on egg diameter is relevant for modeling the turbulence required to maintain drift of these negatively buoyant eggs. Rivers with insufficient velocity or drift length to keep the eggs from settling are not thought to be at risk for use by bigheaded carps for reproduction and recruitment. It is also useful for identification purposes (Chapman and Wang, 2006). In central North America, morphology and size can be used to identify an egg as one of the guild of four invasive Asian carps with drifting eggs (bighead, silver, grass, and black carps). However, egg size and morphology are not sufficient to distinguish between these four species.

\section{Larval Size}

Similar to the work of Korwin-Kossakowski (2008) on grass carp and common carp, there was evidence that rearing temperature affects the size of larvae at any given stage. Whereas warmer temperatures produced larvae that were shorter in comparisons of equal developmental stages, length at age (hours post fertilization) was similar among both temperature treatments, especially in bighead carp. Larvae at any particular stage were shorter than reported by Yi and others (1988), although this is consistent with their observation that laboratory-raised fish grew more slowly than wild fish. This is also consistent with the egg size being smaller than reported by Yi and others (1988). For silver carp especially, smaller egg size may have been related to the size of the maternal parent. Wu and Tan (2000) suggested that younger and smaller brood stock produce somewhat smaller eggs, which produce smaller larvae. The female silver carp in this study was relatively small and probably young.

\section{Photographic History and Comparison of Developmental Landmark Progression}

Determining stage based on the system of Yi and others (1988) can be challenging in several respects:

1. Several of Yi's stages rely upon live, unanesthetized fish (for example, muscular effect is denoted by occasional lashing and color of yolk sac tip). These cannot be determined in preserved specimens.

2. It is difficult to distinguish among some of the early stages (for example, 128-cell stage compared to morula, compared to early blastula.

3. Developmental abnormalities (see appendix figs. 1-41, $2-40$; including irregular cell division and missing heads, and so on) sometimes appeared, making the stage difficult to determine.

4. Some features (tail vesicle, olfactory placode, otic capsule) can be difficult to distinguish, even on embryos in good condition.

5. Sampling time interval led to missed developmental stages, which were of short duration, and inconsistencies among the timing for each stage.

Eye spots did not generally develop until stage 32 in this study series, though other authors (Yi and others, 1988; Chapman and Wang, 2006) have described their occurrence in the late embryonic stages. Soin and Sukhanova (1972) indicated only that they appear after hatching. Murty and others (1986) did not mention eyespots but note that, at $27-30^{\circ} \mathrm{C}$, pigmentation of the eye starts at 6 hours post hatching. The timing of appearance of eyespots may be a variable trait in wild fishes, or this could be an artifact of the fish culture. Fuiman and others (1998) noted that, although ontogenetic events occur sooner by every metric in warmer water, not every ontogenetic event is accelerated equally by warmer temperatures; they cite the appearance of gut pigmentation as a temperature-insensitive event in the development of red drum.

\section{Developmental Rate}

As expected, bighead and silver carp embryos and larvae developed faster at warmer temperatures. Despite natural variation amongst individuals in developmental time (for example, hatching time for silver carp in the "warm" water treatment ranged from 21-33 hours, although most hatching occurred between 27-29 hours), the formula 


$$
C T U=t\left(T_{c}-T_{\min }\right)
$$

provided similar $C T U$ for both incubation temperatures when a $T_{\text {min }}$ of $14.0^{\circ} \mathrm{C}$ was used for bighead carp and $11.1^{\circ} \mathrm{C}$ was used for silver carp. The lower $T_{\min }$ for silver carp is not surprising, because silver carp are thought to be somewhat more cold-adapted than bighead carp, and have a native range that extends much farther north than bighead carp (Kolar and others, 2007).

Larval stages indicate the best alignment when a $T_{\min }$ different from that of the embryos is used. For silver carp larval stages, the best alignment occurs at $13.8^{\circ} \mathrm{C}$, whereas for bighead carp, the best alignment occurs at $13.0^{\circ} \mathrm{C}$. However, because of longer monitoring intervals during the larval period, some stages of development were missed and exact timing of the other stages is less certain than during the embryonic period. Different values for $T_{\text {min }}$ for embryonic and larval phases would be expected, as each life stage has different temperature requirements for development (Herzig and Winkler, 1986). However, because current data on the larval period is insufficient to determine the best $T_{\min }$ for larvae accurately, and to keep the $C T U$ calculations consistent, larval fish $C T U$ s are reported using the same $T_{\min }$ value as embryos. Herzig and Winkler (1986) documented that, for three European cyprinids, the developmental stage at which hatching occurs was affected by temperature, but in this study temperature did not affect the developmental stage when hatching occurred in bighead carp and silver carp.

\section{Behavior}

Yi and others (1988) raised wild-caught eggs and larvae in shallow dishes and, although the shape of the container probably made it impossible to observe the strong vertical swimming and sinking behavior that was observed in this study, they made some observations on swimming behavior of Asian carps that are consistent with this study. They reported that "darting" occurred immediately after hatching and that by stage 36 (melanoid eye stage) black carp occasionally swam normally, but usually swam unbalanced and without complete vertical orientation. They further noted that all four species began horizontal swimming by the stage of gas bladder emergence. Similarly, Murty and others (1986) observed that in silver carp occasional whirling began immediately after hatching, but episodic vertical movements did not begin until 6 hours post hatch (approximately stage 31), and horizontal zig-zag movement began at approximately the melanoid eye stage. Except for the strong vertical swimming observations from the present study, results are consistent with Yi and others (1988).

Bighead and silver carp typically spawn in turbulent areas in large rivers, and the eggs and larvae are carried by the current. They have greater density than water, and they are thought to die if they settle to the bottom (Kolar and others, 2007). They are, therefore, thought to require a river of sufficient length to provide for drift through the nonswimming stages, although it is unclear if this drifting period needs to encompass some of the larval stages, or if drift only is required for the embryonic stages. The strong vertical swimming behavior observed immediately after hatching, and continuing until horizontal swimming began, is important in understanding the minimum river length and turbulence required for early development of bighead and silver carps. If recently hatched larvae are discharged from a river to a lake or reservoir, or if the river velocity and turbulence decrease below the point that physical factors would keep larvae in suspension in the water column, it would not necessarily result in those larvae sinking to the bottom.

Also, it should be noted that the strong swimming ability of these larvae will likely affect their location within the water column in the river, unless current velocity and turbulence overcome that swimming ability. The sinking velocity of eggs could be combined with data on river turbulence to estimate the distribution of eggs in the water column and allow calculation of the total flux of eggs with samples taken from near the surface. That method would not work with larvae, even immediately after hatching.

\section{Implications For Drift Distance and Determining Spawning Locations}

Understanding the rate of development at different temperatures is required for modeling rivers to determine if they have sufficient length to provide for the drifting life stages of Asian carps. This information is useful for estimating the age of larvae collected from the wild, when temperature is known. In the case of Asian carps, understanding the age of larvae collected from the wild or understanding the rate of development of larvae at different temperatures is important for determining locations of spawning events or time of day when spawning aggregations occur.

Various minimum drift distances have been proposed for Asian carp early life stages, but 100 kilometers $(\mathrm{km})$ has often been cited (Gorbach and Krykhtin, 1981) and this distance has been used to assess the potential that Asian carps will successfully use tributaries of the Laurentian Great Lakes for reproduction (Kolar and others, 2007). Proposed minimum drift distances have been based on where Asian carps are known to have established, not on studies of the drifting properties of eggs and larvae. Published literature is unclear as to whether this distance is necessary to support survival only of the drifting egg stages, or if the early larvae also require current to keep them from sinking to the bottom. In any case, the actual minimum distance required for survival of the early life stages of Asian carps will not be a fixed river length, but rather will be dependent on the behavior and developmental rate of the eggs and larvae, and upon physical factors including temperature and current velocity. Understanding these factors is essential for development of models that evaluate the risk that 
bigheaded carps could successfully use tributaries of the Laurentian Great Lakes for spawning and recruitment.

\section{Conclusions}

This study presents data from only a single spawning event for each species (for bighead carp using gametes from 2 females and 3 males, and for silver carp using gametes from 1 female and 3 males). Thus, variability in the early development of these species that results from natural variability between adults was not captured in the study. We intend to repeat these studies with additional adults of both species, and at additional temperatures. However, because the ongoing assessments of the risk of bigheaded carp establishment in the Laurentian Great Lakes and other areas urgently require information on bigheaded carp early development and behavior, these data and images are provided at this time. Especially important for these efforts, note that, in general, the developmental landmarks reported by Yi and others (1988) for fish from the Yangtze River in the 1960s were applicable to these North American bigheaded carps. The strong vertical swimming behavior observed in both species immediately after hatching is not noted elsewhere in the literature, and is important in the assessment of minimum river length and velocity for the establishment of bigheaded carps. The horizontal swimming behavior at the gas bladder emergence stage observed in both species in this study corroborates a field study (unpublished data) in which it appears that at the gas bladder emergence stage, larvae begin to leave the drift and migrate laterally from the river in which they are spawned.

\section{References Cited}

Berven, K.A., 1982, The genetic basis of altitudinal variation in the wood frog Rana sylvatica II. An experimental analysis of larval development: Oecologia, v. 52, no. 3, p. 360-369.

Burrill, S.E., Zimmerman, C.E., Finn, J.E., and Gillikin, D., 2010, Abundance, timing of migration, and egg-to-smolt survival of juvenile chum salmon, Kwethluk River, Alaska, 2007 and 2008: U.S. Geological Survey Open-File Report 2010-1028, $28 \mathrm{p}$.

Chapman, D.C., and Deters, J.E., 2009, Effect of water hardness and dissolved-solid concentration on hatching success and egg size in bighead carp: Transactions of the American Fisheries Society v. 138, no. 6, p. 1,226-1,231.
Chapman, D.C., and Wang, N., 2006, Notes on the translation and use of "A study of the early development of grass carp, black carp, silver carp, and bighead carp in the Yangtze River, China". Chap. 1 of Chapman, D.C., ed., Early development of four cyprinids native to the Yangtze River, China: U.S. Geological Survey Data Series 239, p. 1-9.

Chapman, D.C., ed., 2006, Early development of four cyprinids native to the Yangtze River, China: USGS Data Series $239,51 \mathrm{p}$.

Conover, G., Simmonds, R., and Whalen, M., eds., 2007, Management and control plan for bighead, black, grass, and silver carps in the United States: Asian Carp Working Group, Aquatic Nuisance Species Task Force, Washington, D.C., 223 p.

Daoulas, C., and Economou, A.N., 1986, Seasonal variation of egg size in the sardine, Sardina pilchardus Walb., of the Saronikos Gulf: causes and a probable explanation: Journal of Fish Biology, v. 28, no. 4, p. 449-457.

Fuiman, L.A., and Trojnar, J.R., 1980, Factors affecting egg diameter of white suckers (Catostomus commersoni): Copeia, v. 1980, no. 4, p. 699-704.

Fuiman, L.A., Poling, K.R., and Higgs, D.M., 1998, Quantifying developmental progress for comparative studies of larval fishes: Copeia, v. 1998, no. 3, p. 602-611.

Gonzal, A.C., Aralar, E.V., and Pavico, J.M.F., 1987, The effects of water hardness on the hatching and viability of silver carp (Hypophthalmichthys molitrix) eggs: Aquaculture, v. 62 , no. 2 , p. 111-118.

Gorbach, E. I., and Krykhtin, M. L., 1981, Maturation rate of the white amur Ctenopharyngodon idella and silver carp Hypophthalmichthys molitrix in the Amur River: Voprosi Ikhtiologii, v. 21, no. 5, p. 835-843.

Guma'a, S.A., 1978, The effects of temperature on the development and mortality of eggs of perch, Perca fluviatilis: Freshwater Biology, v. 8, no. 3, p. 221-227.

Hamel, P., Magnan, P., East, P., Lapointe, M., and Laurendeau, P., 1997, Comparison of different models to predict the in situ embryonic developmental rate of fish, with special reference to white sucker (Catostomus commersoni): Canadian Journal of Fisheries and Aquatic Sciences, v. 54, no. 1, p. 190-197. 
Herzig, A., and Winkler, H., 1986, The influence of temperature on the embryonic development of three cyprinid fishes, Abramis brama, Chalcalburnus chalcoides mento and Vimba vimba: Journal of Fish Biology, v. 28, no. 2, p. 171-181.

Jhingran, V.G., and Pullin, R.S.V., 1985, A hatchery manual for the common, Chinese and Indian major carps: Manila, Philippines, Asian Development Bank, Philippines and International Center for Living Aquatic Resources Management, 191 p. Also available at http://pdf.usaid.gov/pdf_docs/ PNAAV716.pdf.

Johnston, T.A., and Leggett, W.C., 2002, Maternal and environmental gradients in the egg size of an iteroparous fish: Ecology, v. 83, no. 7, p. 1,777-1,791.

Kolar, C.S., Chapman, D.C., Courtenay, W.R., Housel, C.M., Williams, J.D., and Jennings, D.P., 2007, Bigheaded carps: a biological synopsis and environmental risk assessment: American Fisheries Society, Special Publication 33, Bethesda, Md.

Korwin-Kossakowski, M., 2008, The influence of temperature during the embryonic period on larval growth and development in carp, Cyprinus carpio L., and grass carp, Ctenopharyngodon idella (Val.): Theoretical and practical aspects: Archives of Polish Fisheries, v. 16, no. 3, p. 231-314.

Kynard, B., and E. Parker, 2005, Ontogenetic behavior and dispersal of Sacramento River white sturgeon, Acipenser transmontanus, with a note on body color: Environmental Biology of Fishes, v. 74, no. 1, p. 145-156.

Lattuca, M.E., Brown, D., Castiñeira, L., Renzi, M., Luizon, C., Urbanski, J., and Cussac, V., 2008, Reproduction of landlocked Aplochiton zebra Jenyns (Pisces, Galaxiidae): Ecology of Freshwater Fish, v. 17, no. 3, p. 394-405.

Leitritz, E., and Lewis R.C., 1976, Trout and salmon culture: California Department of Fish and Game Fishery Bulletin 164, Sacramento, Calif., 197 p.

Miller, T.J., Herra, T., and Leggett, W.C., 1995, An individualbased analysis of the variability of eggs and their newly hatched larvae of Atlantic cod (Gadus morhua) on the Scotian Shelf: Canadian Journal of Fisheries and Aquatic Sciences, v. 52, no. 5, p. 1,083-1,093.
Murty, D.S, Sukramaran, K.K., Reddy, P.V.G.K., and Dey, R.K., 1986, Observations on the life history of silver carp, Hypophthalmichthys molitrix (Valenciennes): Journal of the Inland Fisheries Society of India, v.18, no. 1, p. 4-14.

Piper, R.G., McElwain, I.B., Orme, L.E., McCraren, J.P., Fowler, L.G., and Leonard, J.R., 1982, Fish Hatchery Management: U.S. Fish and Wildlife Service, University of the Pacific Publisher, Stockton, Calif., 544 p.

Rach, J.J., Sass, G.G., Luoma, J.A., and Gaikowski, M.P., 2010, Effects of water hardness on size and hatching success of silver carp eggs: North American Journal of Fisheries Management, v. 30, no. 1, p. 230-237.

Schmidt-Nielsen, K., ed., 1995, Animal physiology, adaptation and environment: 4th ed., Cambridge University Press, Cambridge, $602 \mathrm{p}$.

Soin, S.G., and Sukhanova, A.I., 1972, Comparative morphological analysis of the development of the grass carp, the black carp, the silver carp, and the bighead (Cyprinidae): Journal of Ichthyology, v. 12, no. 1, p. 67-71.

Spade, S., and Bristow, B., 1999, Effects of increasing water hardness on egg diameter and hatch rates of striped bass eggs: North American Journal of Aquaculture, v. 61, no. 3, p. 263-265.

Wu, H., and Tan, J., 2000, Relationships between egg sizes and body weight of parent fish of silver and bighead carps: Inland Water Fisheries, v. 3, p. 7-8. (in Chinese).

Yi, B., Liang, Z., Yu, Z., Lin, R., and He, M., 1988, A comparative study on the early development of grass carp, black carp, silver carp, and big head of the Yangtze River, in Yi, B., Yu, Z., and Liang, Z., eds., Gezhouba water control project and four famous fishes in the Yangtze River, China: Wuhan, China, Hubei Science and Technology Press, p. 69-135. (in Chinese)

Zhu, X.P., Wei, C.Q., Zhao, W.H., Du, H.J., Chen, Y.L., and Gui, J.F., 2006, Effects of incubation temperatures on embryonic development in the Asian yellow pond turtle: Aquaculture, v. 259, no. 1-4, p. 243-248. 
Appendixes 1-2 


\section{Appendix 1. Bighead Carp}

These pictures are images of live and preserved specimens of bighead carp (Hypophthalmichthys nobilis). Text descriptions and line drawings from Chapman and Wang (2006), and Yi and others (1988) are also presented, when available, for comparison purposes. Although Yi and others (1988) describe 45 stages of development, data are presented on only the first 40 stages.

Preliminary data on timing and required cumulative thermal units (CTUs) are also presented, though this data is based on a single experiment, and is likely to be revised with further experiments. The magnification listed is the total magnification (ocular $\mathrm{x}$ objective) for each picture. 
Table 1-1. Timing and required CTUs for achieving developmental stages of bighead carp.

[This data is based on a single experiment, and is likely to be revised with further experiments. CTU, cumulative thermal unit; ${ }^{\circ} \mathrm{C}$, degrees Celsius; $T_{m i n}$, thermal minimum; --, not available]

\begin{tabular}{|c|c|c|c|c|c|c|c|}
\hline \multirow{2}{*}{\multicolumn{2}{|c|}{ Stage }} & \multicolumn{3}{|c|}{ Time } & \multicolumn{3}{|c|}{ CTU (Calculated using $14.0^{\circ} \mathrm{C}$ as $T_{\min }$ ) } \\
\hline & & \multirow{2}{*}{$\begin{array}{c}\mathbf{Y i} \\
--\end{array}$} & \multirow{2}{*}{$\begin{array}{r}\text { High } \\
0\end{array}$} & \multirow{2}{*}{$\begin{array}{r}\text { Low } \\
0\end{array}$} & \multirow{2}{*}{$\frac{\mathrm{Yi}\left(21^{\circ} \mathrm{C}\right)}{--}$} & \multirow{2}{*}{$\begin{array}{c}\text { High }\left(22.3^{\circ} \mathrm{C}\right) \\
0\end{array}$} & \multirow{2}{*}{$\frac{\text { Low }\left(20.1^{\circ} \mathbf{C}\right)}{0}$} \\
\hline 1 & 1-cell & & & & & & \\
\hline 2 & 2-cell & $0: 55$ & $0: 47$ & $1: 12$ & 6.05 & 6.5 & 7.32 \\
\hline 3 & 4-cell & 1:03 & 1:05 & $1: 58$ & 6.93 & 8.99 & 12.00 \\
\hline 4 & 8-cell & $1: 12$ & $1: 32$ & -- & 7.92 & 12.73 & -- \\
\hline 5 & 16-cell & $1: 24$ & $1: 48$ & $2: 37$ & 9.24 & 14.94 & 18.30 \\
\hline 6 & 32-cell & $2: 00$ & $2: 31$ & -- & 13.20 & 20.89 & -- \\
\hline 7 & 64-cell & $2: 20$ & -- & $3: 29$ & 15.40 & -- & 21.25 \\
\hline 8 & 128-cell & $3: 00$ & $3: 11$ & $4: 34$ & 19.80 & 26.42 & 27.86 \\
\hline 9 & Morula & $3: 38$ & $4: 04$ & $4: 59$ & 23.98 & 33.75 & 34.36 \\
\hline 10 & Early blastula & $4: 10$ & $4: 38$ & $6: 02$ & 27.50 & 38.46 & 36.80 \\
\hline 11 & Mid-blastula & $5: 30$ & $5: 06$ & $8: 49$ & 36.30 & 42.33 & 53.78 \\
\hline 12 & Late blastula & $7: 20$ & $6: 30$ & $9: 42$ & 48.40 & 53.95 & 59.17 \\
\hline 13 & Early gastrula & $8: 10$ & $8: 00$ & $10: 21$ & 53.90 & 66.40 & 63.14 \\
\hline 14 & Mid-gastrula & $9: 55$ & 10:07 & $13: 18$ & 65.45 & 83.97 & 81.13 \\
\hline 15 & Late gastrula & $11: 20$ & $12: 10$ & $15: 16$ & 74.80 & 100.98 & 93.13 \\
\hline 16 & Neurula & $12: 45$ & $12: 53$ & $16: 17$ & 84.15 & 106.93 & 99.33 \\
\hline 17 & Blastopore closure & $14: 00$ & $13: 26$ & $18: 34$ & 92.40 & 111.50 & 113.26 \\
\hline 18 & Somite appearance & $14: 50$ & $14: 22$ & 19:59 & 97.90 & 119.24 & 121.90 \\
\hline 19 & Optic primordium & $15: 40$ & $15: 20$ & $21: 38$ & 103.40 & 127.27 & 131.96 \\
\hline 20 & Optic vesicle & $16: 35$ & $16: 20$ & $22: 06$ & 109.45 & 135.57 & 134.81 \\
\hline 21 & Olfactory placode & $17: 45$ & $17: 58$ & $23: 16$ & 117.15 & 149.12 & 141.92 \\
\hline 22 & Tail bud & 19:05 & $18: 57$ & $23: 54$ & 125.95 & 157.29 & 145.79 \\
\hline 23 & Otic capsule & $19: 35$ & $19: 23$ & $24: 48$ & 129.25 & 160.88 & 151.28 \\
\hline 24 & Tail vesicle & $22: 00$ & $19: 47$ & $27: 17$ & 145.20 & 164.20 & 166.53 \\
\hline 25 & Caudal fin & $24: 28$ & $21: 20$ & 29:16 & 161.48 & 177.07 & 178.53 \\
\hline 26 & Lens formation & $25: 20$ & $21: 57$ & $30: 23$ & 167.20 & 182.19 & 185.34 \\
\hline 27 & Muscular effect & $26: 25$ & $24: 19$ & $32: 33$ & 174.35 & 201.83 & 198.56 \\
\hline 28 & Heart rudiment & $28: 40$ & $25: 22$ & $33: 50$ & 189.20 & 210.54 & 206.38 \\
\hline 29 & Otolith appearance & $32: 30$ & $26: 53$ & $35: 45$ & 214.50 & 223.13 & 218.08 \\
\hline 30 & Heart pulsation & $33: 00$ & $28: 48$ & $38: 48$ & 217.80 & 239.04 & 236.68 \\
\hline 31 & Hatching & $39: 00$ & $31: 11$ & 45:05 & 257.40 & 255.70 & 275.01 \\
\hline 32 & Pectoral fin bud & 49:00 & $36: 34$ & -- & 323.40 & 299.85 & -- \\
\hline 33 & Gill arch & $59: 00$ & -- & $68: 35$ & 389.40 & -- & 418.36 \\
\hline 34 & Xanthic eye & $65: 00$ & $68: 40$ & $80: 23$ & 429.00 & 563.07 & 490.34 \\
\hline 35 & Gill filament & $76: 00$ & $76: 07$ & $99: 45$ & 501.60 & 624.16 & 608.48 \\
\hline 36 & Melanoid eye & 98:00 & $92: 29$ & $106: 49$ & 646.80 & 758.36 & 651.58 \\
\hline 37 & Gas bladder emergence & 111:00 & $117: 11$ & $131: 52$ & 732.60 & 960.90 & 804.39 \\
\hline 38 & One chamber gas bladder & $135: 00$ & $131: 53$ & $167: 07$ & 891.00 & $1,081.44$ & $1,019.42$ \\
\hline 39 & Dorsal fin differentiation & $166: 00$ & -- & 213:00 & $1,095.60$ & -- & $1,299.30$ \\
\hline 40 & Yolk absorption & 202:00 & $189: 48$ & $261: 00$ & $1,333.20$ & $1,556.36$ & $1,592.10$ \\
\hline
\end{tabular}



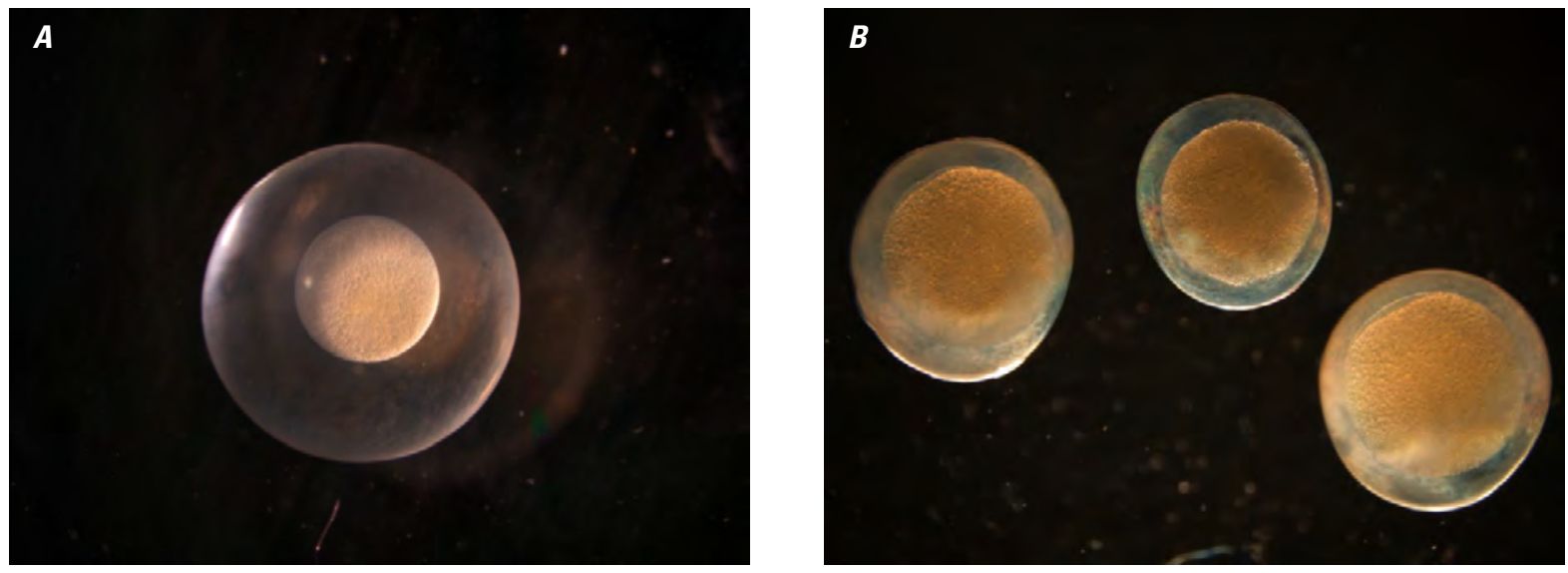

Figure 1-1. Stage 1: 1-cell stage of bighead carp development. $A$, Live specimen, high-temperature treatment, 0:47 post fertilization, picture taken with $20 \mathrm{x}$ magnification. $B$, Preserved specimen, high temperature treatment, 0:16 post fertilization, picture taken with 40x magnification.

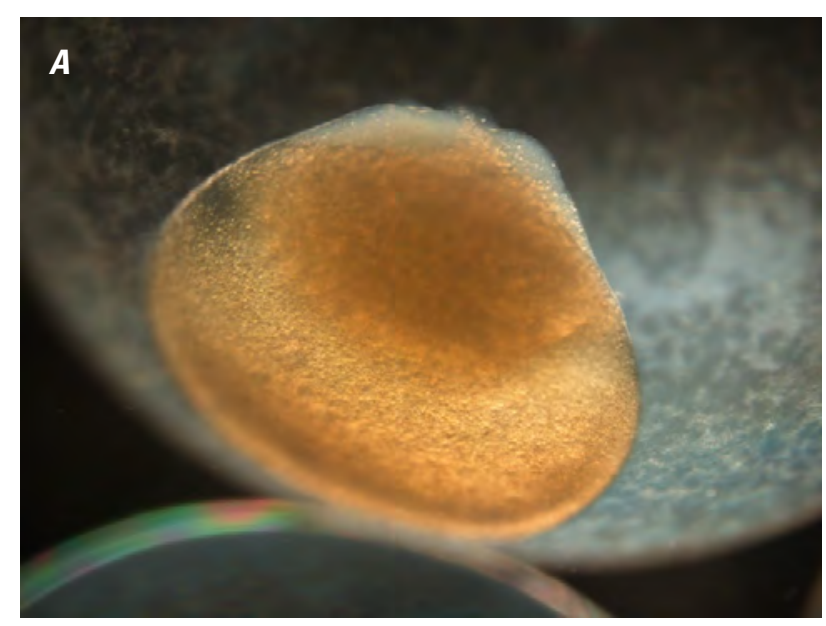

B

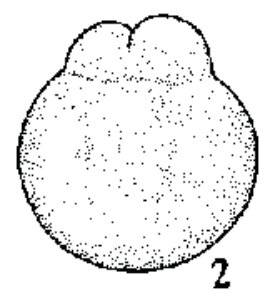

Figure 1-2. Stage 2: 2-cell stage of bighead carp development. The cytoplasm is widely distributed in the yolk (Yi and others, 1988). A, Preserved specimen, low temperature treatment, 1:38 post fertilization, picture taken with 50x magnification. $B$, Line drawing of 2-cell stage from Yi and others (1988). 

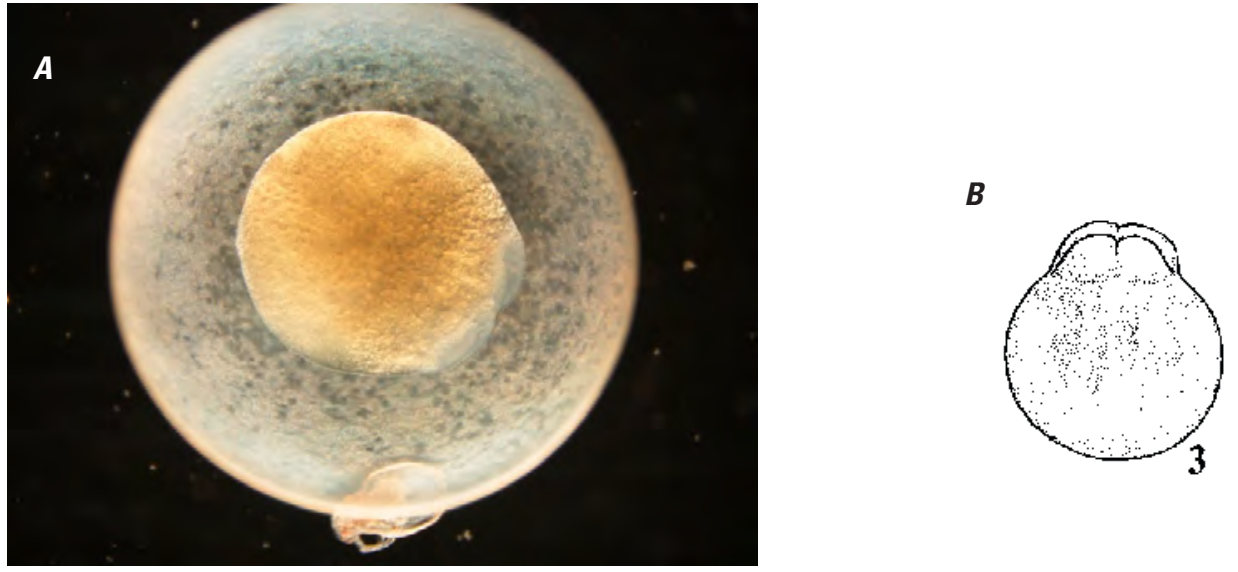

Figure 1-3. Stage 3: 4-cell stage of bighead carp development. Cells divide vertically and the cytoplasm diminishes gradually (Yi and others, 1988). A, Preserved specimen, high temperature treatment, 1:05 post fertilization, picture taken with 40x magnification. $B$, Line drawing of 4-cell stage from Yi and others (1988).
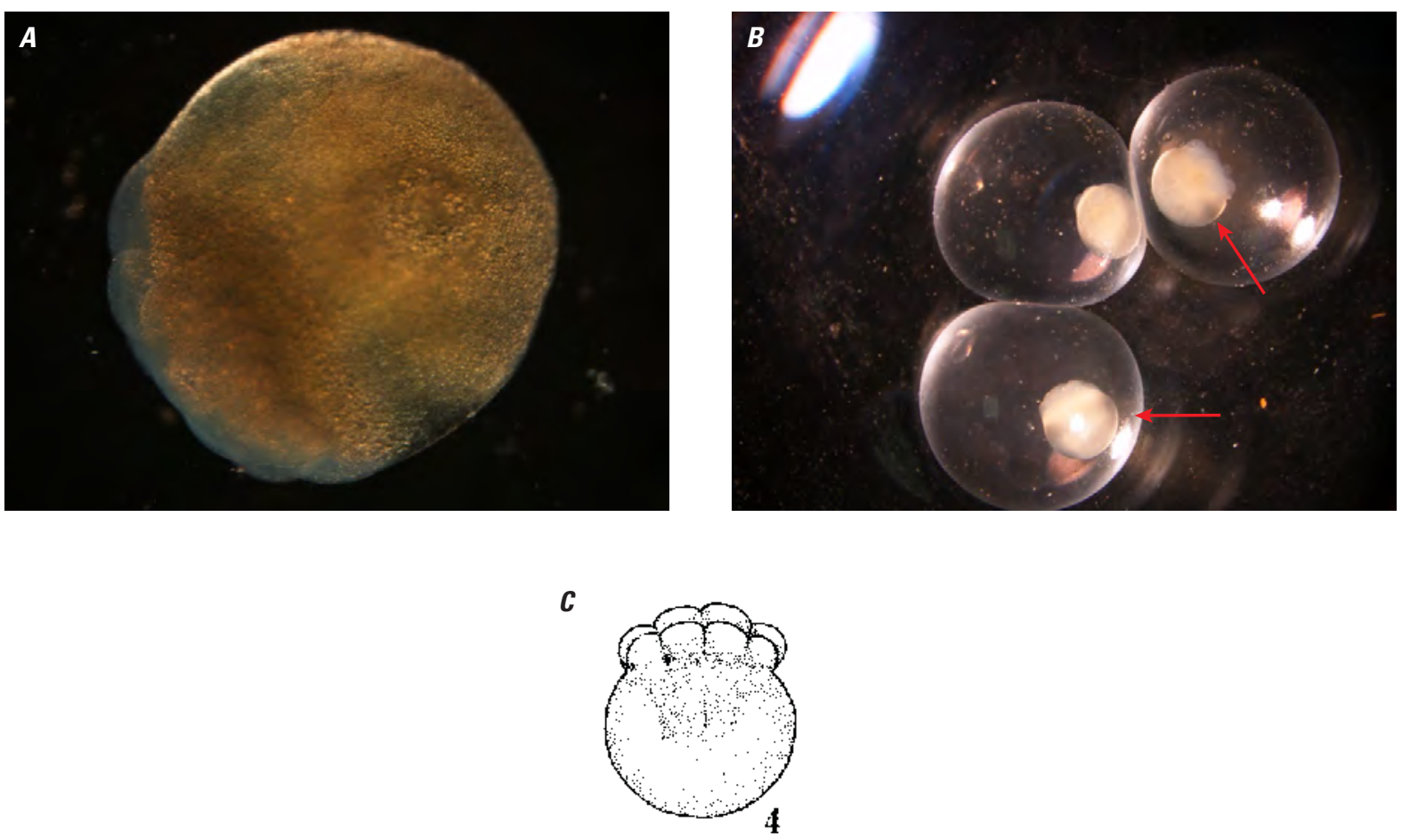

Figure 1-4. Stage 4: 8-cell stage of bighead carp development. Cells divide vertically and the cytoplasm diminishes gradually (Yi and others, 1988). A, Preserved specimen, high temperature treatment, 1:32 post fertilization, picture taken with 50x magnification. $B$, Live specimen, high temperature treatment, 1:32 post fertilization, picture taken with 10x magnification. $C$, Line drawing of 8-cell stage from Yi and others (1988). 


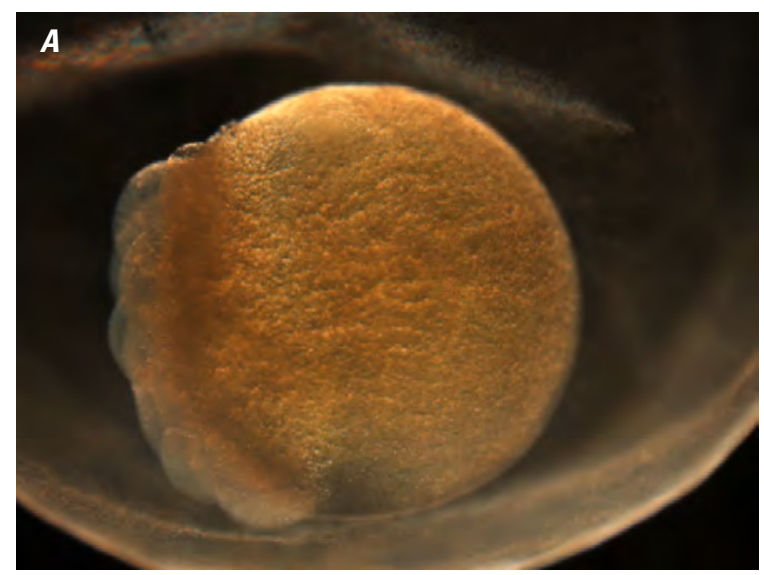

B

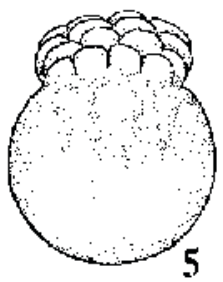

Figure 1-5. Stage 5: 16-cell stage of bighead carp development. Cells divide vertically and the cytoplasm diminishes gradually (Yi and others, 1988). A, Preserved specimen, low temperature treatment, 2:37 post fertilization, picture taken with $50 \mathrm{x}$ magnification. $B$, Line drawing of 16-cell stage from Yi and others (1988).

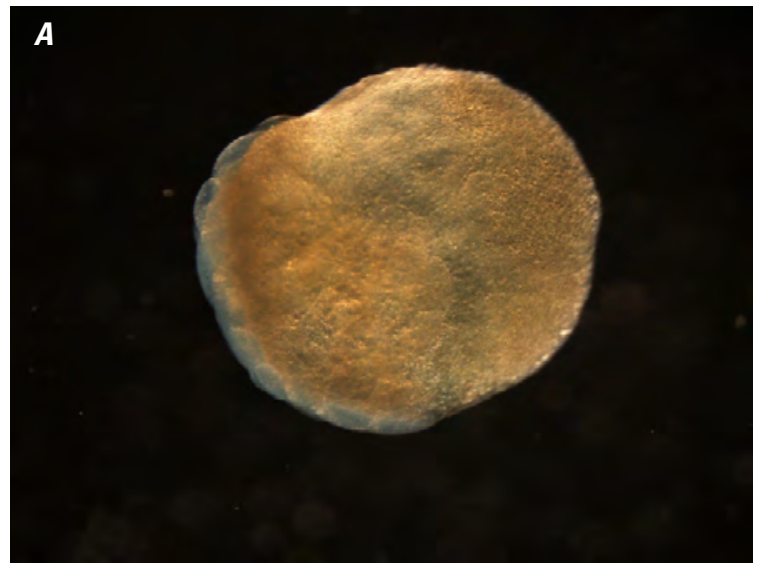

B

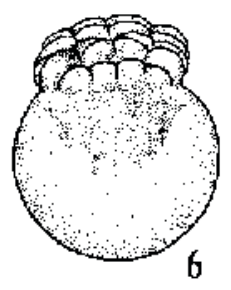

Figure 1-6. Stage 6: 32-cell stage of bighead carp development. Cells divide vertically and the cytoplasm diminishes gradually (Yi and others, 1988). A, Preserved specimen, high temperature treatment, 2:31 post fertilization, picture taken with 40x magnification. $B$, Line drawing of 32-cell stage from Yi and others (1988). 


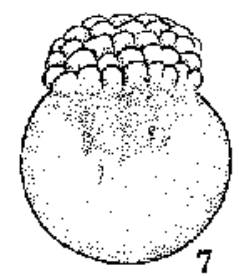

Figure 1-7. Stage 7: 64-cell stage of bighead carp development. Cells divide vertically and the cytoplasm diminishes gradually ( $Y i$ and others, 1988). Line drawing of 64-cell stage from Yi and others (1988).

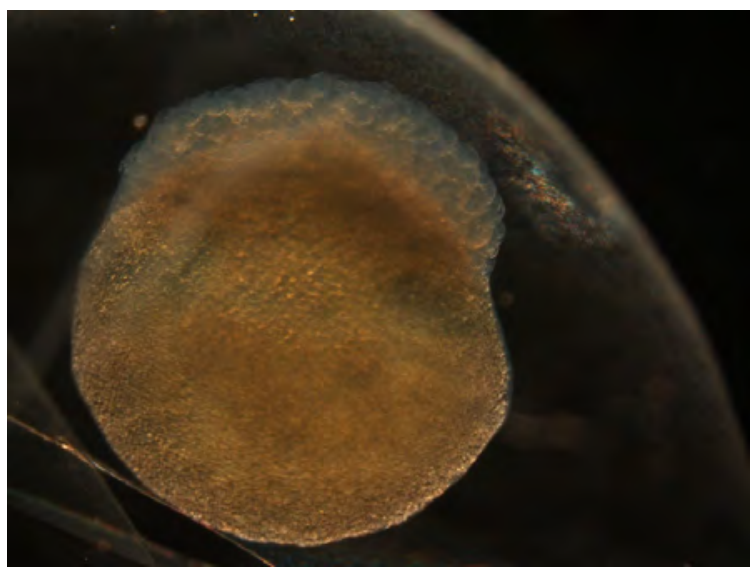

Figure 1-8. Stage 8: 128-cell stage of bighead carp development. Cells divide horizontally (Yi and others, 1988). Preserved specimen, high temperature treatment, 3:11 post fertilization, picture taken with 50x magnification. 

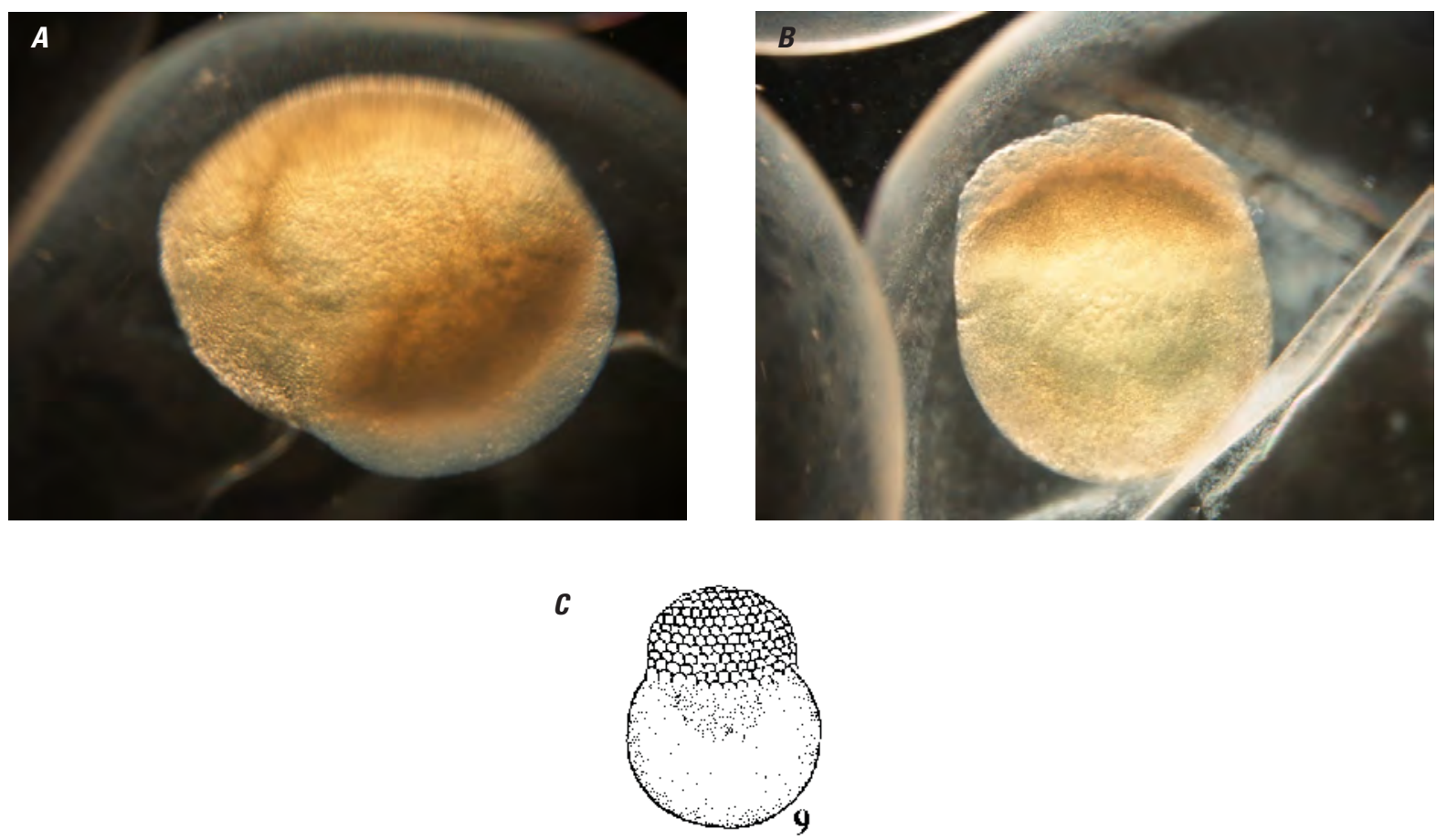

Figure 1-9. Stage 9: Morula stage of bighead carp development. The blastodisc is highly raised above the yolk (Yi and others, 1988). A, Preserved specimen, high temperature treatment, 4:04 post fertilization, picture taken with $50 \mathrm{x}$ magnification. $B$, Preserved specimen, low temperature treatment, 4:59 post fertilization, picture taken with $40 \mathrm{x}$ magnification. $C$, Line drawing of morula stage from Yi and others (1988).
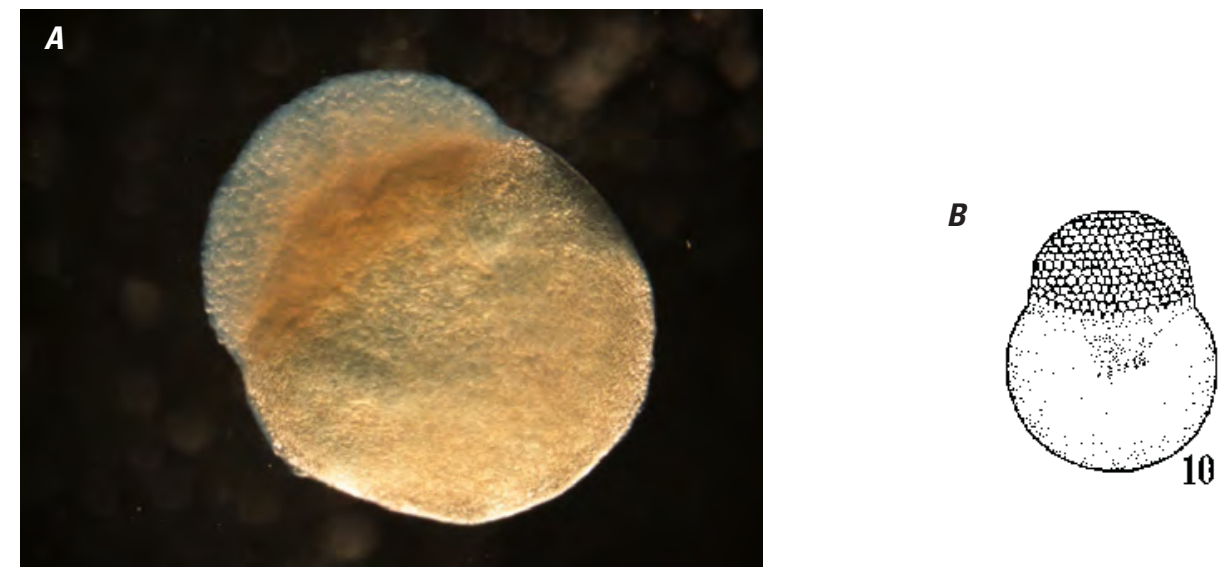

Figure 1-10. Stage10: Early blastula stage of bighead carp development. Blastodisc remains high, cells small (Yi and others, 1988). A, Preserved specimen, low temperature treatment, 6:02 post fertilization, picture taken with 50x magnification $B$, Line drawing of early blastula stage from Yi and others (1988). 

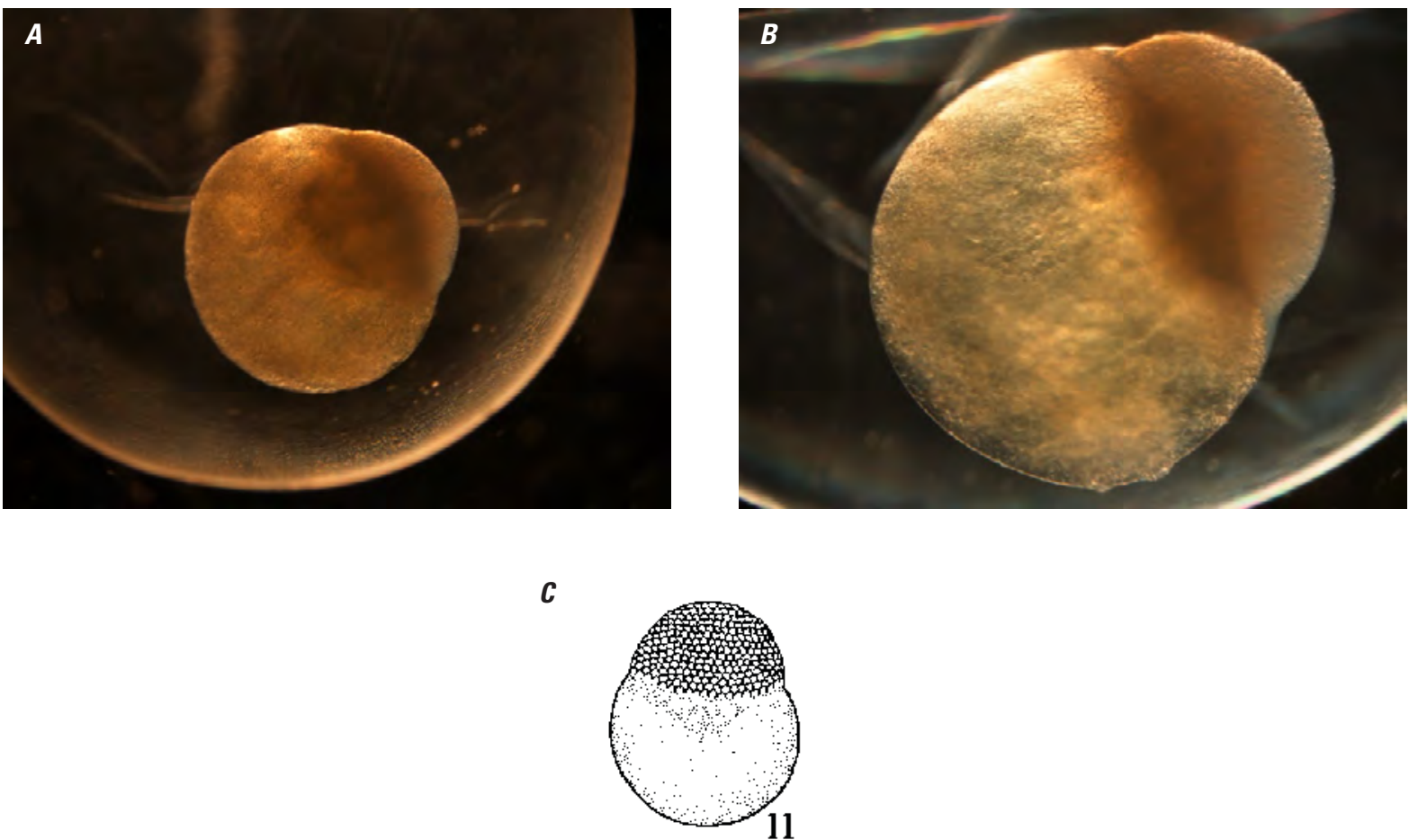

Figure 1-11. Stage 11: Mid-blastula stage of bighead carp development. Blastodisc begins flattening (Yi and others, 1988). A, Preserved specimen, high temperature treatment, 5:55 post fertilization, picture taken with $30 \mathrm{x}$ magnification. $B$, Preserved specimen, low temperature treatment, 9:11 post fertilization, picture taken with 60x magnification. $C$, Line drawing of mid-blastula stage from Yi and others (1988).
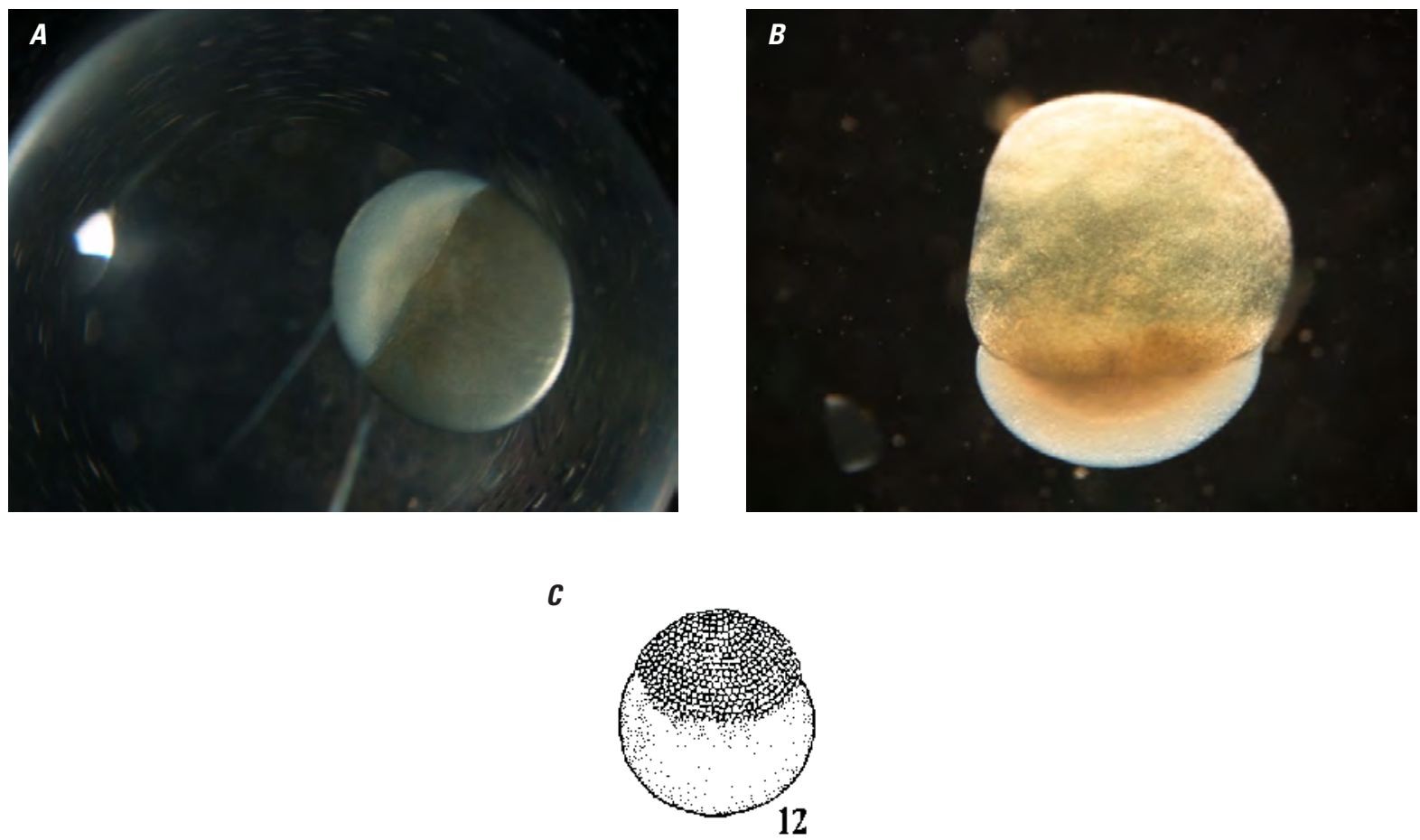

Figure 1-12. Stage 12: Late blastula stage of bighead carp development. Blastodisc gradually expands over yolk, cytoplasm almost disappears ( $\mathrm{Yi}$ and others, 1988). A, Live specimen, low temperature treatment, 9:47 post fertilization, picture taken with 30x magnification. $B$, Preserved specimen, low temperature treatment, 9:42 post fertilization, picture taken with 40x magnification. $C$, Line drawing of late blastula stage from Yi and others (1988). 

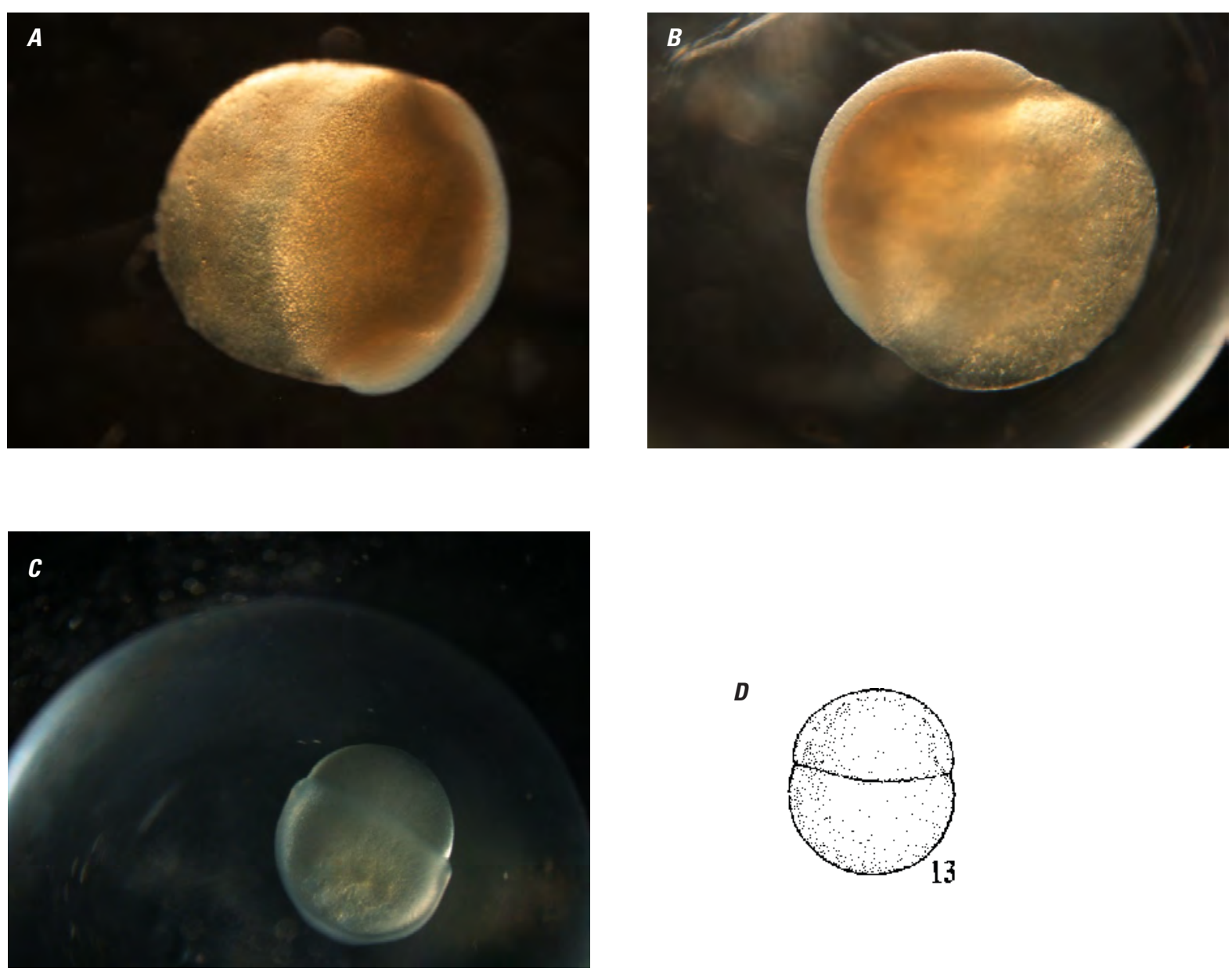

D

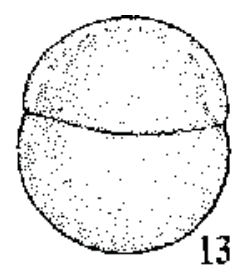

Figure 1-13. Stage 13: Early gastrula stage of bighead carp development. Egg looks round, dorsal lip appears, germ ring forms, blastoderm covers $1 / 3$ of yolk (Yi and others, 1988). $A$, Preserved specimen, high temperature treatment, 8:51 post fertilization, picture taken with 50x magnification. $B$, Preserved specimen, high temperature treatment, 8:00 post fertilization, picture taken with 40x magnification. $C$, Live specimen, high temperature treatment, 10:09 post fertilization, picture taken with 30x magnification. D, Line drawing of early gastrula stage from Yi and others (1988). 

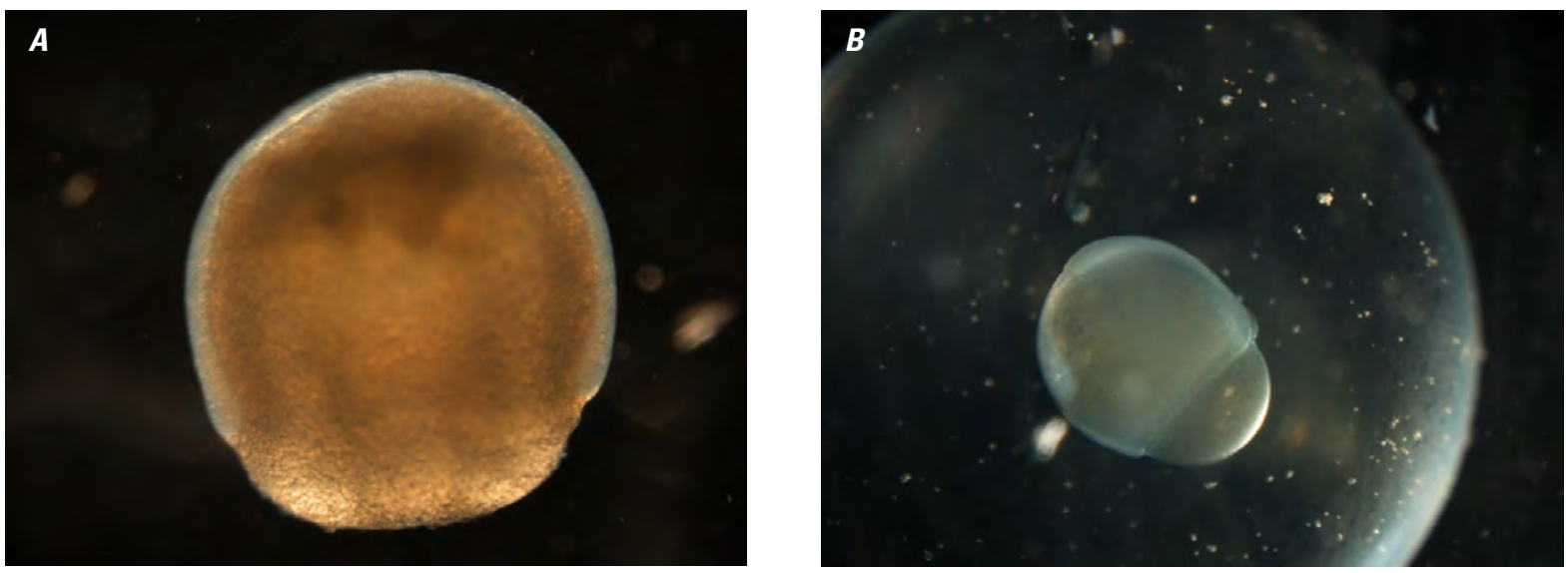

C

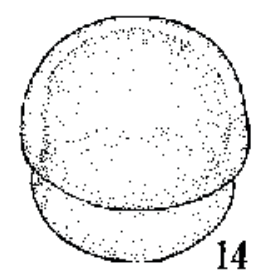

Figure 1-14. Stage 14: Mid-gastrula stage of bighead carp development. Blastoderm covers 2/3 of yolk, embryonic shield appears (Yi and others, 1988). A, Preserved specimen, high temperature treatment, 10:59 post fertilization, picture taken with $60 \mathrm{x}$ magnification. $B$, Live specimen, high temperature treatment, 11:03 post fertilization, picture taken with 30x magnification. $C$, Line drawing of mid-gastrula stage from Yi and others (1988).
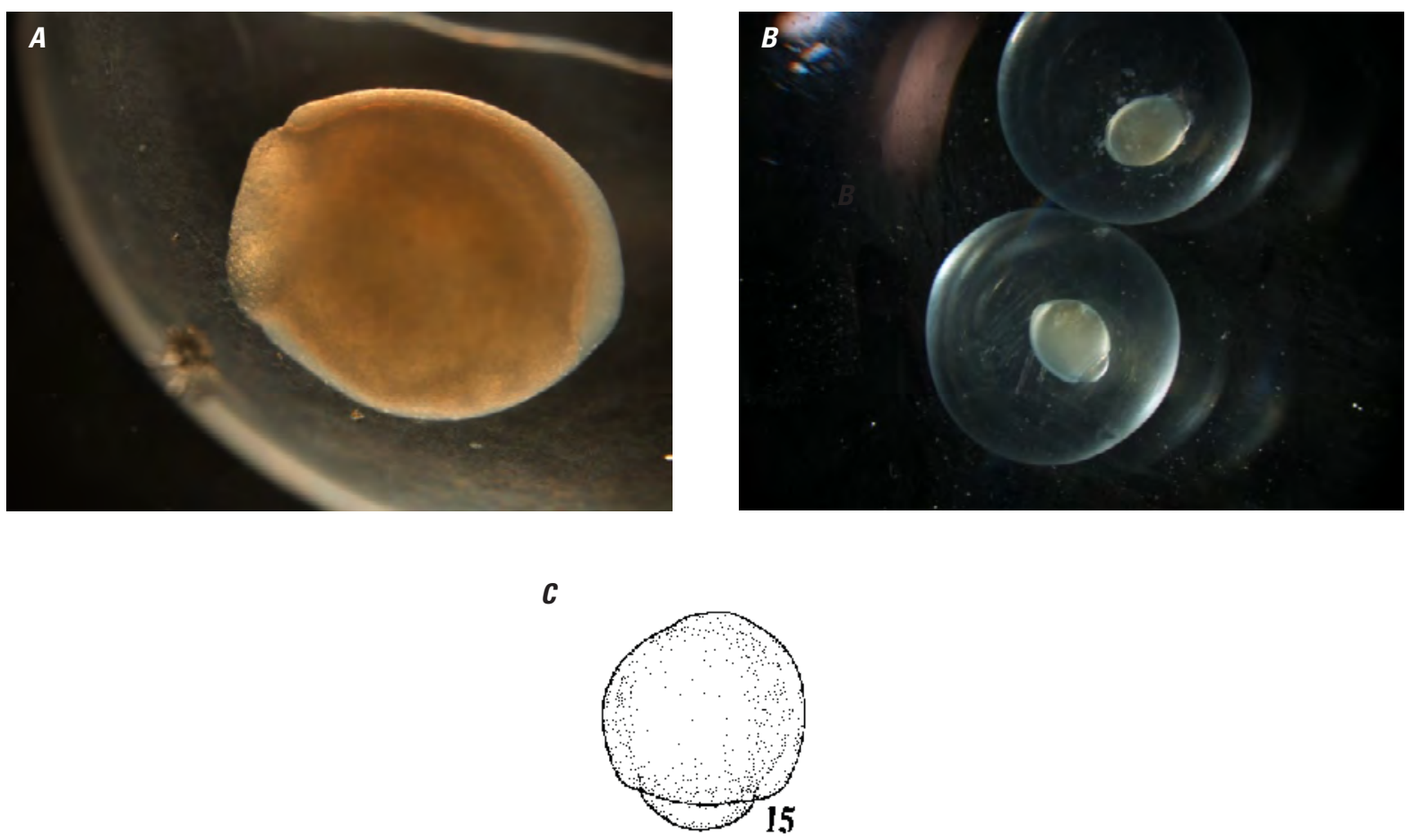

Figure 1-15. Stage 15: Late gastrula stage of bighead carp development. Blastoderm covers $5 / 6$ of yolk, rudimentary embryo visible (Yi and others, 1988). A, Preserved specimen, high temperature treatment, 12:10 post fertilization, picture taken with 50x magnification. $B$, Live specimen, high temperature treatment, 11:35 post fertilization, picture taken with 10x magnification. $C$, Line drawing of late gastrula stage from $Y i$ and others (1988). 


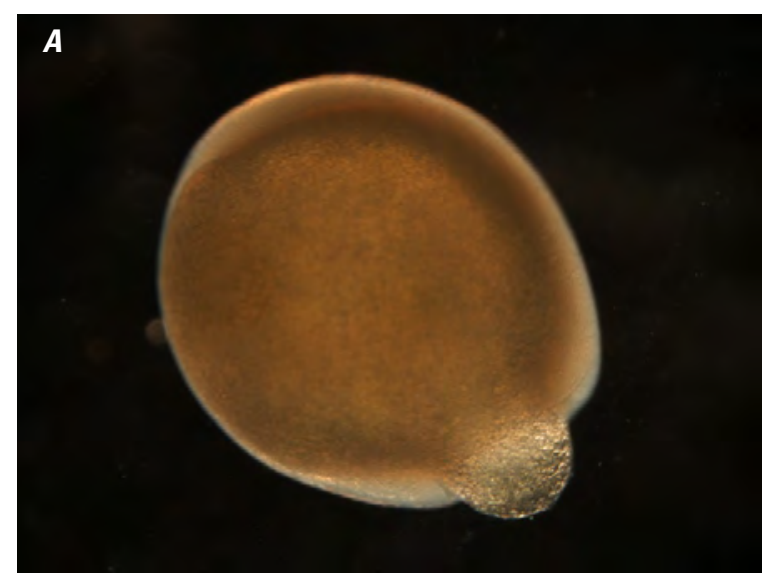

$B$

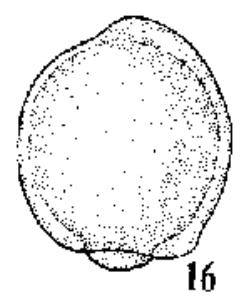

Figure 1-16. Stage 16: Neurula stage of bighead carp development. Head enlarges, blastoderm covers almost entire yolk, except for yolk plug (Yi and others, 1988). A, Preserved specimen, high temperature treatment, 12:53 post fertilization, picture taken with 50x magnification. $B$, Line drawing of neurula stage from Yi and others (1988).
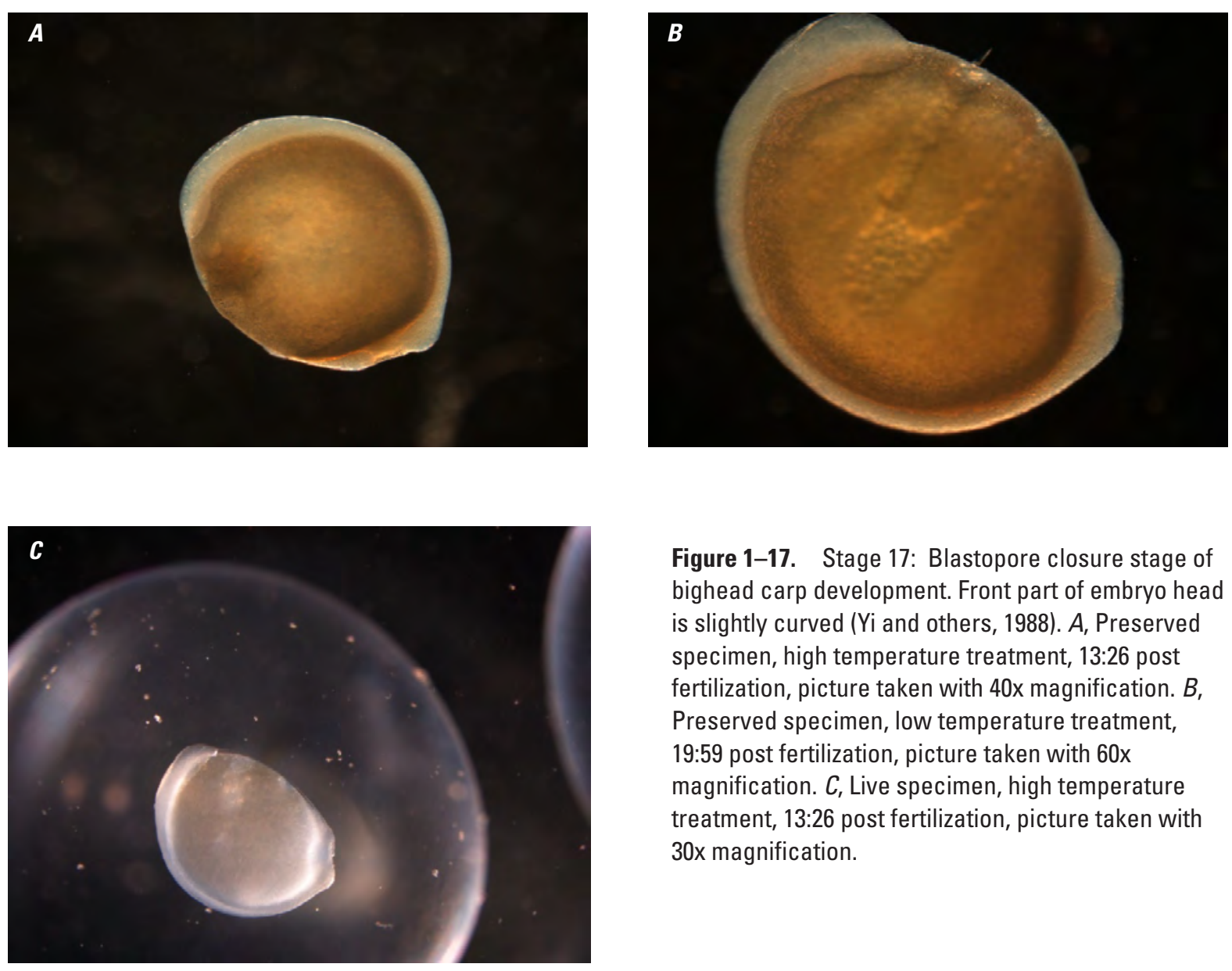

Figure 1-17. Stage 17: Blastopore closure stage of bighead carp development. Front part of embryo head is slightly curved (Yi and others, 1988). A, Preserved specimen, high temperature treatment, 13:26 post fertilization, picture taken with $40 x$ magnification. $B$, Preserved specimen, low temperature treatment, 19:59 post fertilization, picture taken with $60 \mathrm{x}$ magnification. $C$, Live specimen, high temperature treatment, 13:26 post fertilization, picture taken with 30x magnification. 


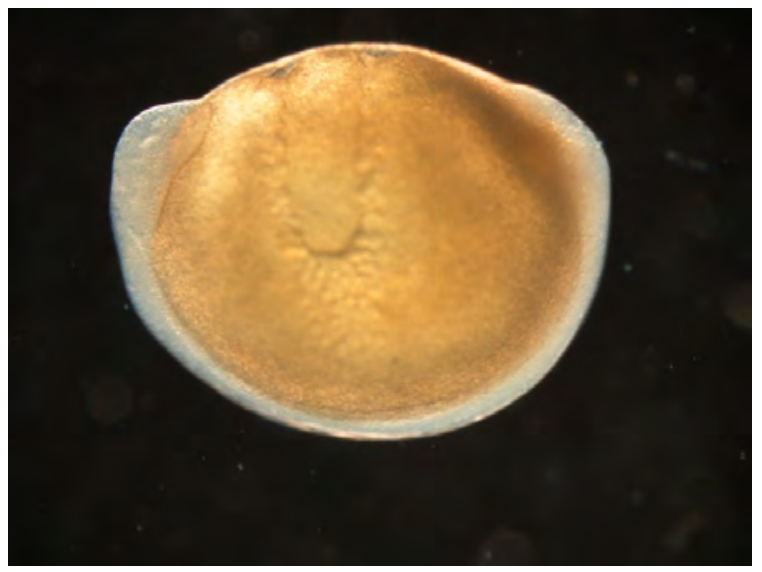

Figure 1-18. Stage 18: Somite appearance stage of bighead carp development, 1-3 pairs of somites present, head is round with a flat front margin ( $\mathrm{Yi}$ and others, 1988). Preserved specimen, low temperature treatment, 19:59 post fertilization, picture taken with 50x magnification.

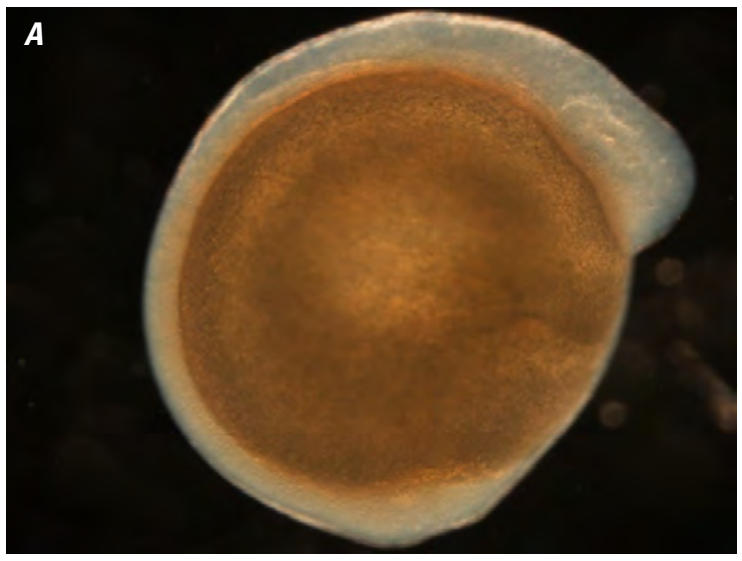

B

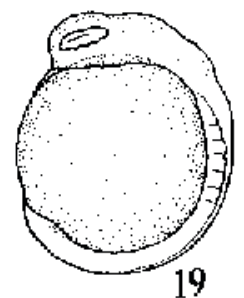

Figure 1-19. Stage 19: Optic primordium stage of bighead carp development. Optic primordium dimly visible as a long oval shape with a slightly crenulated lower margin. Embryo embraces 3/4 of yolk, no oil droplets in yolk, 4-6 pairs of somites present (Yi and others, 1988). $A$, Preserved specimen, high temperature treatment, 15:20 post fertilization, picture taken with 50x magnification. $B$, Line drawing of optic primordium stage from $\mathrm{Yi}$ and others (1988). 

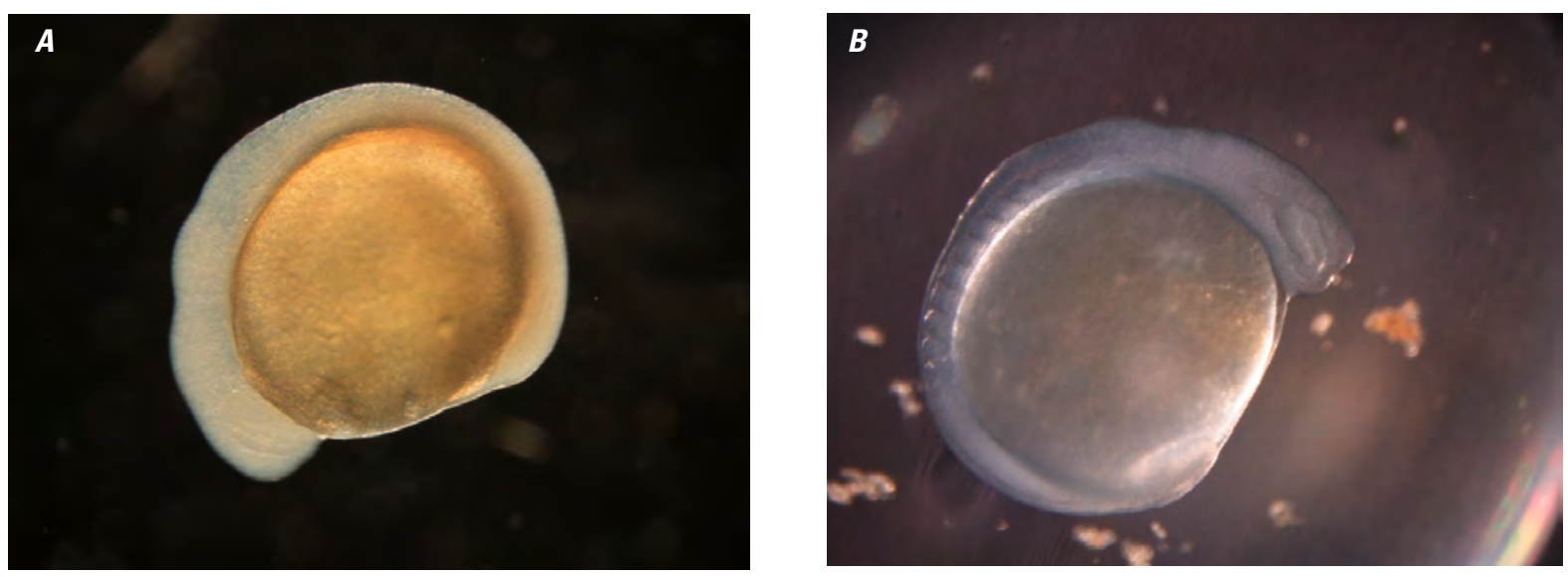

Figure 1-20. Stage 20: Optic vesicle stage of bighead carp development. Eyes enlarge, 7-10 pairs of somites present (Yi and others, 1988). A, Preserved specimen, high temperature treatment, 16:20 post fertilization, picture taken with 40x magnification. $B$, Live specimen, high temperature treatment, 16:52 post fertilization, picture taken with 50x magnification.
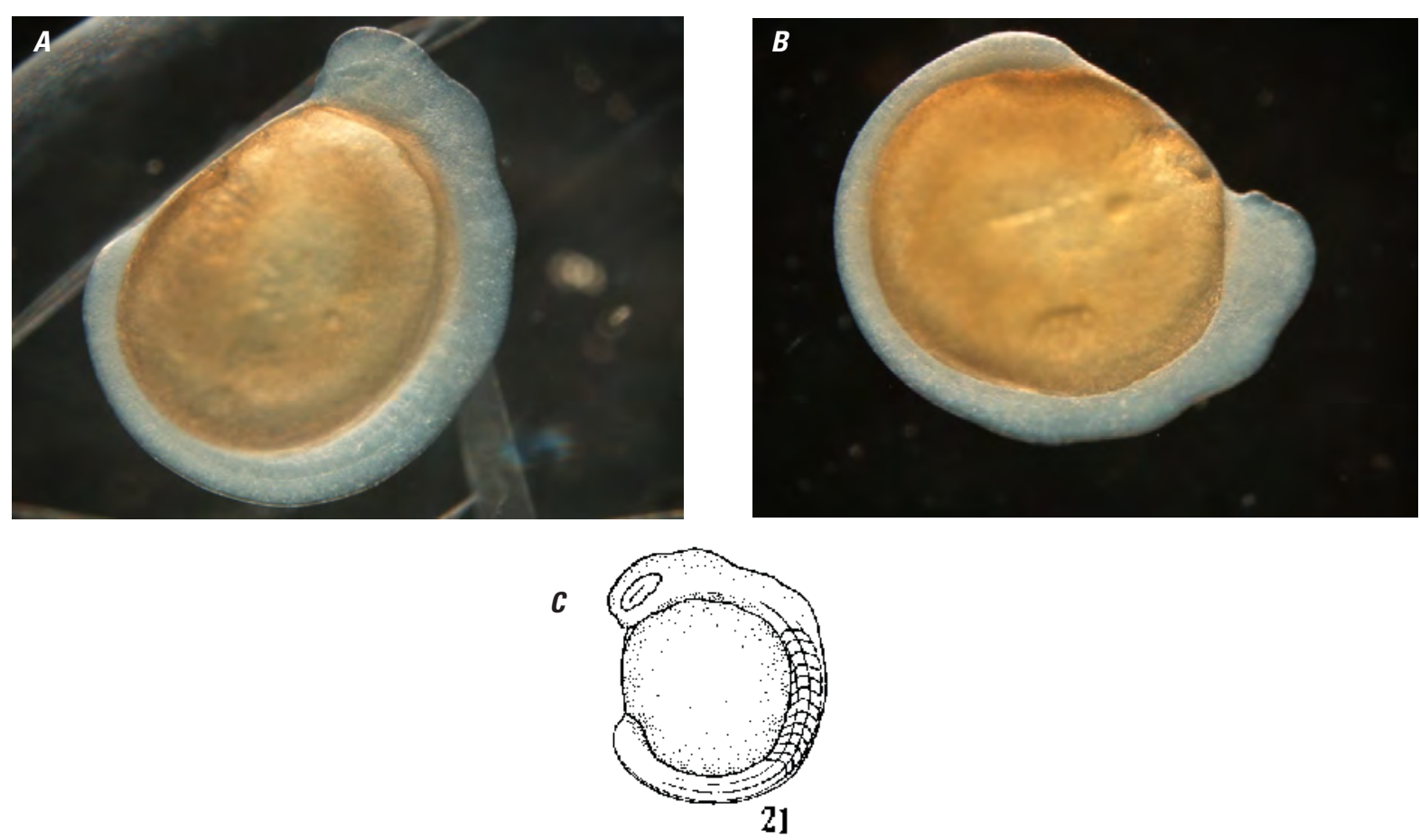

Figure 1-21. Stage 21: Olfactory placode stage of bighead carp development. Eyes enlarging, lower edge of eye still slightly crenulated, olfactory placode appears, notochord clearly visible, 11-14 pairs of somites present ( $Y$ i and others, 1988). $A$, Preserved specimen, high temperature treatment, 17:58 post fertilization, picture taken with 50x magnification. $B$, Preserved specimen, low temperature treatment, 23:16 post fertilization, picture taken with 50x magnification. $C$, Line drawing of olfactory placode stage from $\mathrm{Yi}$ and others (1988). 

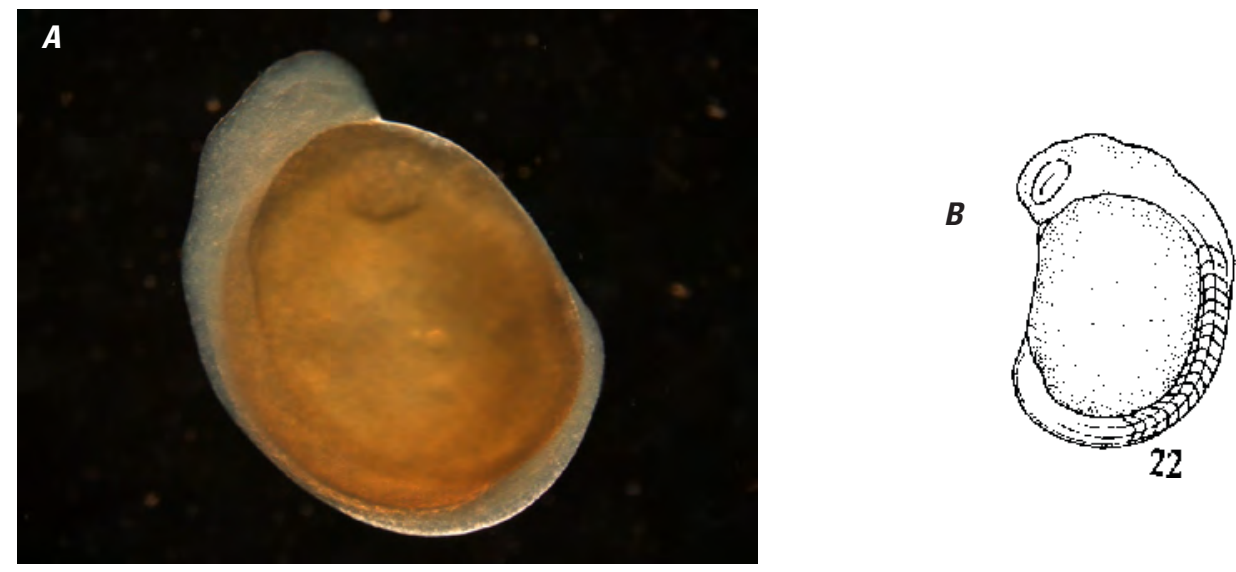

Figure 1-22. Stage 22: Tail bud stage of bighead carp development. Optic vesicle large and clearly visible, tail bud appears, yolk elongates, 15-17 pairs of somites present (Yi and others, 1988). A, Preserved specimen, low temperature treatment, 23:54 post fertilization, picture taken with 50x magnification. $B$, Line drawing of tail bud stage from Yi and others (1988).
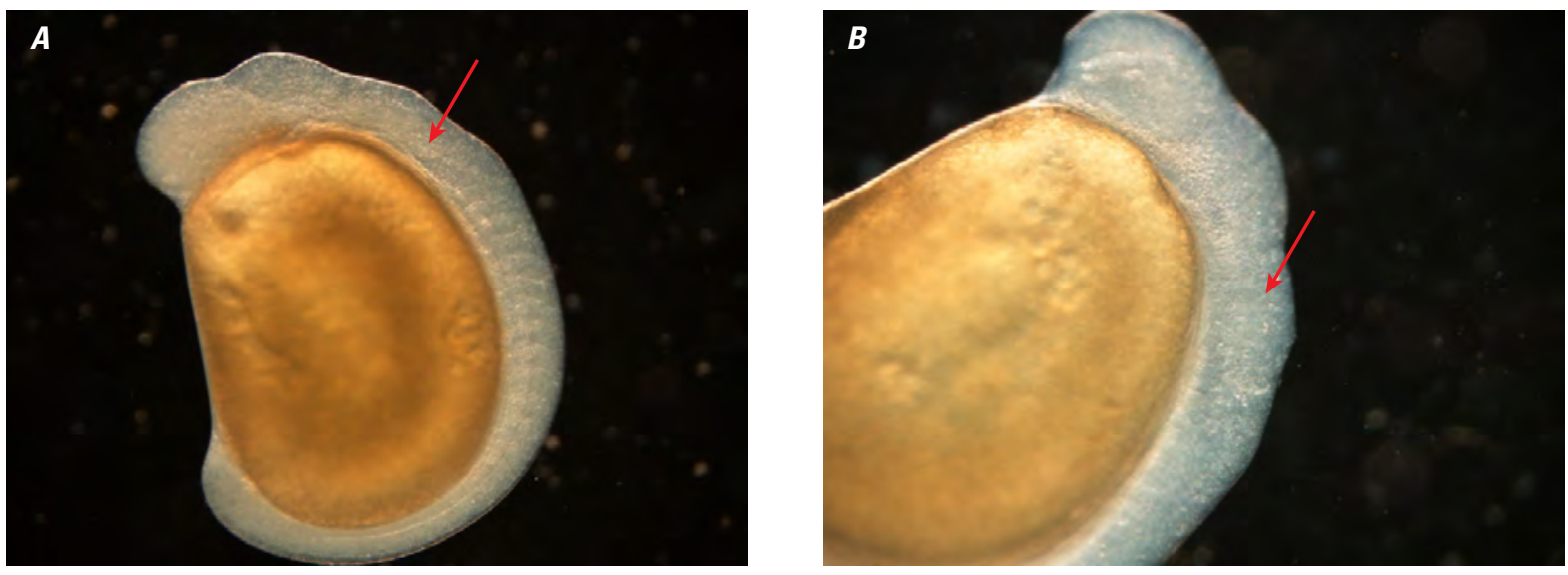

Figure 1-23. Stage 23: Otic capsule stage of bighead carp development. Yolk between head and tail begins invagination, 18-19 pairs of somites present (Yi and others, 1988). A, Preserved specimen, low temperature treatment, 26:18 post fertilization, picture taken with 50x magnification. Arrow points to the otic capsule. $B$, Preserved specimen, low temperature treatment, 25:16 post fertilization, picture taken with 60x magnification. Arrow points to the otic capsule. 

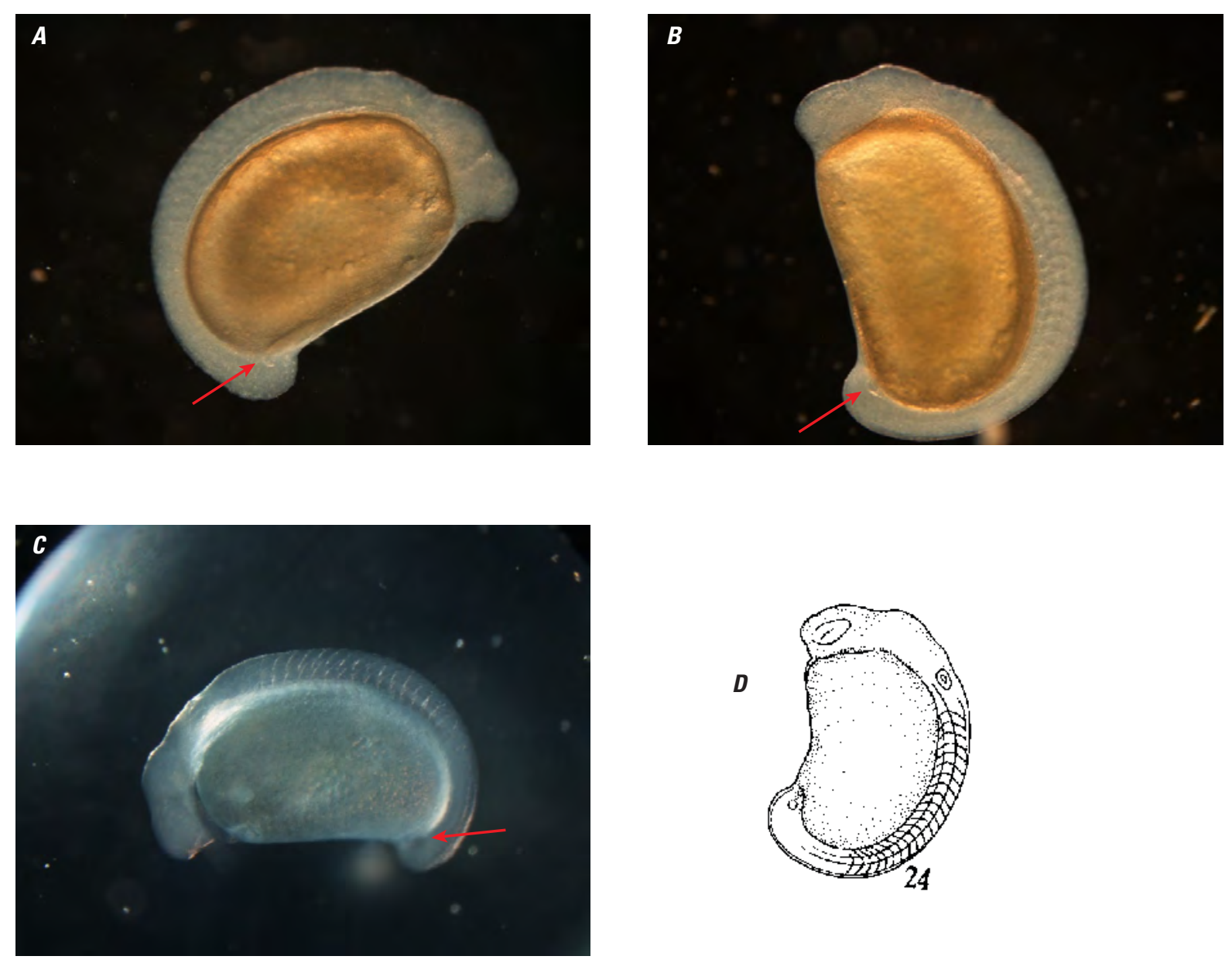

Figure 1-24. Stage 24: Tail vesicle stage of bighead carp development. Otic capsule clearly visible, tail bud expands outward, tail vesicle appears, embryo becomes thicker, yolk elongates and becomes kidney shaped, 20-21 pairs of somites present (Yi and others, 1988). A, Preserved specimen, low temperature treatment, 28:52 post fertilization, picture taken with $40 \mathrm{x}$ magnification. Arrow points to the tail vesicle. $B$, Preserved specimen, high temperature treatment, 19:47 post fertilization, picture taken with 40x magnification. Arrow points to the tail vesicle. $C$, Live specimen, high temperature treatment, 20:06 post fertilization, picture taken with 40x magnification. Arrow points to the tail vesicle. $D$, Line drawing of tail vesicle stage from Yi and others (1988).
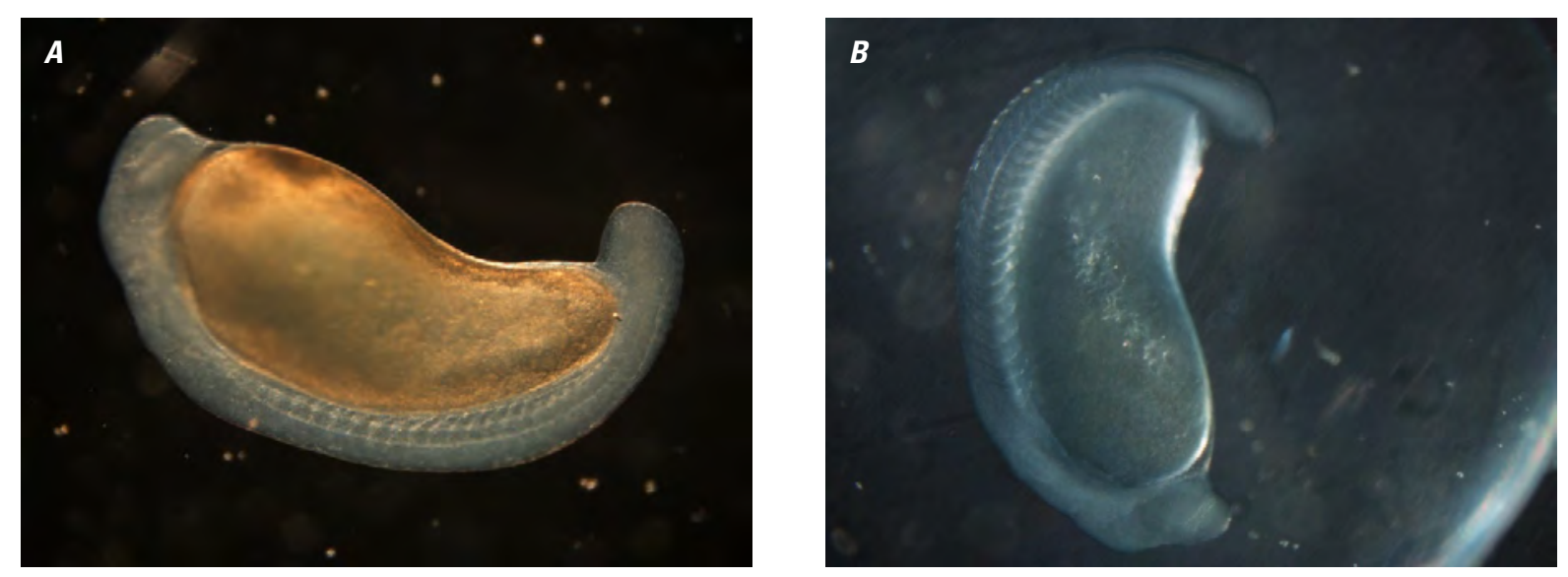

Figure 1-25. Stage 25: Caudal fin stage of bighead carp development. Caudal fin expands outward, 22-23 pairs of somites present ( $\mathrm{Yi}$ and others, 1988). A, Preserved specimen, high temperature treatment, 21:20 post fertilization, picture taken with $40 x$ magnification. $B$, Live specimen, high temperature treatment, 20:55 post fertilization, picture taken with 40x magnification. 

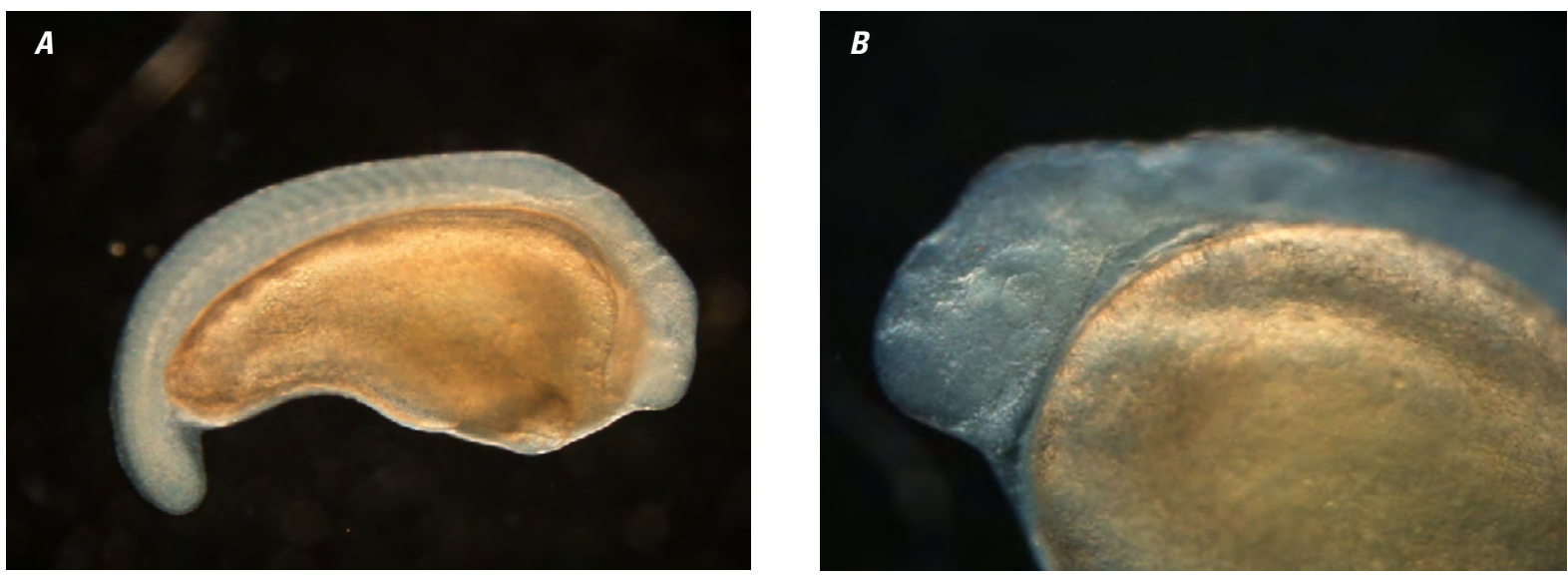

C

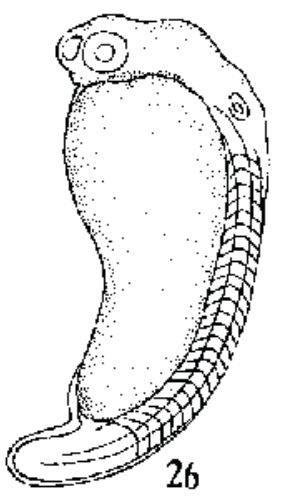

Figure 1-26. Stage 26: Lens formation stage of bighead carp development. Olfactory vesicle clearly visible; lens forms, embryo and yolk elongate. Bump on brain area slightly raised, tail vesicle disappears, 24 pairs of somites present (Yi and others, 1988). A, Preserved specimen, high temperature treatment, 21:57 post fertilization, picture taken with 40x magnification. $B$, Preserved specimen, high temperature treatment, 24:19 post fertilization, picture taken with 100x magnification. $C$, Line drawing of lens formation stage from Yi and others (1988).

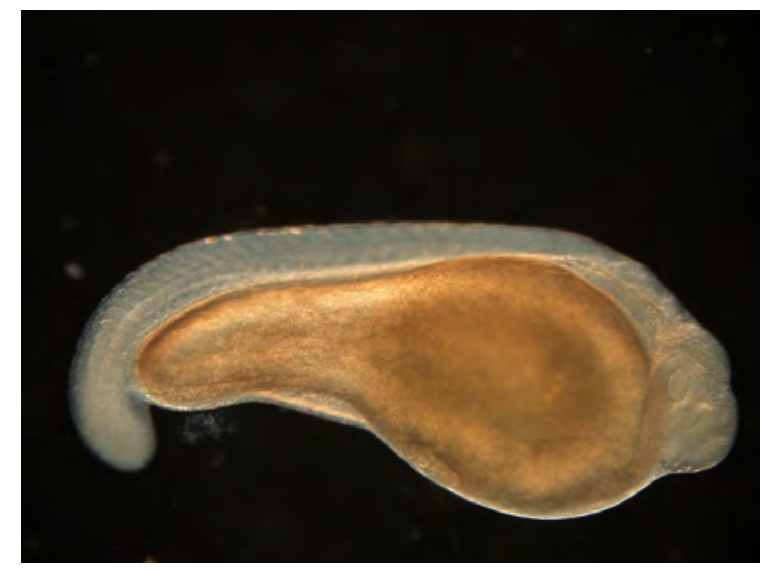

Figure 1-27. Stage 27: Muscular effect stage of bighead carp development. Embryo lashes slightly, end of yolk-light gray/blue, 25-27 pairs of somites present (Yi and others 1988). Preserved specimen, low temperature treatment, 32:33 post fertilization, picture taken with $40 x$ magnification. 


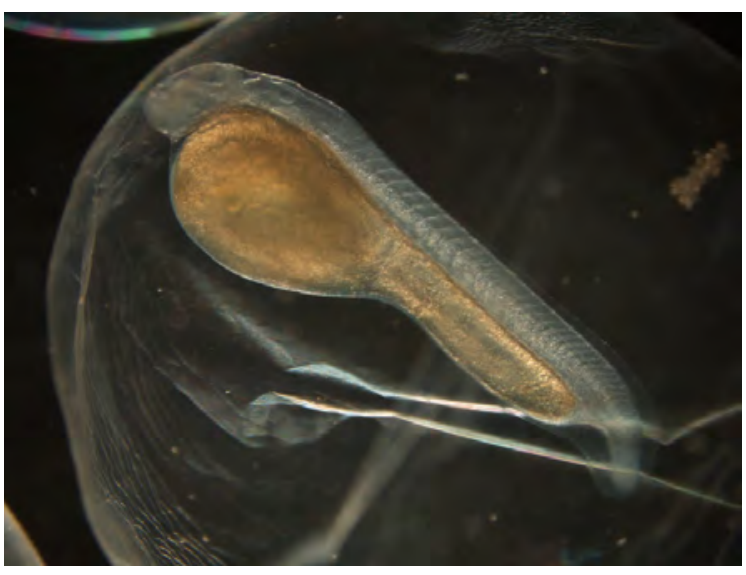

Figure 1-28. Stage 28: Heart rudiment stage of bighead carp development. Embryo lashes occasionally, 28-29 pairs of somites present (Yi and others, 1988). Preserved specimen, high temperature treatment, 27:24 post fertilization, picture taken with 30x magnification (Yi and others, 1988).
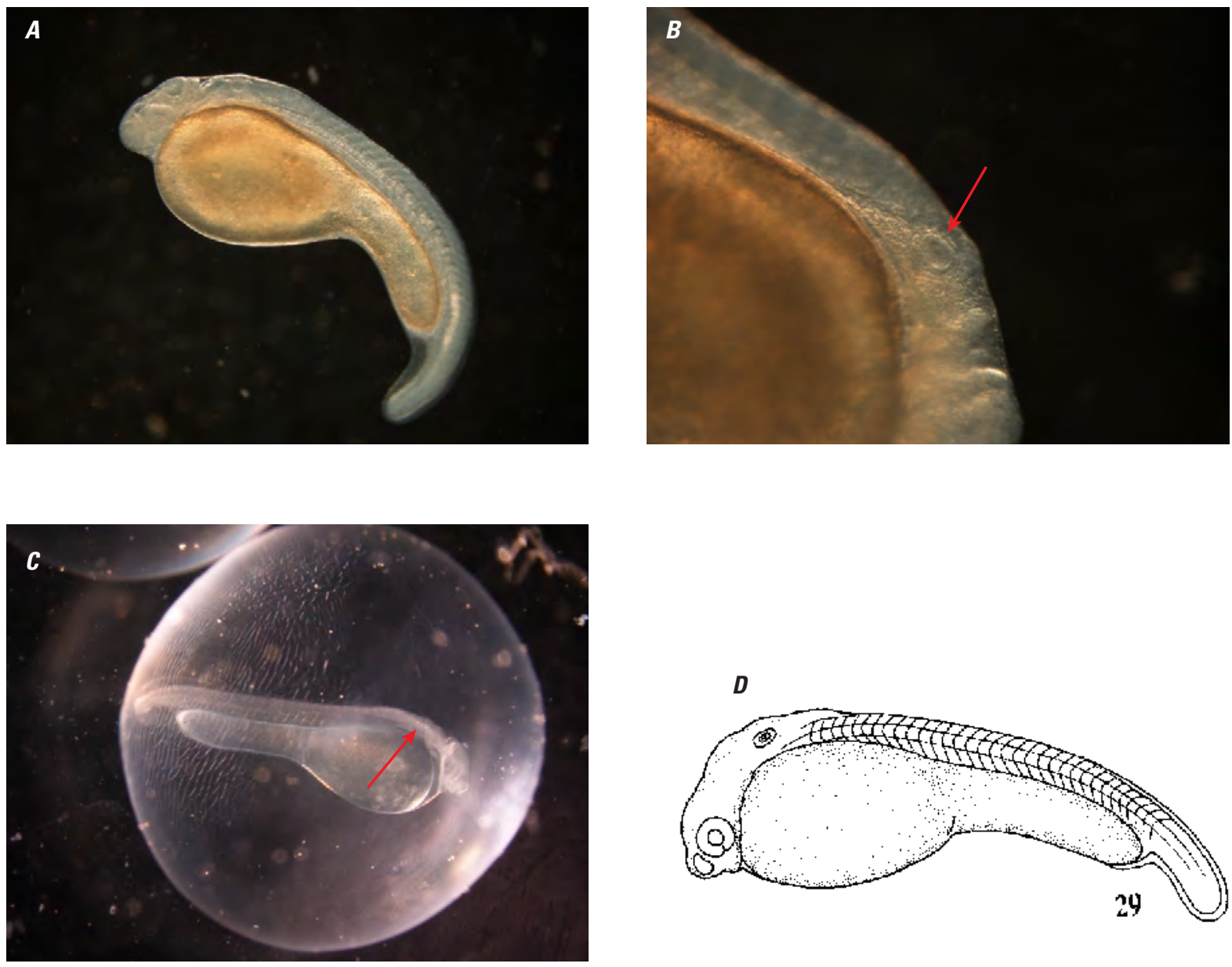

Figure 1-29. Stage 29: Otolith appearance stage of bighead carp development. Otolith appears, embryo further elongates, tail relatively long and often moves to one side, embryo rotates occasionally, anterior half of yolk sac oval and wide, whereas posterior half is narrow, 30-32 pairs of somites present (Yi and others, 1988). $A$, Preserved specimen, low temperature treatment, 37:45 post fertilization, picture taken with 30x magnification. $B$, Preserved specimen, low temperature treatment, 35:45 post fertilization, picture taken with 80x magnification. Arrow points to otoliths. $C$, Live specimen,high temperature treatment, 27:24 post fertilization, picture taken with 20x magnification. Arrow points to otoliths. D, Line drawing of otolith appearance stage from Yi and others (1988). 

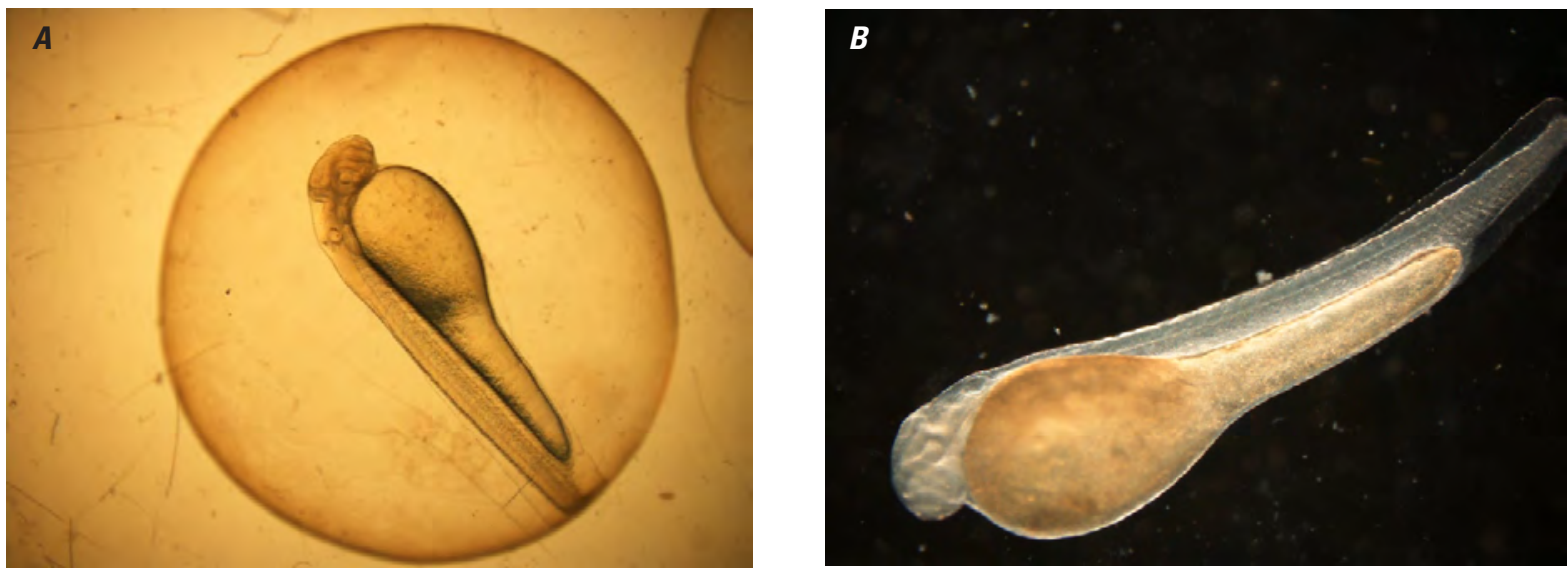

Figure 1-30. Stage 30: Heart pulsation stage of bighead carp development. Heart begins to pulsate; embryo rotates continuously. 33-35 pairs somites present ( $Y i$ and others, 1988). A, Live specimen, low temperature treatment, 45:03 post fertilization, picture taken with 20x magnification. $B$, Preserved specimen, low temperature treatment, 41:41 post fertilization, picture taken with 30x magnification.
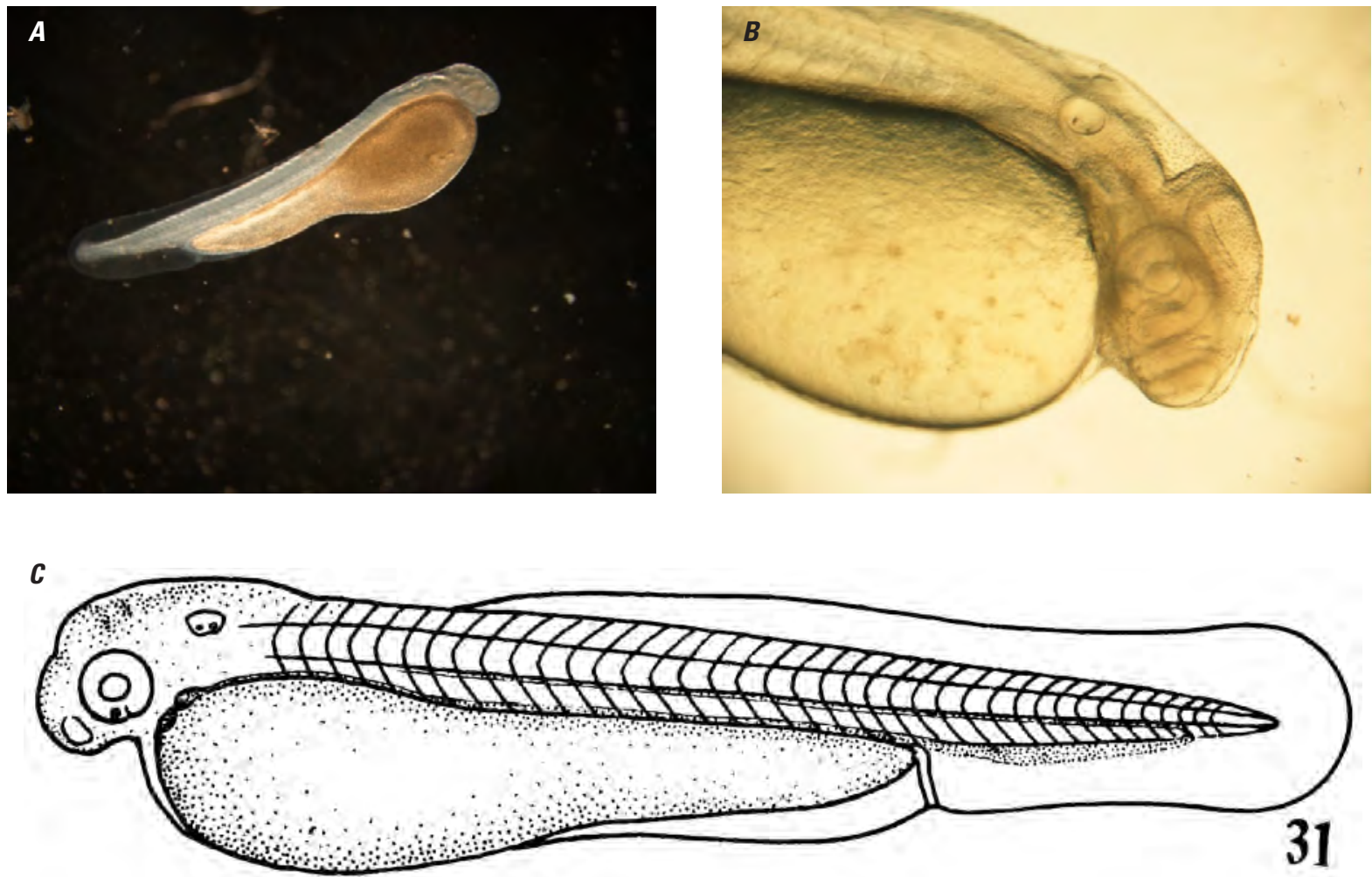

Figure 1-31. Stage 31: Hatching stage of bighead carp development. The larvae is approximately 7.0 millimeters; tail length long; head extends straight forward; anterior part of yolk sac large and oval, posterior part of yolk sac narrow and lengthened tear drop shape. Heart at the top of anterior edge of yolk sac. Black spot appears below eye, caudal vein large and flat (Yi and others, 1988). The black spot below eye was not apparent until stage 32. A, Preserved specimen, high temperature treatment, 31:11 post fertilization, picture taken with 30x magnification. $B$, Live specimen, low temperature treatment, 45:05 post fertilization, picture taken with 70x magnification. $C$, Line drawing of hatching stage from Yi and others (1988). 

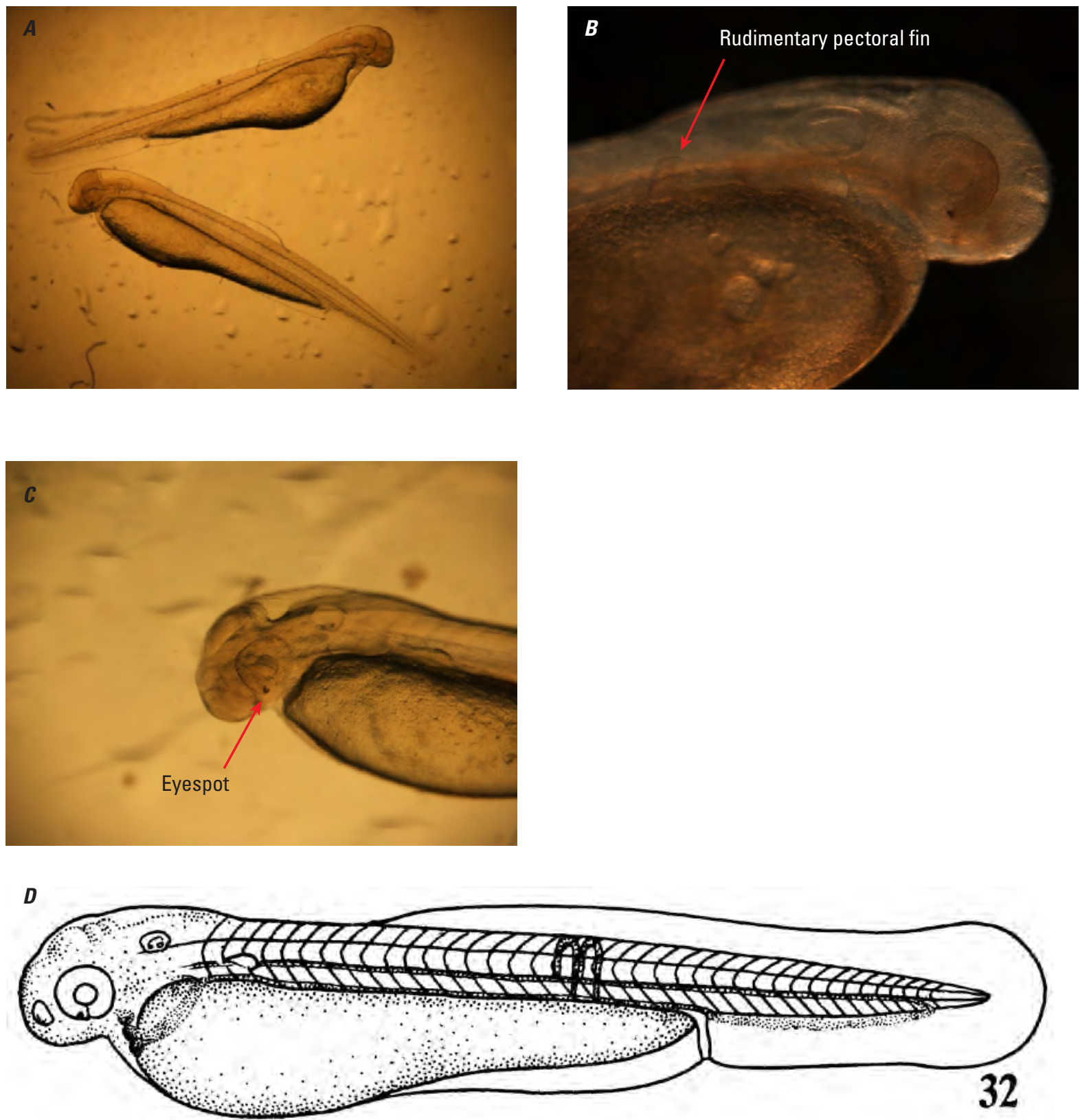

Figure 1-32. Stage 32: Rudimentary pectoral fin stage of bighead carp development. The larvae are approximately 7.1 millimeters; rudimentary pectoral fin appears between myomeres 2 and 3 . Caudal vein wide and long. Cuvierian ducts appear on anterior tip of yolk sac (Yi and others, 1988). $A$, Live specimen, high temperature treatment, $42: 35$ post fertilization, picture taken with $20 x$ magnification. $B$, Preserved specimen, high temperature treatment, 36:34 post fertilization, picture taken with 80x magnification. Arrow points to the rudimentary pectoral fin. $C$, Live specimen, high temperature treatment, $42: 35$ post fertilization, picture taken with 50x magnification. Arrow points to the eyespot. $D$, Line drawing of rudimentary pectoral fin stage from Yi and others (1988). 


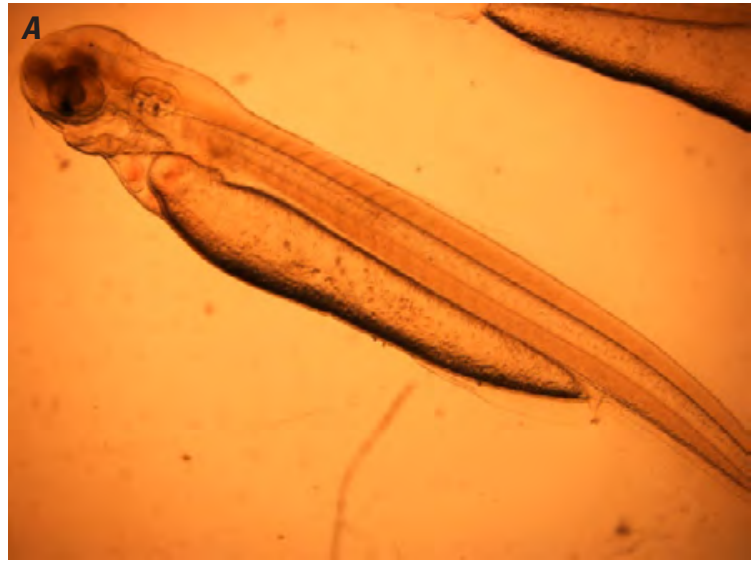

Figure 1-33. Stage 33: Gill arch stage of bighead carp development. The larvae are 7.5 millimeters; four gill arches appear. Indentation of mouth appears; caudal vein and cuvierian ducts obvious. Yolk sac shrinks and anterior potion narrows (Yi and others, 1988). A, Live specimen, low temperature treatment, 68:35 post fertilization, picture taken with 30x magnification. $B$, Line drawing of gill arch stage from Yi and others (1988).

$\boldsymbol{B}$
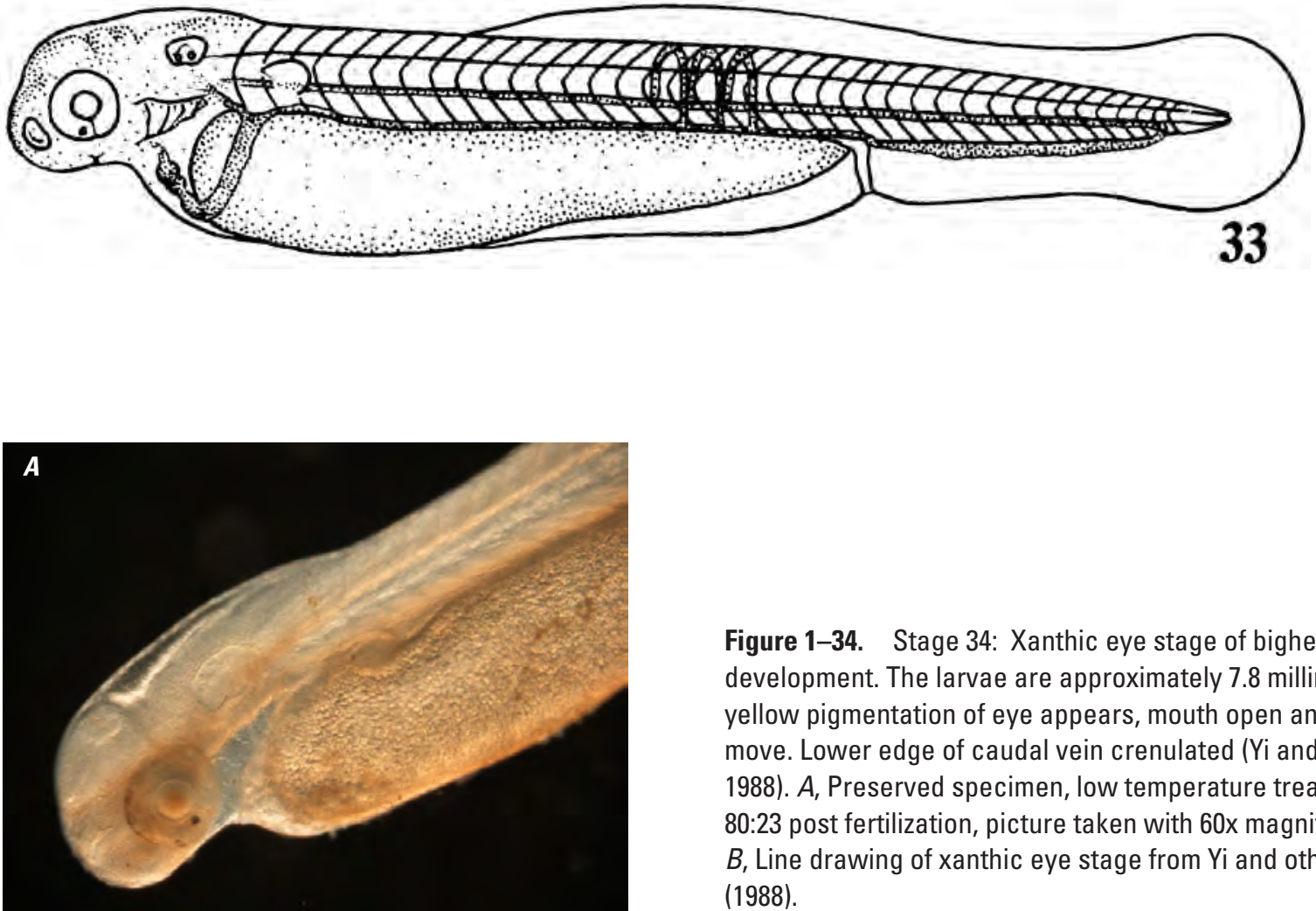

Figure 1-34. Stage 34: Xanthic eye stage of bighead carp development. The larvae are approximately 7.8 millimeters; yellow pigmentation of eye appears, mouth open and can move. Lower edge of caudal vein crenulated (Yi and others, 1988). A, Preserved specimen, low temperature treatment, 80:23 post fertilization, picture taken with $60 \mathrm{x}$ magnification. $B$, Line drawing of xanthic eye stage from $\mathrm{Yi}$ and others (1988).

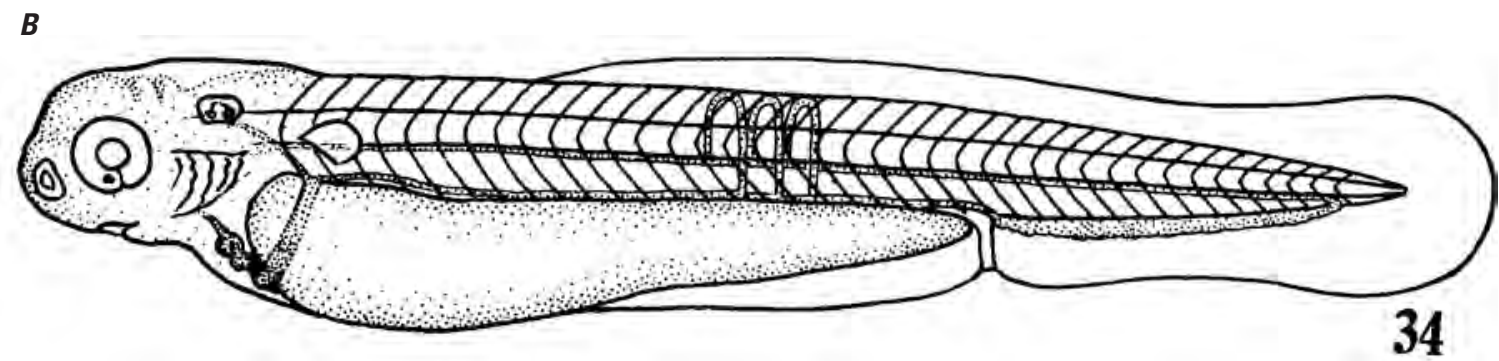




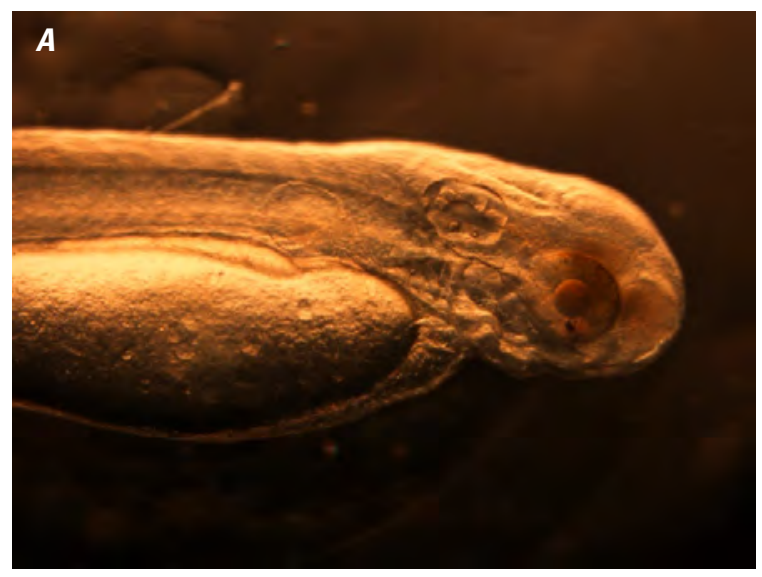

Figure 1-35. Stage 35: Gill filament stage of bighead carp development. The larvae is approximately 8.1 millimeters; gill filaments appear, otic capsule and pectoral fins enlarge. Body relatively thick (Yi and others, 1988). A, Live specimen, low temperature treatment, 99:45 post fertilization, picture taken with 50x magnification. $B$, Line drawing of gill filament stage from Yi and others (1988).

B
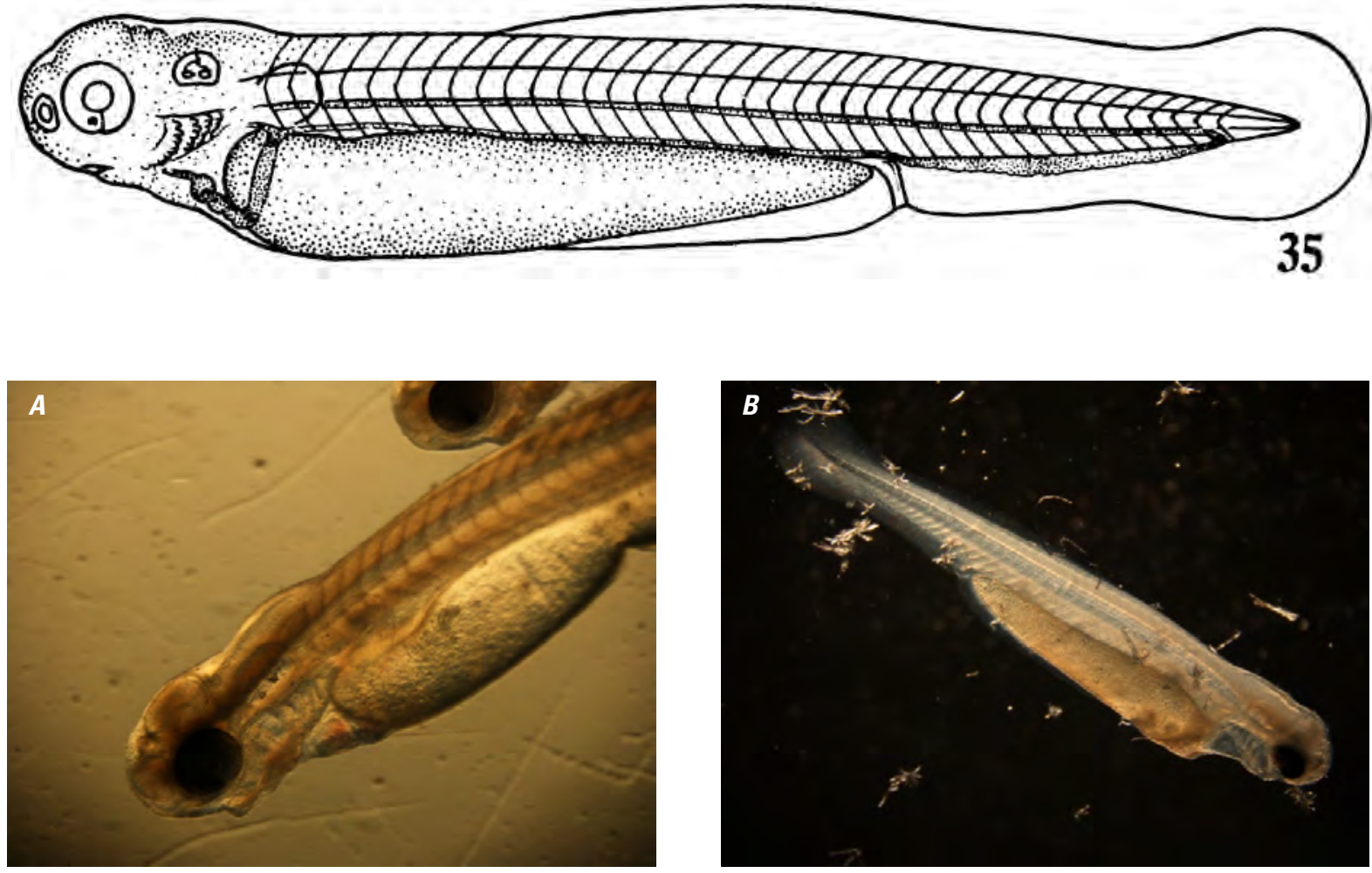

C

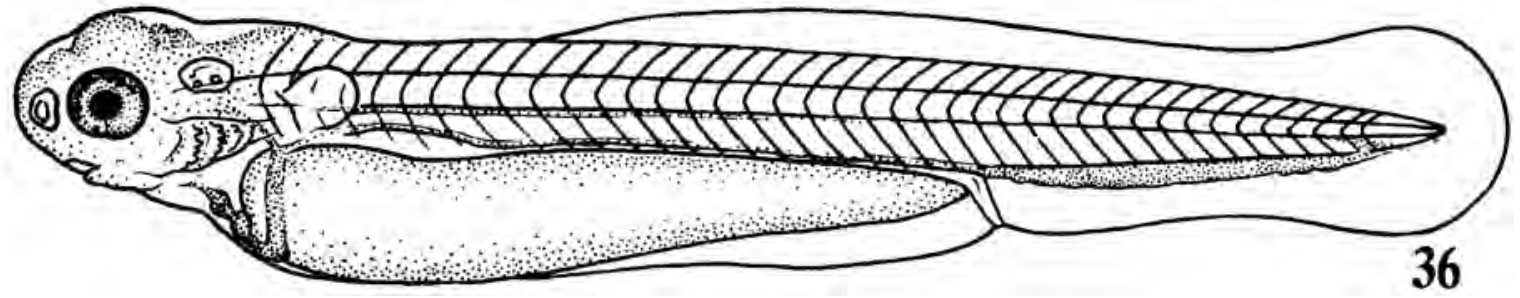

Figure 1-36. Stage 36: Melanoid eye stage of bighead carp development. The larvae is approximately 8.3 millimeters; melanophores appear around eye. Caudal fin wide, long, dark yellow. Normal swimming begins (Yi and others, 1988). A, Live specimen, high temperature treatment, 79:50 post fertilization, picture taken with 40x magnification. $B$, Preserved specimen, high temperature treatment, 99:43 post fertilization, picture taken with 20x

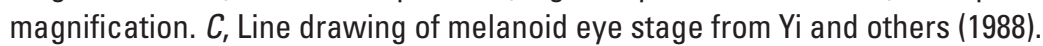



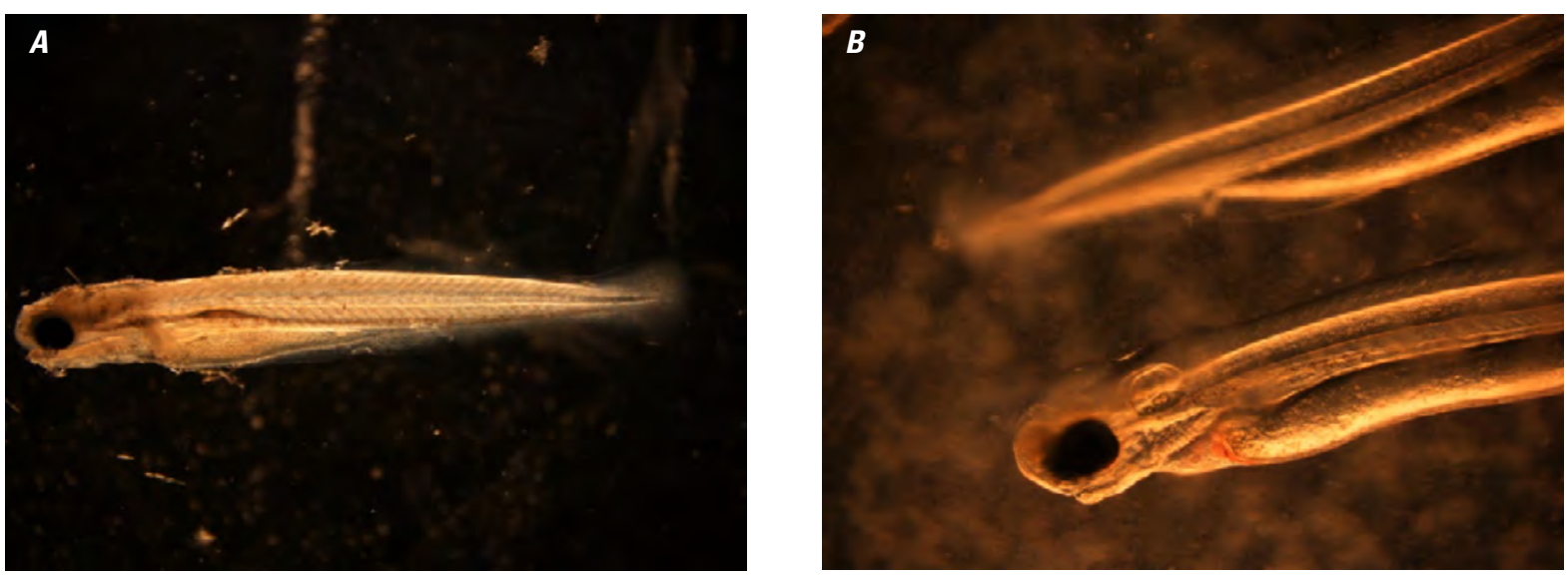

C

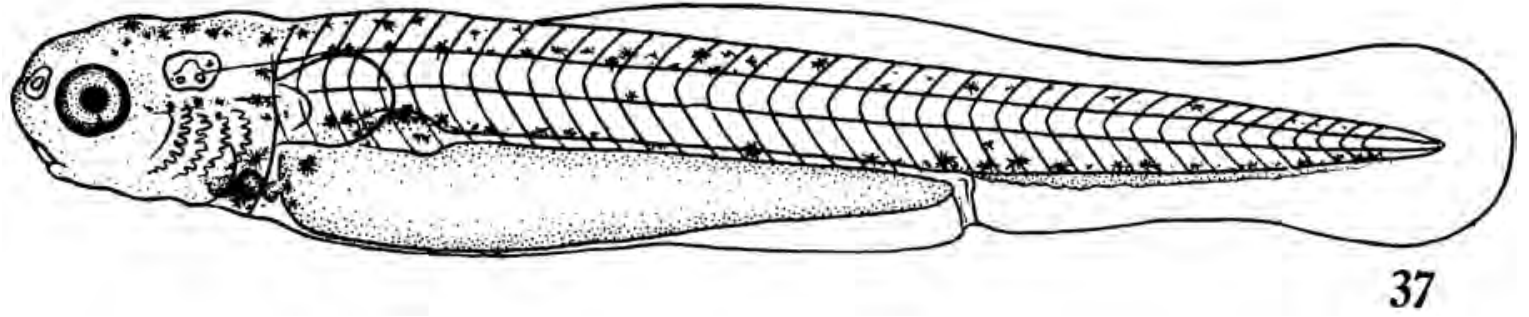

Figure 1-37. Stage 37: Gas bladder emergence stage of bighead carp development. The larvae is approximately 9.2 millimeters; blunt snout, initial gas bladder appears. Gill filaments extend, gut continuous, increasing pigmentation. Swims normally (Yi and others, 1988). A, Preserved specimen, high temperature treatment, 117:11 post fertilization, picture taken with 20x magnification. $B$, Live specimen, high temperature treatment, 117:11 post fertilization, picture taken with 30x magnification. $C$, Line drawing of gas bladder emergence stage from Yi and others (1988). 

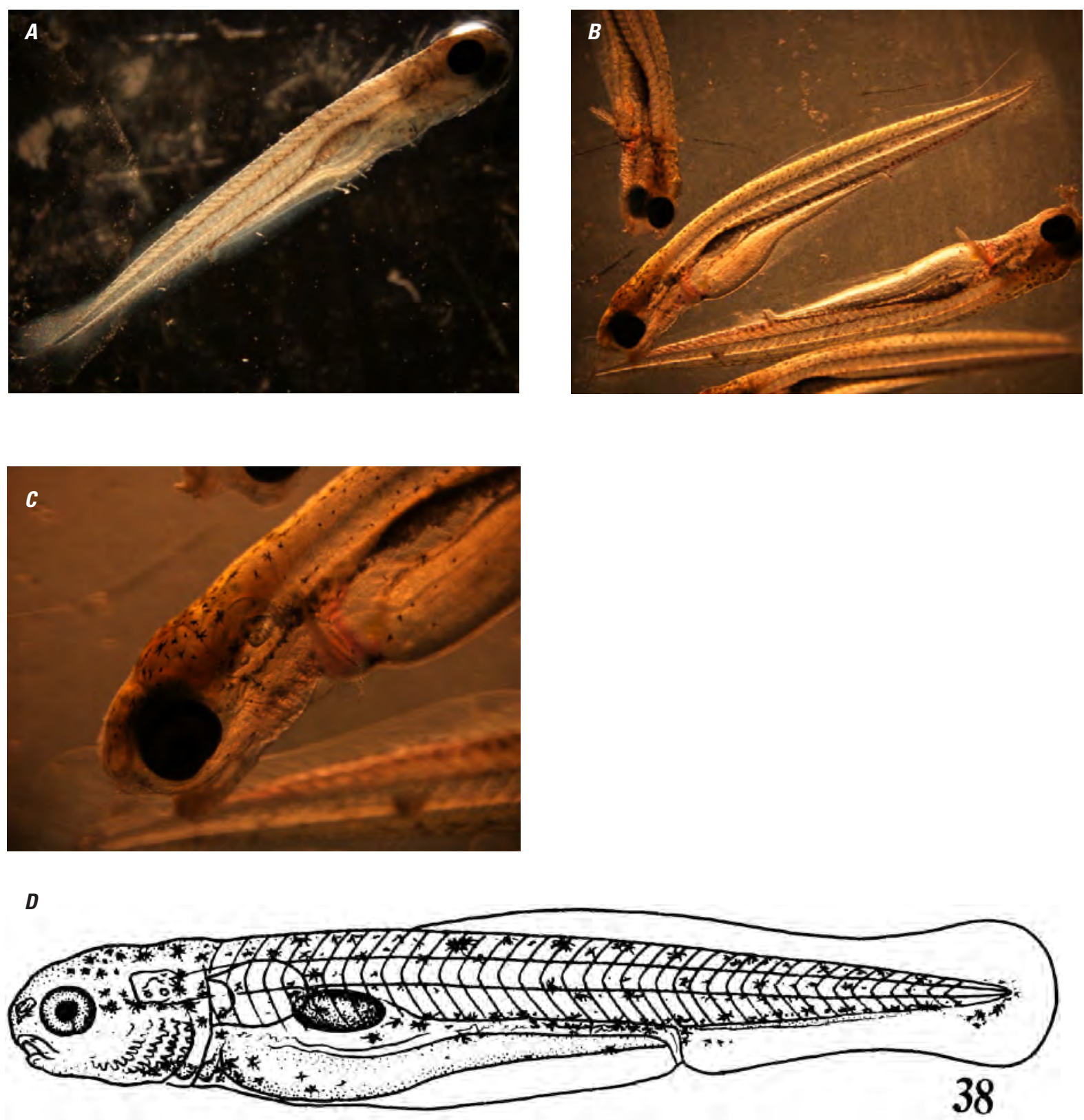

Figure 1-38. Stage 38: 1-chamber gas bladder stage. The larvae is approximately 9.4 millimeters; the gas bladder appears and is oval. Inside of gut appears wavy. Yolk sac shrinks to become a curved strip. Upper jaw forms. Pigment on head increases. Pre-anal finfold extends forward to posterior margin of gas bladder (Yi and others, 1988). $A$, Preserved specimen, low temperature treatment, 189:46 post fertilization, picture taken with 20x magnification. $B$, Live specimen, high temperature treatment, 141:21 post fertilization, picture taken with 20x magnification. $C$, Live specimen, high temperature treatment, 141:21 post fertilization, picture taken with 50x magnification. $D$, Line drawing of one chamber gas bladder stage from Yi and others (1988). 

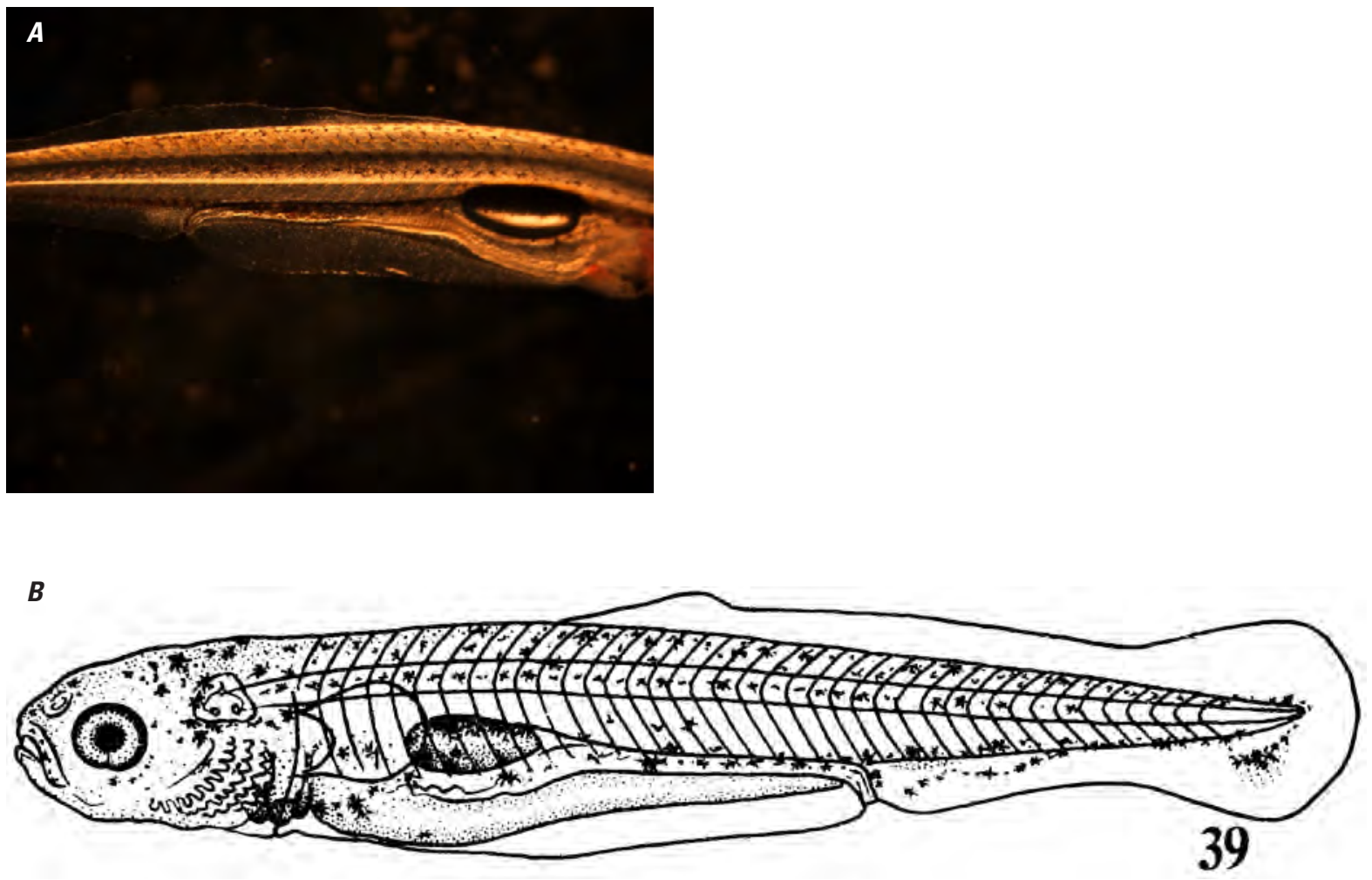

Figure 1-39. Stage 39: Dorsal fin differentiation stage of bighead carp development. The larvae is approximately 9.7 millimeters; dorsal margin of anterior part of dorsal finfold has a sigmoid shape. Narrow strip of yolk sac remains. $A$, Preserved specimen, low temperature treatment, 213:00 post fertilization, picture taken with 30x magnification. $B$, Line drawing of dorsal fin differentiation stage from Yi and others (1988). 

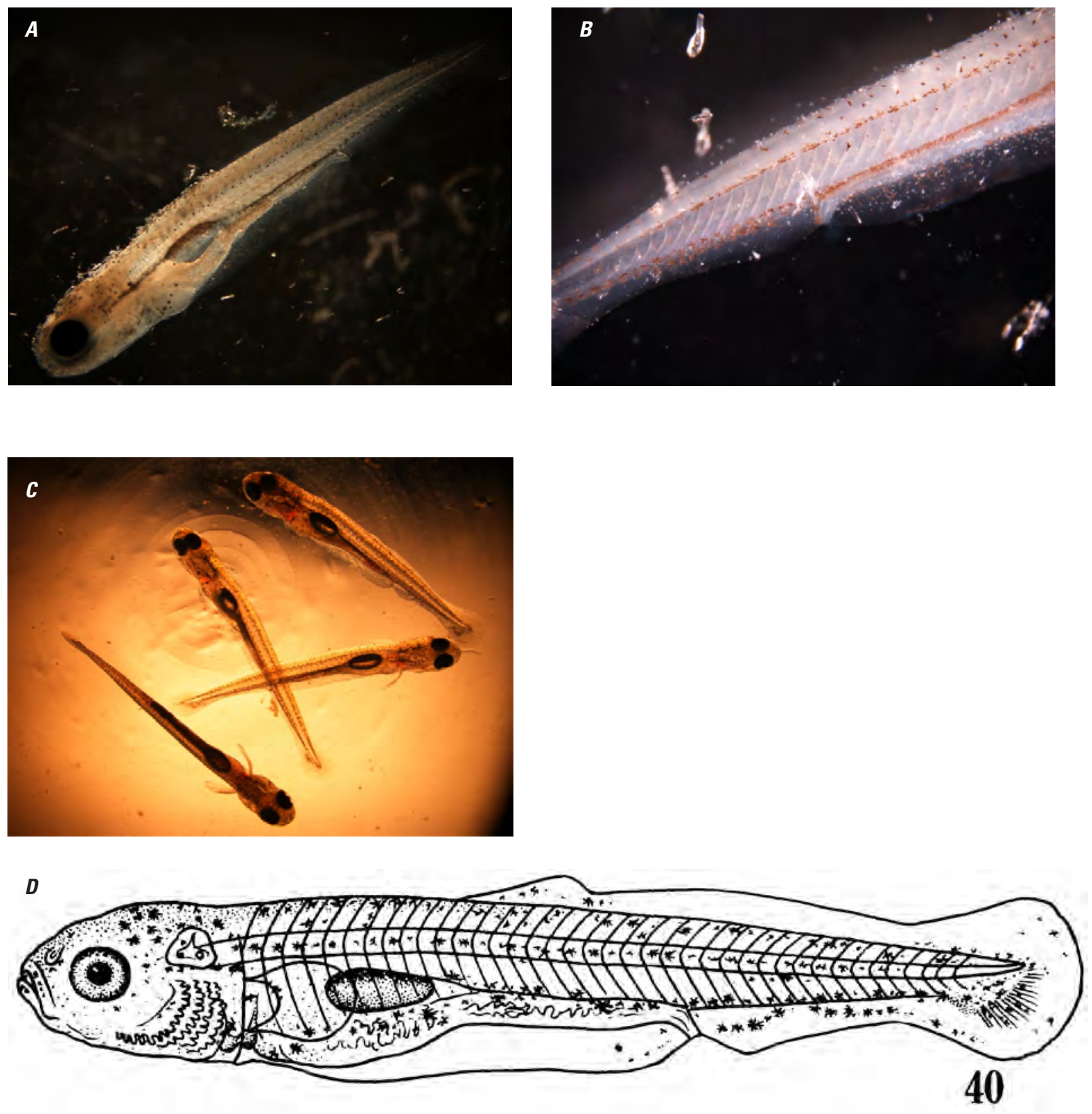

Figure 1-40. Stage 40: Yolk absorption stage of bighead carp development. The larvae is approximately 10.0 millimeters; yolk sac exhausted; dorsal fin further differentiates; posterior margin of caudal finfold becomes crenulated. Pre-anal finfold enlarges (Yi and others, 1988). A, Preserved specimen, low temperature treatment, 261:00 post fertilization, picture taken with 20x magnification. $B$, Preserved specimen, high temperature treatment, 213:00 post fertilization, picture taken with 40x magnification (melanophore detail). $C$, Live specimen, low temperature treatment, 261:00 post fertilization, picture taken with 10x magnification. $D$, Line drawing of yolk absorption stage from Yi and others (1988). 


\section{Abnormalities}
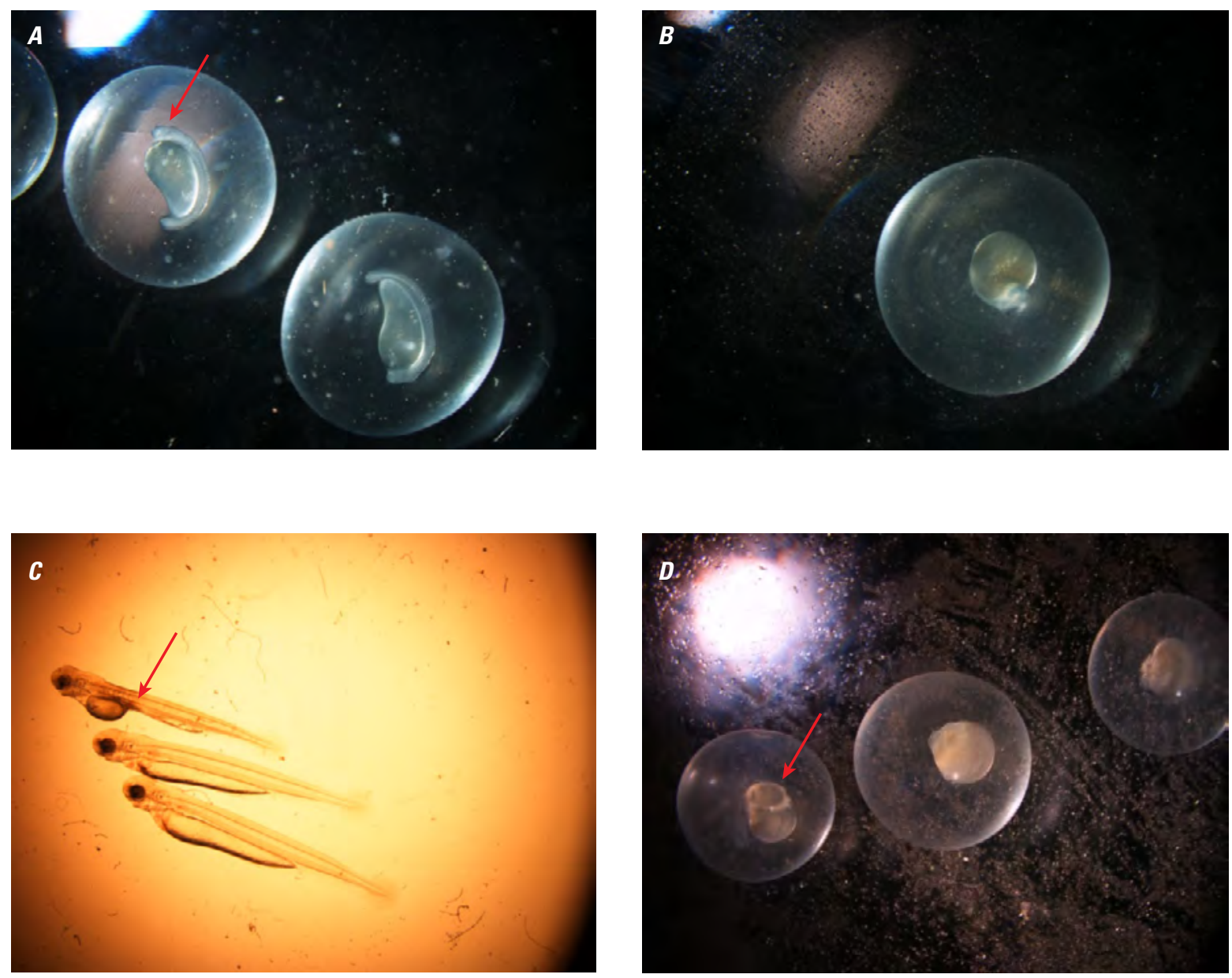

Figure 1-41. Developmental abnormalities of bighead carp. $A$, Missing heads. $B$, Cell development abnormality. $C$, Yolk sac abonormality. D, Cell development abnormality. 


\section{Appendix 2. Silver Carp}

These pictures are images of live and preserved specimens of silver carp (Hypophthalmichthys molitrix). Text descriptions and line drawings from Chapman and Wang (2006), and Yi and others (1988) are also presented, when available, for comparison purposes.

Preliminary data on timing and required cumulative thermal units (CTUs) are also presented, though this data is based on a single experiment, and is likely to be revised with further experiments. The magnification listed is the total magnification (ocular $\mathrm{x}$ objective) for each picture. 
Table 2-1. Timing and required CTUs for achieving developmental stages of silver carp.

[This data is based on a single experiment, and is likely to be revised with further experiments. CTU, cumulative thermal unit; ${ }^{\circ} \mathrm{C}$, degrees Celsius; $T_{m i n}$, thermal minimum; --, not available]

\begin{tabular}{|c|c|c|c|c|c|c|c|}
\hline \multirow{2}{*}{\multicolumn{2}{|c|}{ Stage }} & \multicolumn{3}{|c|}{ Time } & \multicolumn{3}{|c|}{ CTU (Calculated using $11.1^{\circ} \mathrm{C}$ as $T_{\min }$ ) } \\
\hline & & \multirow{2}{*}{$\begin{array}{l}\mathbf{Y i} \\
--\end{array}$} & \multirow{2}{*}{$\begin{array}{r}\text { High } \\
0\end{array}$} & \multirow{2}{*}{$\begin{array}{r}\text { Low } \\
0\end{array}$} & \multirow{2}{*}{$\frac{\mathrm{Yi}\left(21^{\circ} \mathrm{C}\right)}{--}$} & \multirow{2}{*}{$\begin{array}{c}\text { High }\left(22.5^{\circ} \mathrm{C}\right) \\
0\end{array}$} & \multirow{2}{*}{$\begin{array}{c}\operatorname{Low}\left(19.6^{\circ} \mathrm{C}\right) \\
0\end{array}$} \\
\hline 1 & $1-$ cell & & & & & & \\
\hline 2 & 2-cell & -- & $0: 58$ & $1: 30$ & -- & 11.02 & 12.75 \\
\hline 3 & 4-cell & -- & $1: 21$ & $1: 48$ & -- & 15.39 & 15.30 \\
\hline 4 & 8-cell & $1: 20$ & $1: 46$ & $2: 18$ & 13.33 & 20.14 & 19.55 \\
\hline 5 & 16-cell & $1: 45$ & $2: 14$ & $2: 49$ & 17.50 & 25.46 & 23.94 \\
\hline 6 & 32-cell & $1: 57$ & $2: 29$ & $3: 33$ & 19.50 & 28.31 & 30.18 \\
\hline 7 & 64-cell & $2: 30$ & $3: 03$ & 4:02 & 25.00 & 34.77 & 34.28 \\
\hline 8 & 128-cell & $3: 35$ & $3: 45$ & $4: 31$ & 35.83 & 42.75 & 38.39 \\
\hline 9 & Morula & $4: 20$ & $4: 30$ & $5: 03$ & 43.33 & 51.30 & 42.93 \\
\hline 10 & Early blastula & $4: 55$ & $5: 00$ & $6: 03$ & 49.17 & 57.00 & 51.43 \\
\hline 11 & Mid-blastula & $5: 20$ & $6: 29$ & $8: 37$ & 53.33 & 73.91 & 73.24 \\
\hline 12 & Late blastula & $6: 40$ & $7: 29$ & 9:08 & 66.67 & 85.31 & 77.63 \\
\hline 13 & Early gastrula & $8: 40$ & $8: 31$ & $11: 39$ & 86.67 & 97.09 & 99.03 \\
\hline 14 & Mid-gastrula & $10: 15$ & $9: 31$ & $13: 07$ & 102.50 & 108.49 & 111.49 \\
\hline 15 & Late gastrula & $12: 50$ & $10: 01$ & $14: 12$ & 128.33 & 114.19 & 120.70 \\
\hline 16 & Neurula & $14: 10$ & $11: 34$ & $15: 36$ & 141.67 & 131.86 & 132.60 \\
\hline 17 & Blastopore closure & $14: 45$ & $12: 00$ & $17: 49$ & 115.00 & 136.80 & 151.44 \\
\hline 18 & Somite appearance & $15: 20$ & $13: 39$ & $18: 24$ & 153.33 & 153.71 & 156.40 \\
\hline 19 & Optic primordium & $16: 15$ & $14: 36$ & $19: 52$ & 162.50 & 166.44 & 168.87 \\
\hline 20 & Optic vesicle & $17: 00$ & $16: 35$ & $21: 32$ & 170.00 & 189.05 & 183.03 \\
\hline 21 & Olfactory placode & $18: 25$ & $17: 39$ & $22: 37$ & 184.17 & 201.21 & 192.24 \\
\hline 22 & Tail bud & $19: 30$ & $18: 13$ & $24: 10$ & 195.00 & 207.67 & 205.42 \\
\hline 23 & Otic capsule & $20: 45$ & -- & $25: 33$ & 207.50 & -- & 217.18 \\
\hline 24 & Tail vesicle & $22: 00$ & -- & $26: 30$ & 220.00 & -- & 225.25 \\
\hline 25 & Caudal fin & $22: 35$ & 20:07 & $27: 11$ & 225.83 & 229.33 & 231.06 \\
\hline 26 & Lens formation & $23: 00$ & $20: 55$ & $27: 38$ & 230.00 & 238.45 & 234.88 \\
\hline 27 & Muscular effect & $24: 25$ & $22: 10$ & $28: 59$ & 244.17 & 252.70 & 246.36 \\
\hline 28 & Heart rudiment & $28: 20$ & $23: 02$ & $29: 31$ & 283.33 & 262.58 & 250.89 \\
\hline 29 & Otolith appearance & $30: 00$ & $23: 29$ & $31: 29$ & 300.00 & 267.71 & 267.61 \\
\hline 30 & Heart pulsation & $34: 15$ & -- & $34: 31$ & 342.50 & 280.82 & 293.39 \\
\hline 31 & Hatching & $38: 00$ & $26: 41$ & $45: 26$ & 380.00 & 306.86 & 390.73 \\
\hline 32 & Pectoral fin bud & 48:00 & $33: 12$ & $60: 22$ & 480.00 & 381.80 & 519.15 \\
\hline 33 & Gill arch & $53: 00$ & $45: 06$ & $77: 34$ & 530.00 & 518.65 & 667.07 \\
\hline 34 & Xanthic eye & $63: 00$ & $53: 53$ & -- & 630.00 & 619.66 & -- \\
\hline 35 & Gill filament & $74: 00$ & $60: 39$ & $94: 33$ & 740.00 & 697.48 & 813.13 \\
\hline 36 & Melanoid eye & $92: 00$ & $77: 36$ & $119: 20$ & 920.00 & 892.40 & $1,026.27$ \\
\hline 37 & Gas bladder emergence & 106:00 & 109:00 & $159: 50$ & $1,060.00$ & $1,253.50$ & $1,374.57$ \\
\hline 38 & One chamber gas bladder & $146: 00$ & $137: 00$ & $183: 30$ & $1,460.00$ & $1,575.50$ & $1,578.10$ \\
\hline 39 & Yolk absorption & 168:00 & $168: 17$ & -- & $1,680.00$ & $1,935.26$ & -- \\
\hline 40 & Dorsal fin differentiation & 212:00 & -- & -- & $2,120.00$ & -- & -- \\
\hline
\end{tabular}



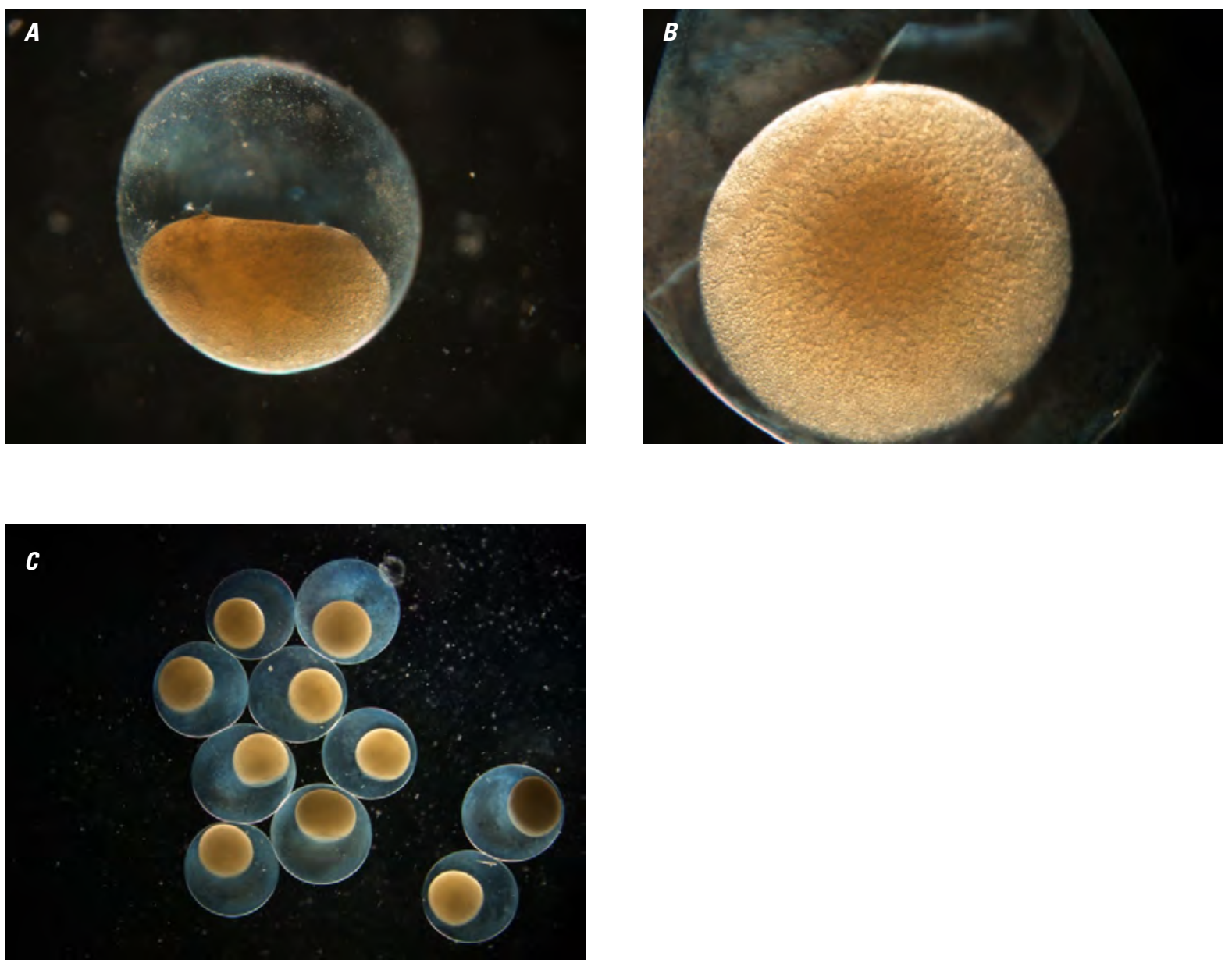

Figure 2-1. Stage 1: 1-cell stage of silver carp development. $A$, Preserved specimen, high temperature treatment, 0:48 post fertilization, picture taken with $40 \mathrm{x}$ magnification. $B$, Preserved specimen, low temperature treatment, 1:19 post fertilization, picture taken with $50 x$ magnification. $C$, Live specimen, low temperature treatment, 0:45 post fertilization, picture taken with 10x magnification.

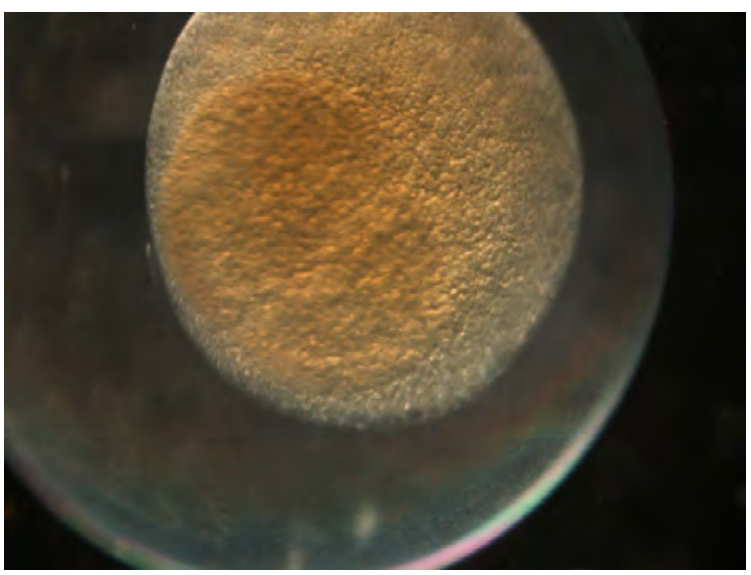

Figure 2-2. Stage 2: 2-cell stage of silver carp development. Preserved specimen, high temperature treatment, 0:58 post fertilization, picture taken with 60x magnification. 

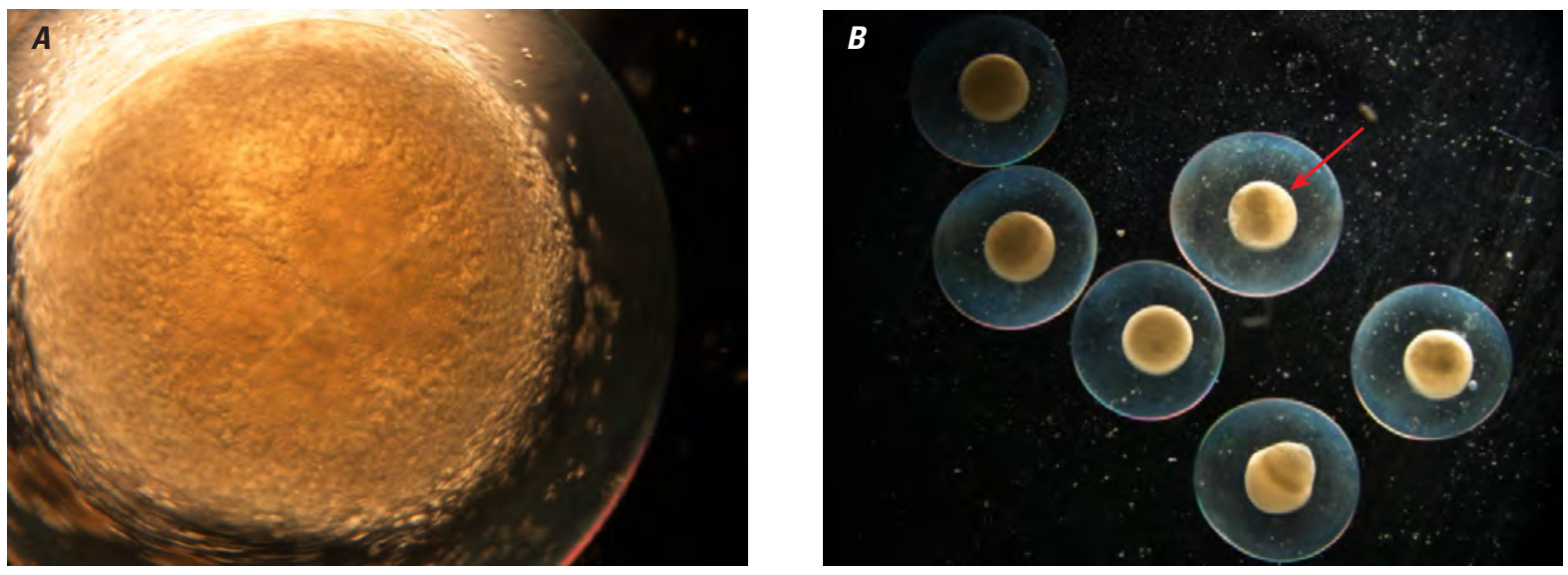

Figure 2-3. Stage 3: 4-cell stage of silver carp development. A, Preserved specimen, low temperature treatment, 1:48 post fertilization, picture taken with 50x magnification. $B$, Live specimen, low temperature treatment, 2:04 post fertilization, picture taken with 10x magnification. Arrow indicates the 4-cell stage egg.

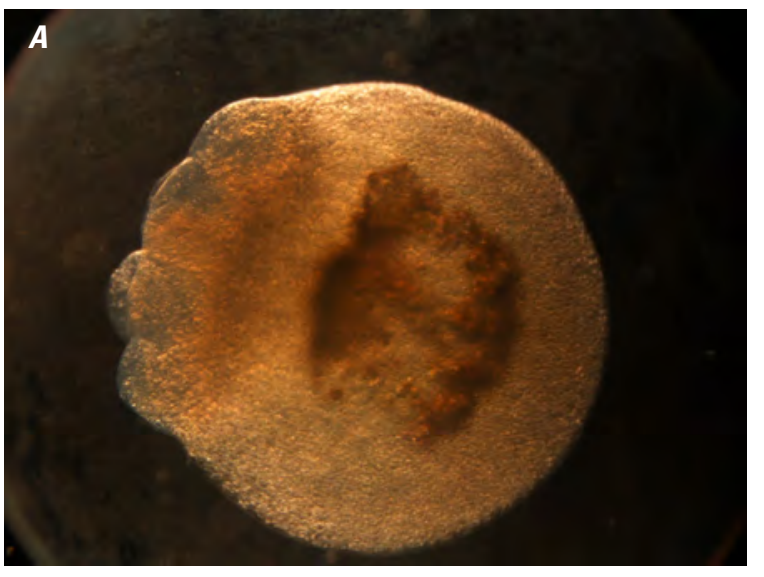

B

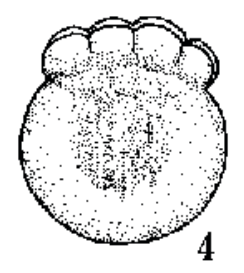

Figure 2-4. Stage 4: 8-cell stage of silver carp development. Cytoplasm widely distributed in yolk (Yi and others, 1988). A, Preserved specimen, low temperature treatment, 2:33 post fertilization, picture taken with 50x magnification. The dark pigment on this embryo is abnormal and indicates the cell will probably not develop much further. $B$, Line drawing of 8-cell stage from Yi and others (1988). 


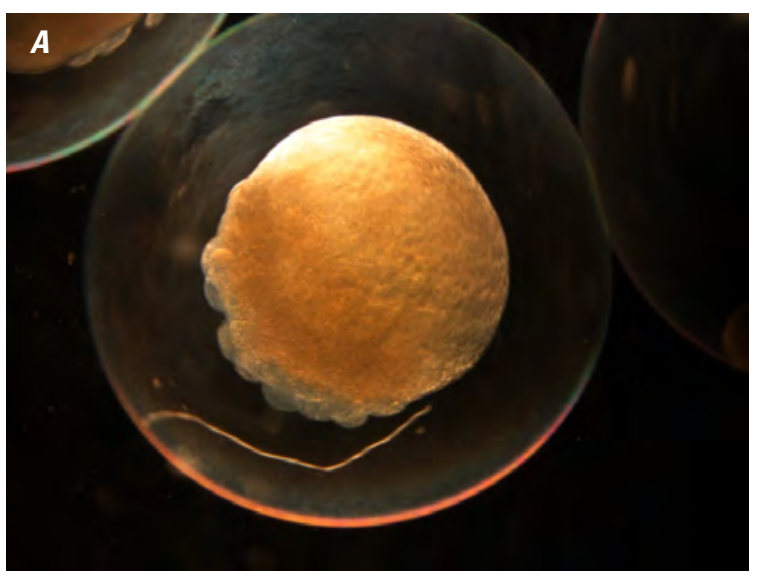

$\boldsymbol{B}$

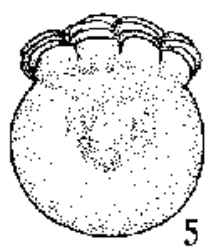

Figure 2-5. Stage 5: 16-cell stage of silver carp development. Cytoplasm diminishing (Yi and others, 1988). A, Preserved specimen, low temperature treatment, 3:20 post fertilization, picture taken with 30x magnification. $B$, Line drawing of 16-cell stage from Yi and others (1988).

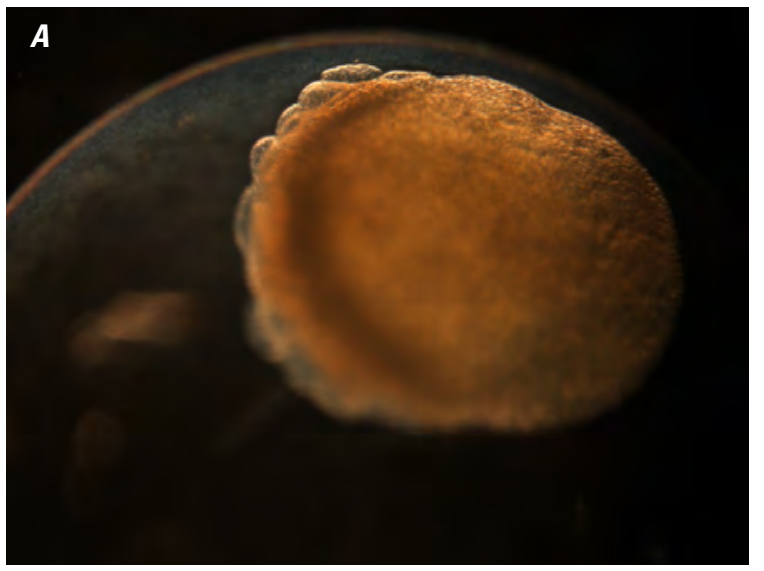

$\boldsymbol{B}$

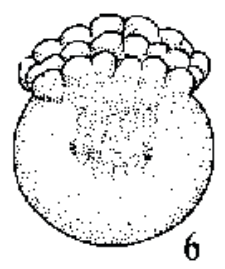

Figure 2-6. Stage 6: 32-cell stage of silver carp development. Cytoplasm diminishing (Yi and others, 1988). A, Preserved specimen, low temperature treatment, 3:33 post fertilization, picture taken with 50x magnification. $B$, Line drawing of 32-cell stage from Yi and others (1988). 


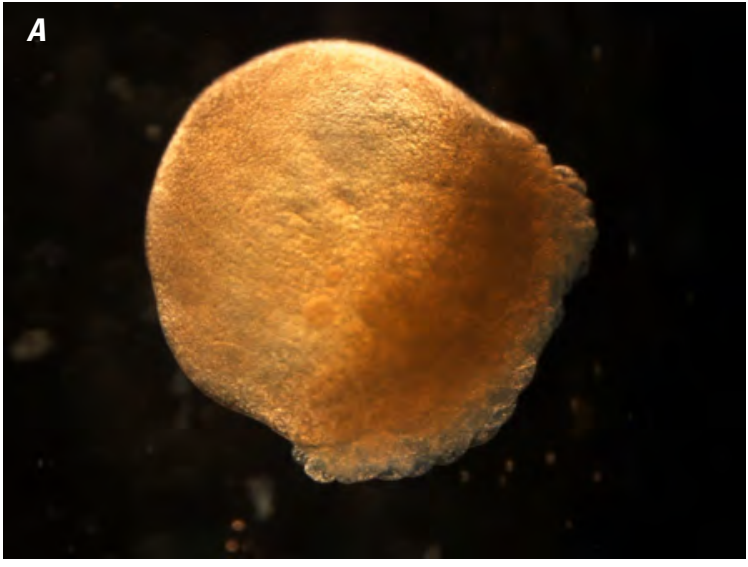

B

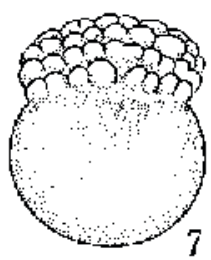

Figure 2-7. Stage 7: 64-cell stage of silver carp development. Cytoplasm diminishing (Yi and others, 1988). A, Preserved specimen, low temperature treatment, 4:02 post fertilization, picture taken with 50x magnification. $B$, Line drawing of 64-cell stage from Yi and others (1988).

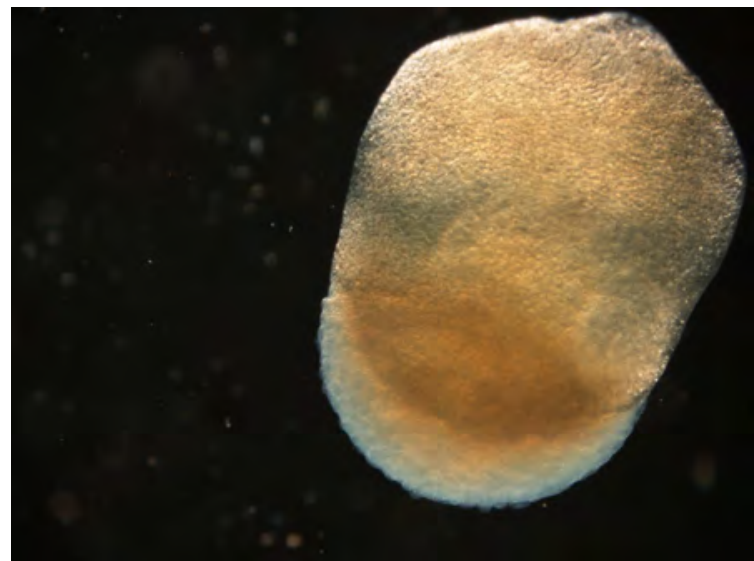

Figure 2-8. Stage 8: 128-cell stage of silver carp development. Cytoplasm almost gone. Blastodisc mound-like, several oil droplets on yolk cell (Yi and others, 1988). Preserved specimen, high temperature treatment, 3:45 post fertilization, picture taken with $50 x$ magnification. 

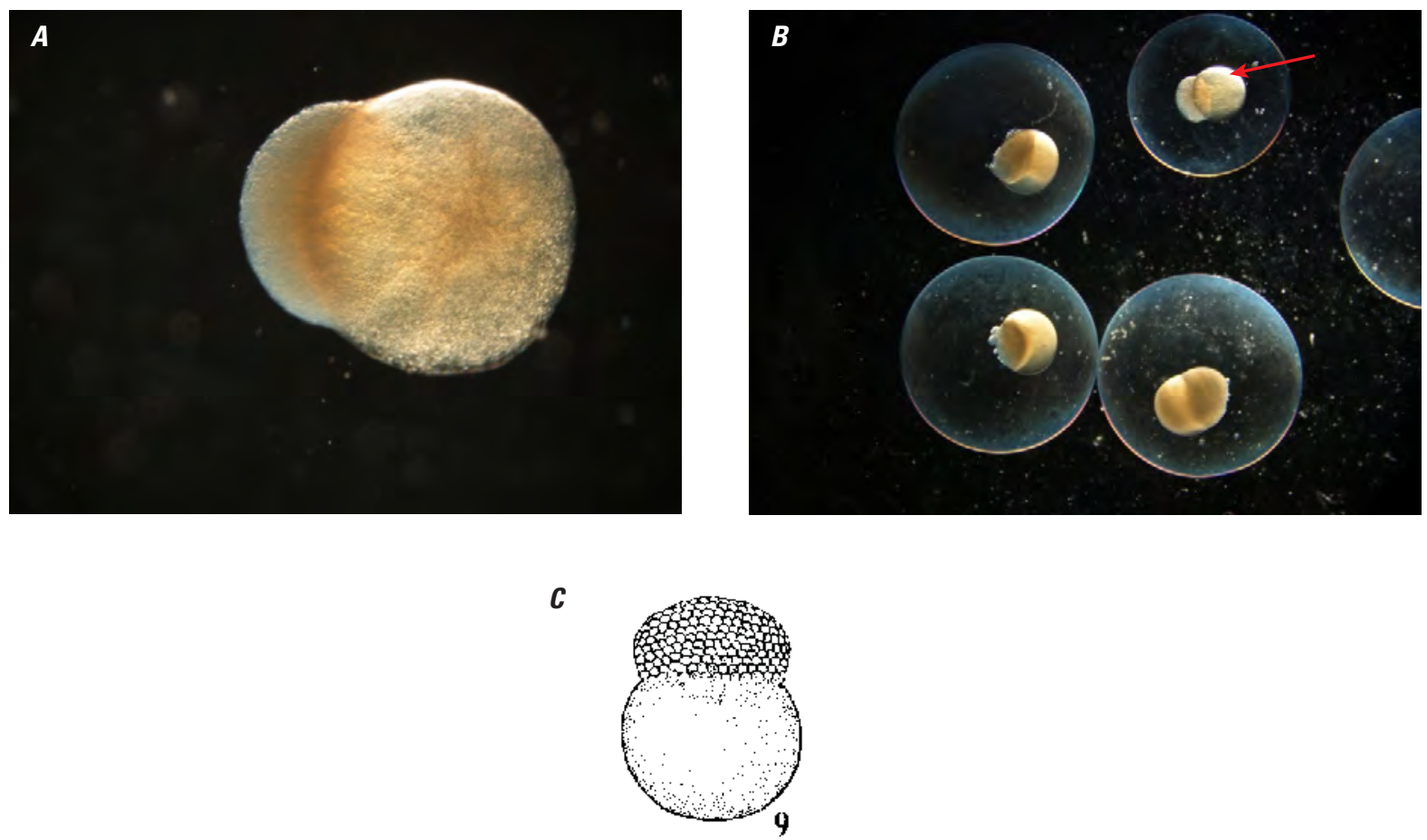

Figure 2-9. Stage 9: Morula stage of silver carp development. Cells become smaller, blastodisc highly raised above yolk, cytoplasm disappears (Yi and others, 1988). A, Preserved specimen, high temperature treatment, 4:30 post fertilization, picture taken with 40x magnification. $B$, Live specimen, low temperature treatment, 5:31 post fertilization, picture taken with 10x magnification. Arrow indicates the morula stage egg. $C$, Line drawing of morula stage from $\mathrm{Yi}$ and others (1988).
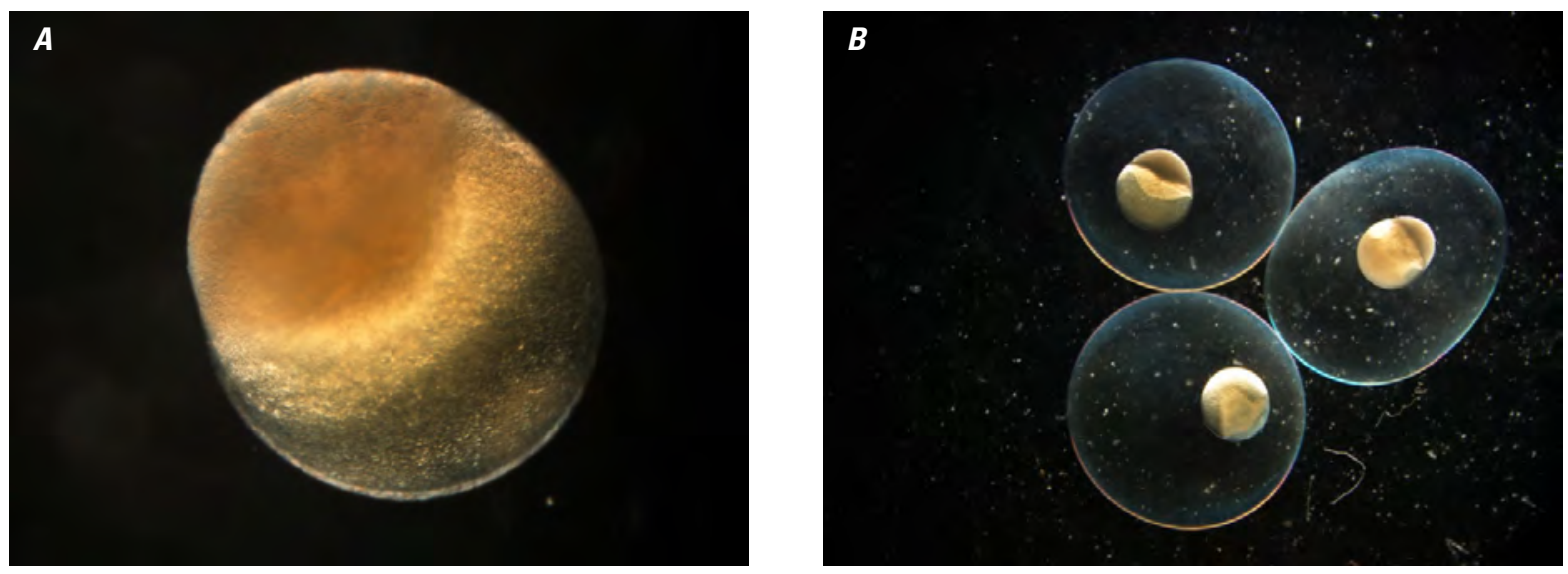

Figure 2-10. Stage10: Early blastula stage of silver carp development. Blastodisc forms half-sphere (Yi and others, 1988). A, Preserved specimen, low temperature treatment, 7:06 post fertilization, picture taken with 60x magnification. $B$, Live specimen, high temperature treatment, 5:33 post fertilization, picture taken with 10x magnification. 

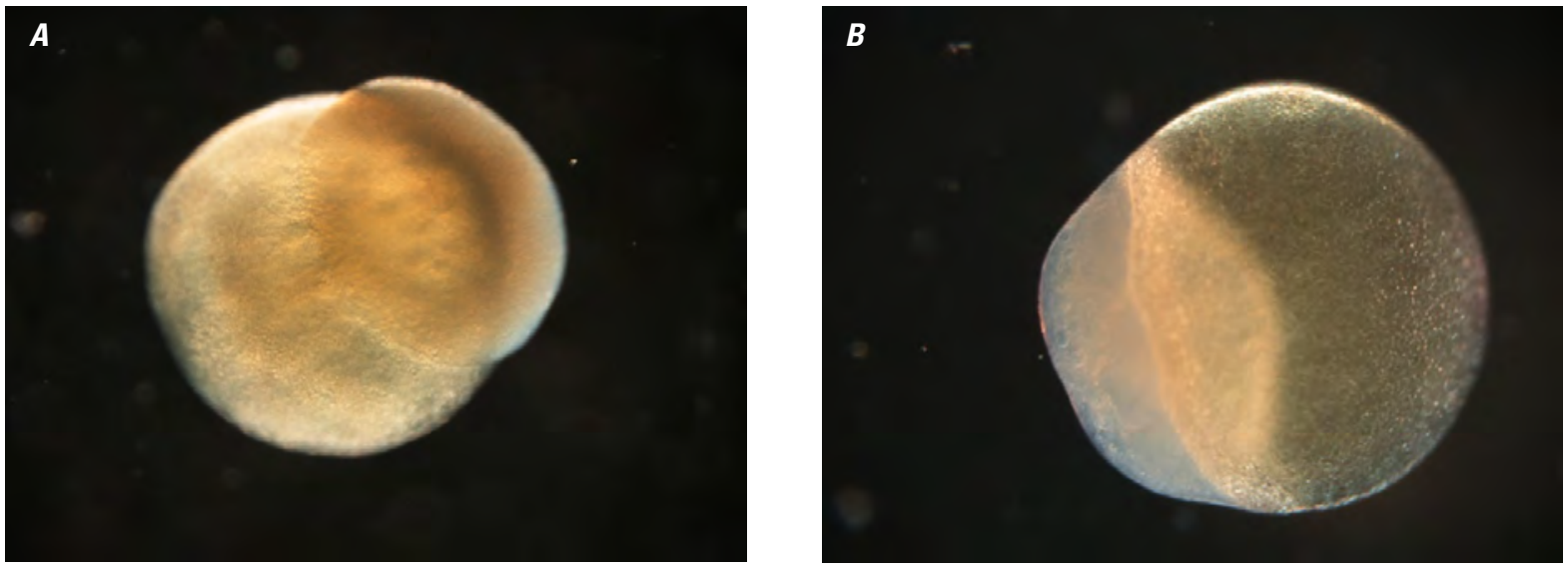

Figure 2-11. Stage 11: Mid-blastula stage of silver carp development. Blastodisc begins flattening (Yi and others, 1988). A, Preserved specimen, high temperature treatment, 7:02 post fertilization, picture taken with 50x magnification. $B$, Preserved specimen, high temperature treatment, 6:29 post fertilization, picture taken with 50x magnification.

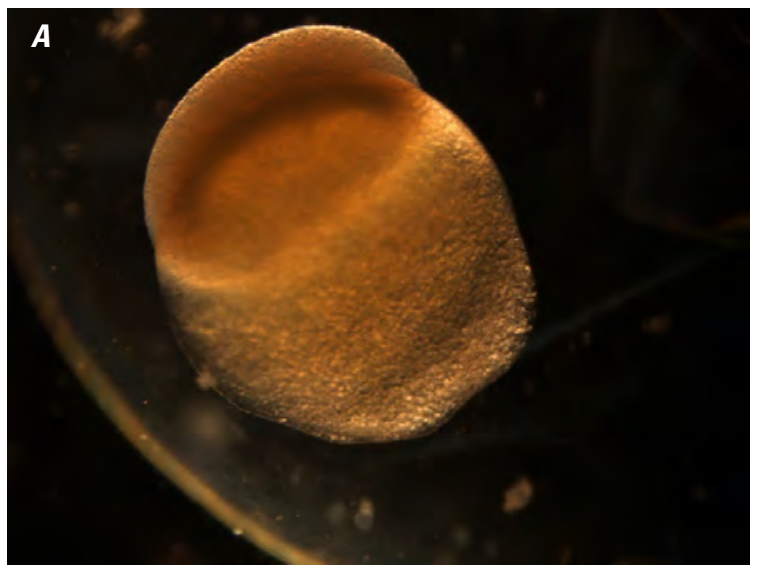

$B$

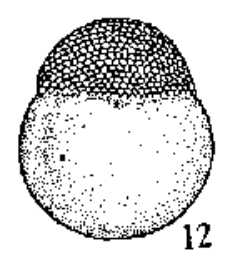

Figure 2-12. Stage 12: Late blastula stage of silver carp development. Blastodisc flattens and gradually moves over yolk (Yi and others, 1988). $A$, Preserved specimen, low temperature treatment, 10:08 post fertilization, picture taken with 50x magnification. $B$, Line drawing of late blastula stage from $\mathrm{Yi}$ and others (1988). 


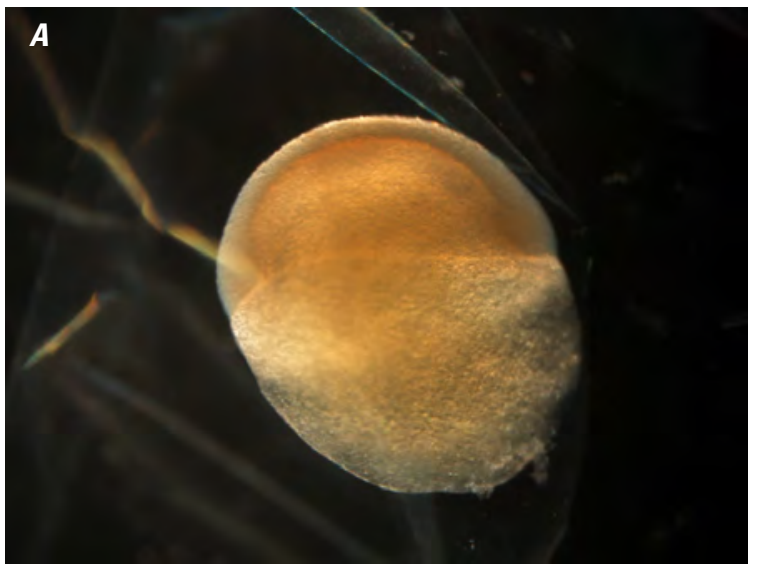

\section{B}

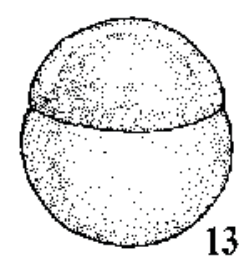

Figure 2-13. Stage 13: Early gastrula stage of silver carp development. Germ ring visible, blastoderm covers $1 / 3$ of yolk cell. Egg appears round. (Yi and others, 1988). A, Preserved specimen, low temperature treatment, 11:39 post fertilization, picture taken with 50x magnification. $B$, Line drawing of early gastrula stage from Yi and others (1988).

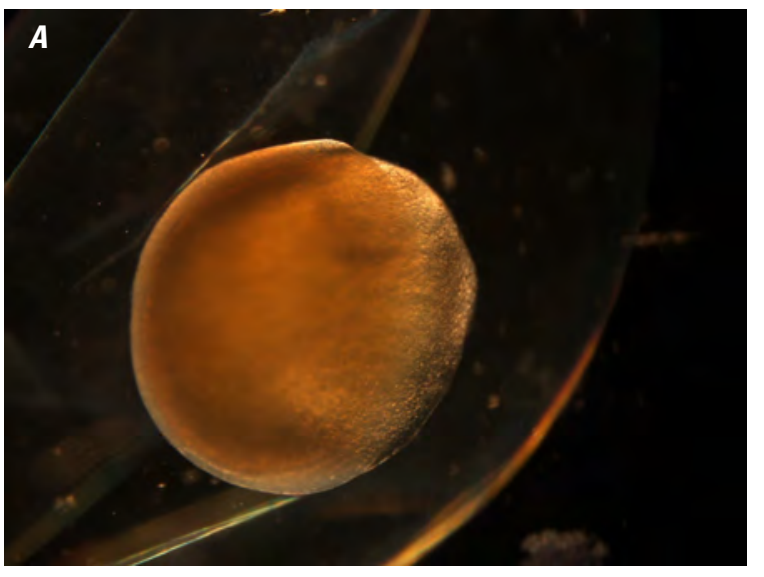

B

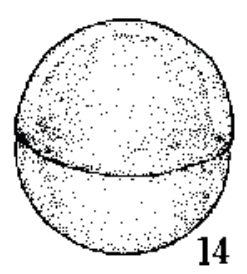

Figure 2-14. Stage 14: Mid-gastrula stage of silver carp development. Blastoderm covers $1 / 2$ of yolk cell (Yi and others, 1988). A, Preserved specimen, low temperature treatment, 13:07 post fertilization, picture taken with 50x magnification. $B$, Line drawing of mid-gastrula stage from Yi and others (1988). 

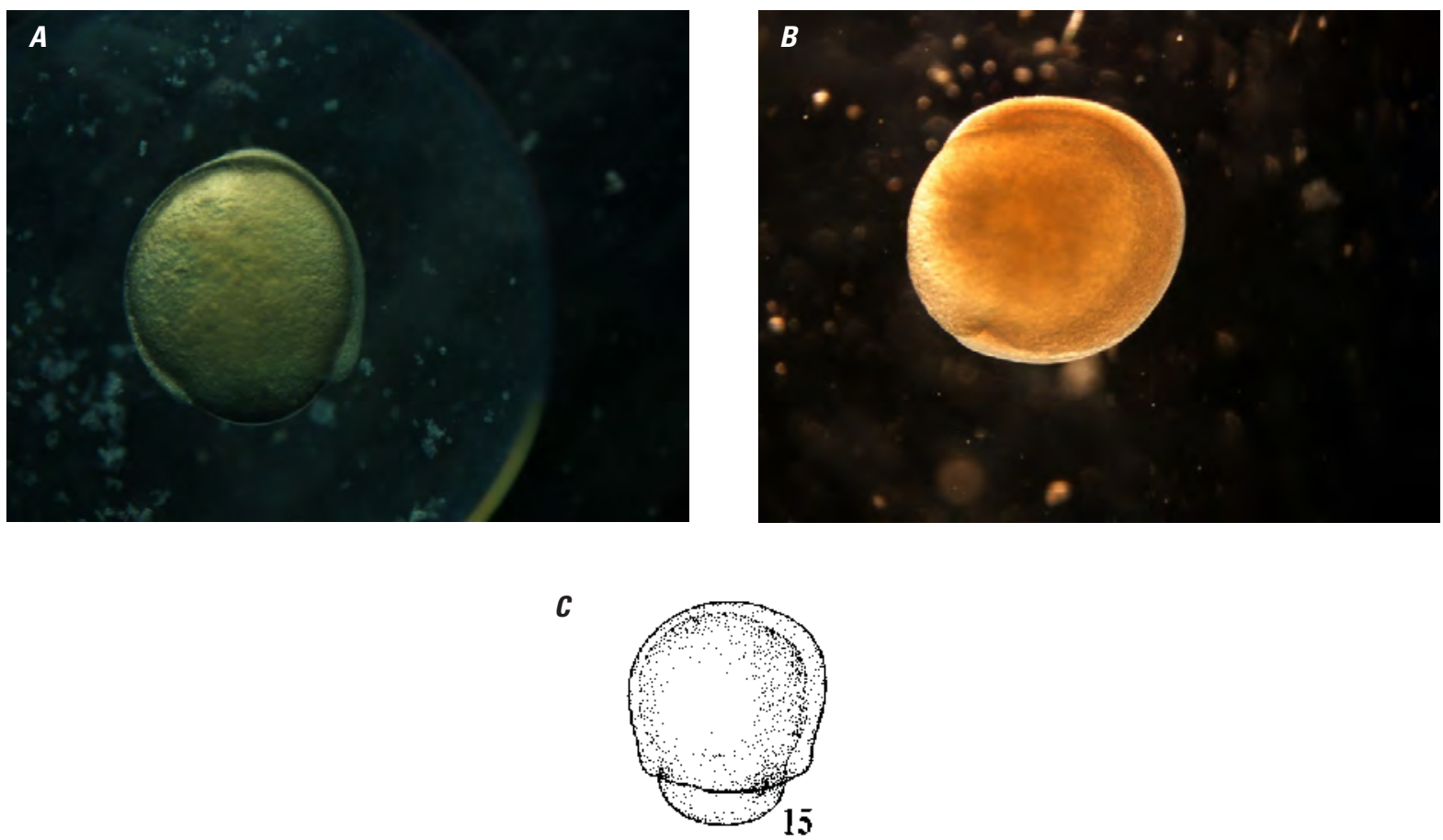

Figure 2-15. Stage 15: Late gastrula stage of silver carp development. Embryo head enlarged, blastoderm covers 3/4 of yolk cell (Yi and others, 1988). A, Live specimen, low temperature treatment, 17:17 post fertilization, picture taken with 40x magnification. $B$, Preserved specimen, low temperature treatment, 14:30 post fertilization, picture taken with 40x magnification. $C$, Line drawing of late gastrula stage from Yi and others (1988).
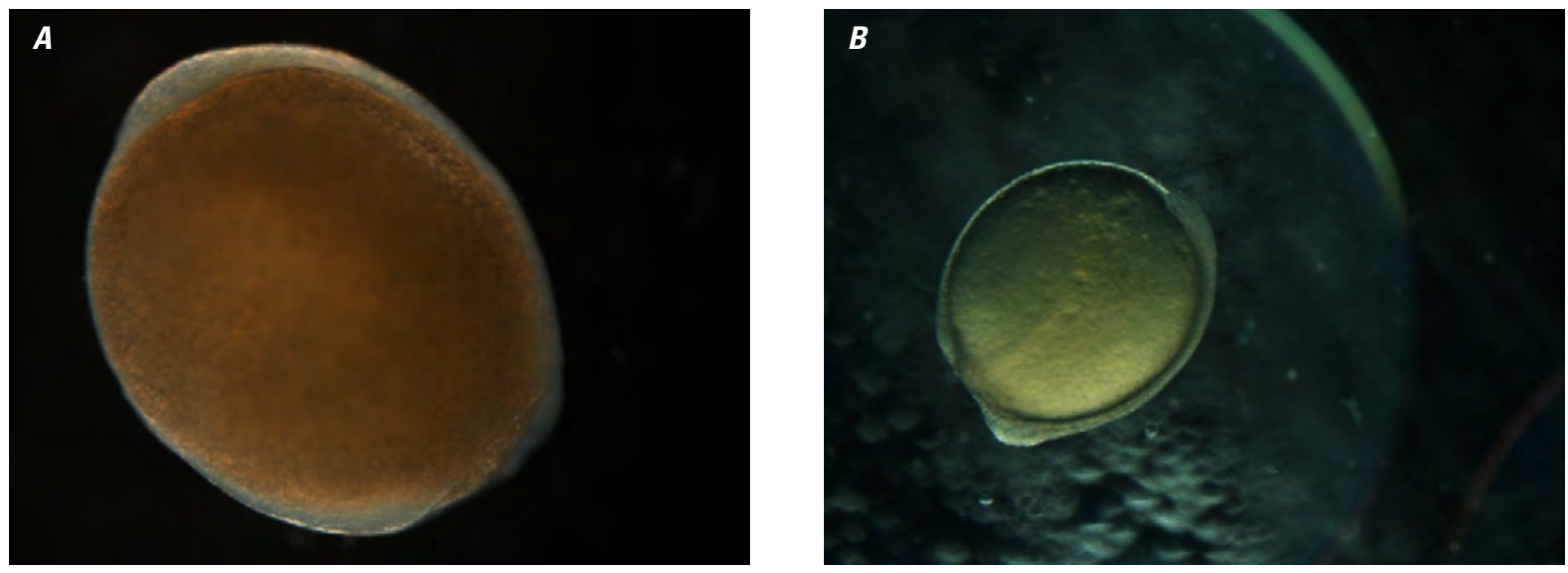

Figure 2-16. Stage 16: Neurula stage of silver carp development. Head clearly visible, blastoderm covers almost whole yolk, except for yolk plug (Yi and others, 1988). A, Preserved specimen, low temperature treatment, 17:25 post fertilization, picture taken with 70x magnification. $B$, Live specimen, low temperature treatment, 17:17 post fertilization, picture taken with 40x magnification. 

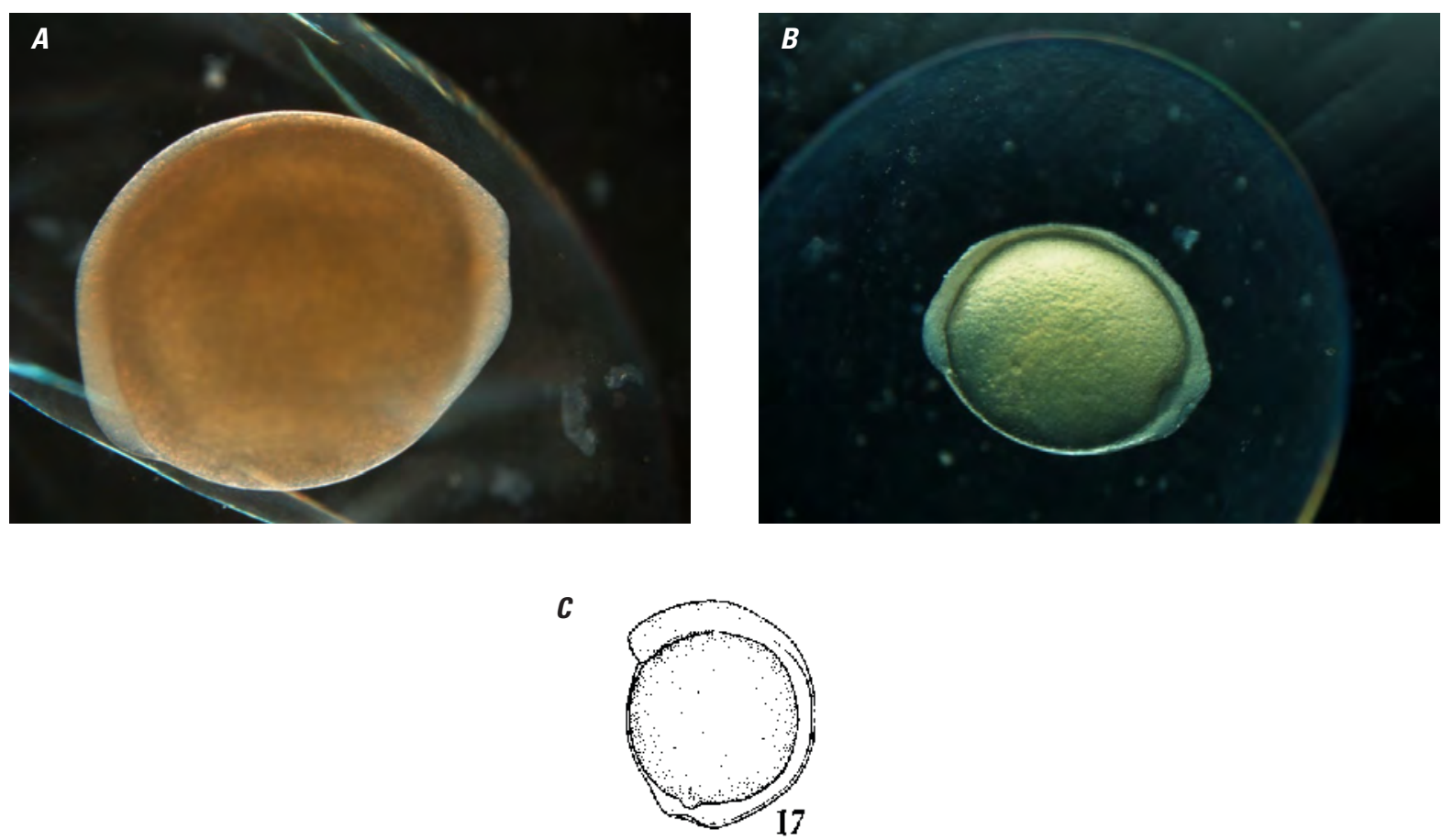

Figure 2-17. Stage 17: Blastopore closure stage of silver carp development. Front of head square, yolk round (Yi and others, 1988). A, Preserved specimen, high temperature treatment, 12:30 post fertilization, picture taken with $60 \mathrm{x}$ magnification. $B$, Live specimen, low temperature treatment, 17:44 post fertilization, picture taken with 40x magnification. $C$, Line drawing of blastopore closure stage from Yi and others (1988).
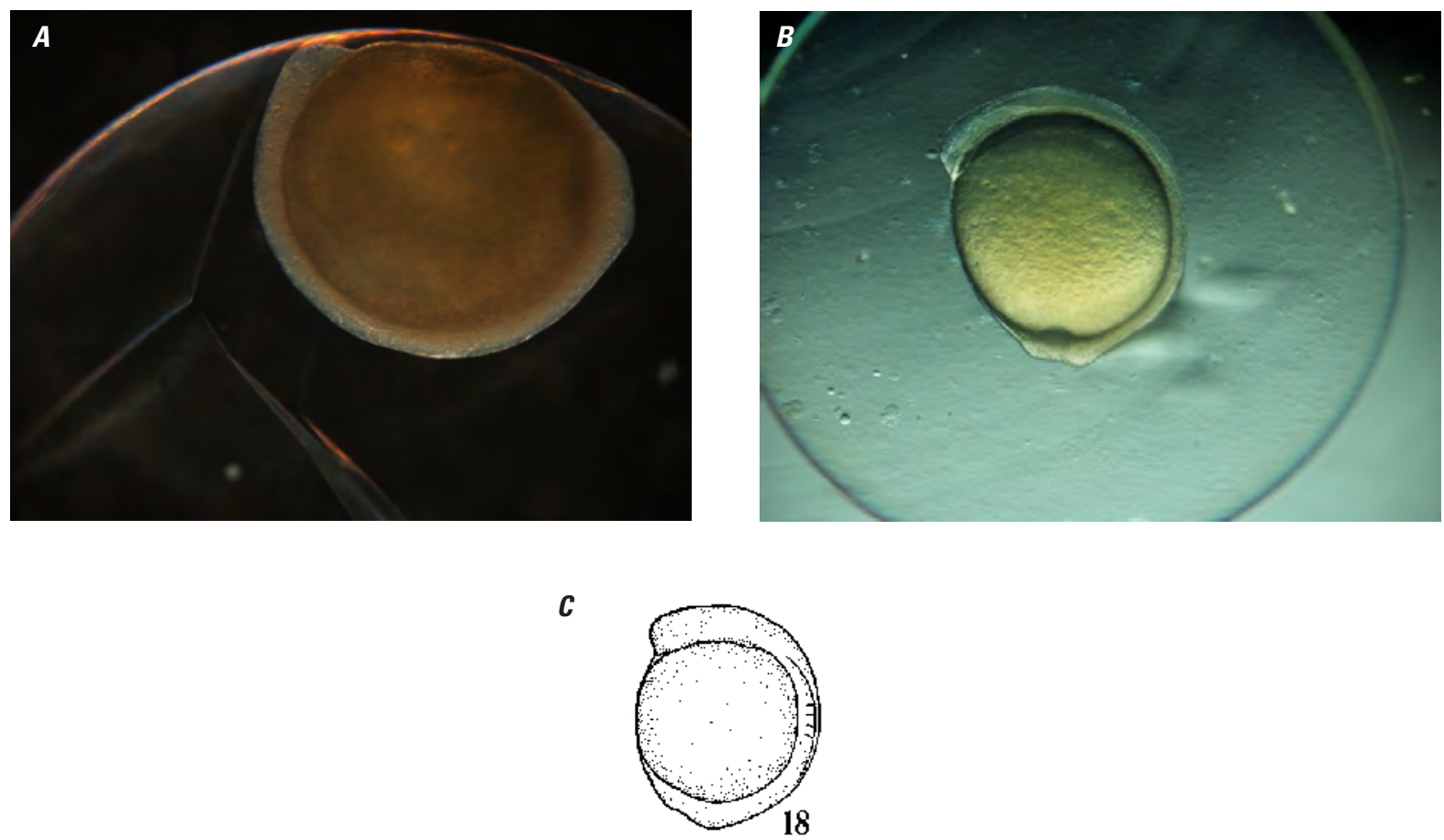

Figure 2-18. Stage 18: Somite appearance stage of silver carp development. Somites number 1-3 pairs and optic primordium dimly visible (Yi and others, 1988). A, Preserved specimen, high temperature treatment, 13:29 post fertilization, picture taken with 50x magnification. $B$, Live specimen, low temperature treatment, 18:20 post fertilization, picture taken with 40x magnification. $C$, Line drawing of somite appearance stage from Yi and others (1988). 

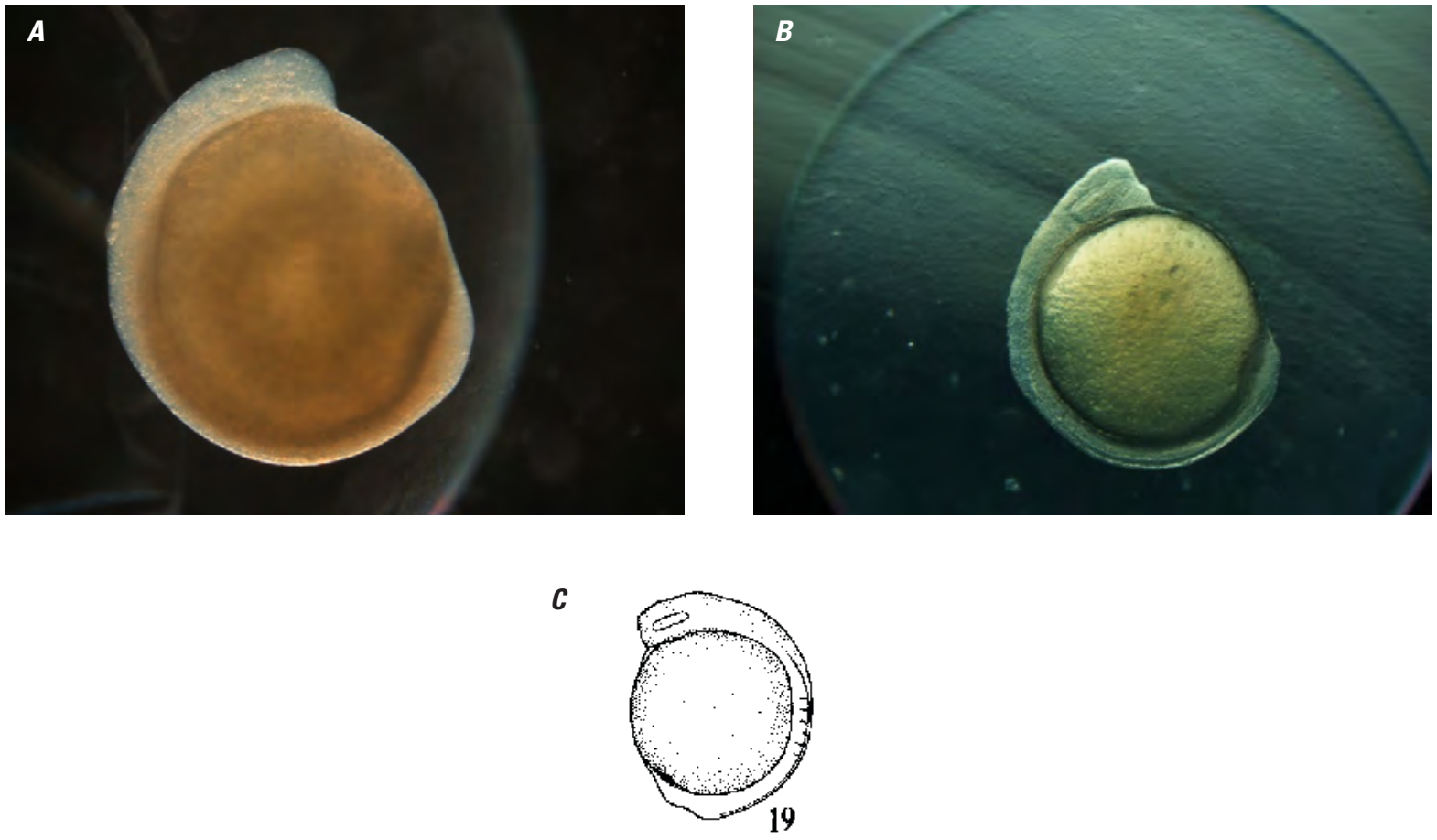

Figure 2-19. Stage 19: Optic primordium stage of silver carp development. Optic primordium clearly visible, long and oval shaped. Embryo covers 3/4 of yolk, unencircled yolk margin is convex, 4-6 pairs of somites present. (Yi and others, 1988). A, Preserved specimen, high temperature treatment, 14:35 post fertilization, picture taken with 50x magnification. $B$, Live specimen, low temperature treatment, 21:27 post fertilization, picture taken with 40x magnification. $C$, Line drawing of optic primordium stage from Yi and others (1988).
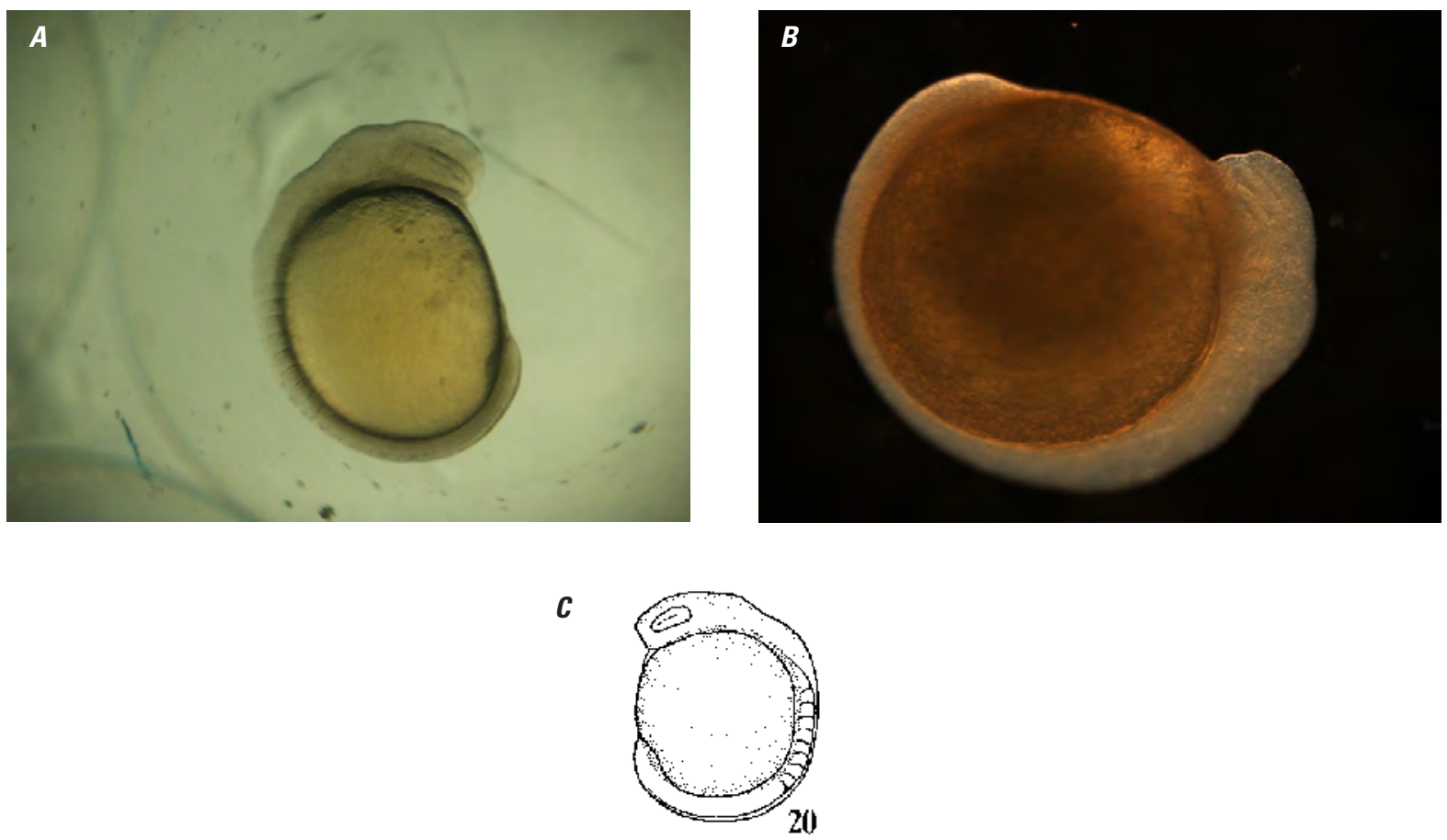

Figure 2-20. Stage 20: Optic vesicle stage of silver carp development. Eyes enlarge, 7-9 pairs of somites present ( $\mathrm{Yi}$ and others, 1988). A, Live specimen, high temperature treatment, 16:06 post fertilization, picture taken with 40x magnification. $B$, Preserved specimen, low temperature treatment, 23:32 post fertilization, picture taken with $60 \mathrm{x}$ magnification. $C$, Line drawing of optic vesicle stage from $Y i$ and others (1988). 


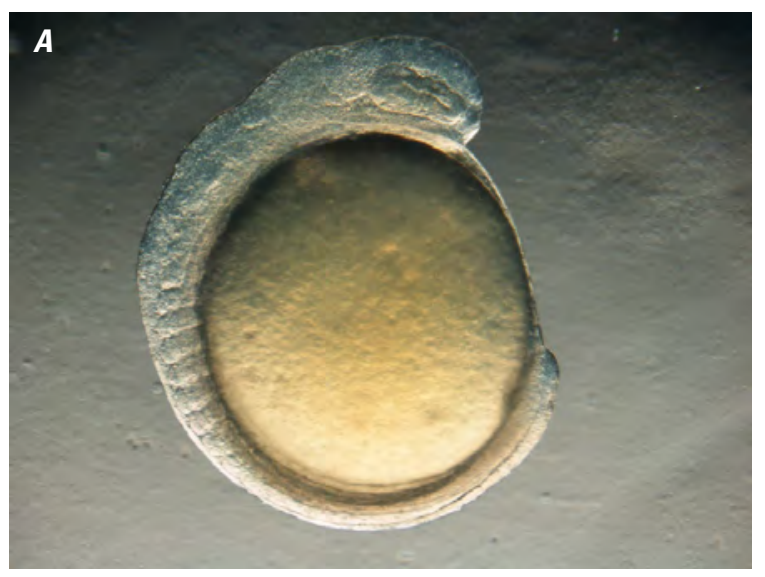

B

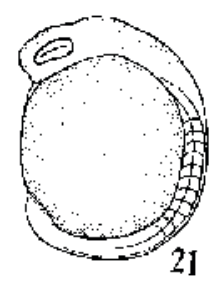

Figure 2-21. Stage 21: Olfactory placode stage of silver carp development. Olfactory placode barely visible above optic vesicle, 10-13 pairs of somites present (Yi and others, 1988). A, Live specimen, low temperature treatment, 22:37 post fertilization, picture taken with 60x magnification. $B$, Line drawing of olfactory placode stage from $Y i$ and others (1988).
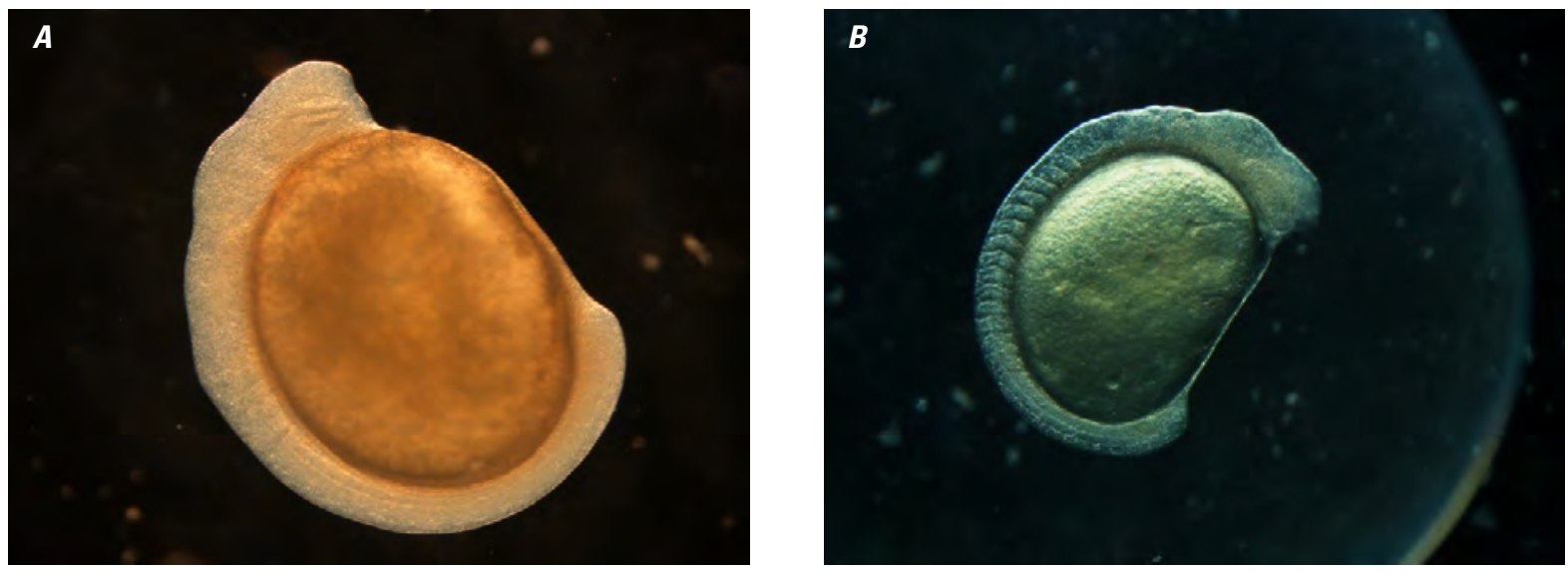

C

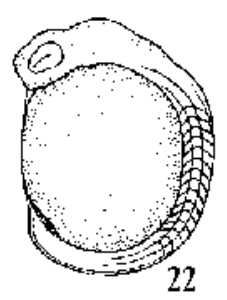

Figure 2-22. Stage 22: Tail bud stage of silver carp development. Eyes enlarge, shaped like watermelon seed. Slightly differentiated brain rudiment. Tail bud appears, $14-16$ pairs of somites present (Yi and others, 1988). $A$, Preserved specimen, low temperature treatment, 24:33 post fertilization, picture taken with 50x magnification. $B$, Live specimen, high temperature treatment, 18:05 post fertilization, picture taken with 40x magnification. 


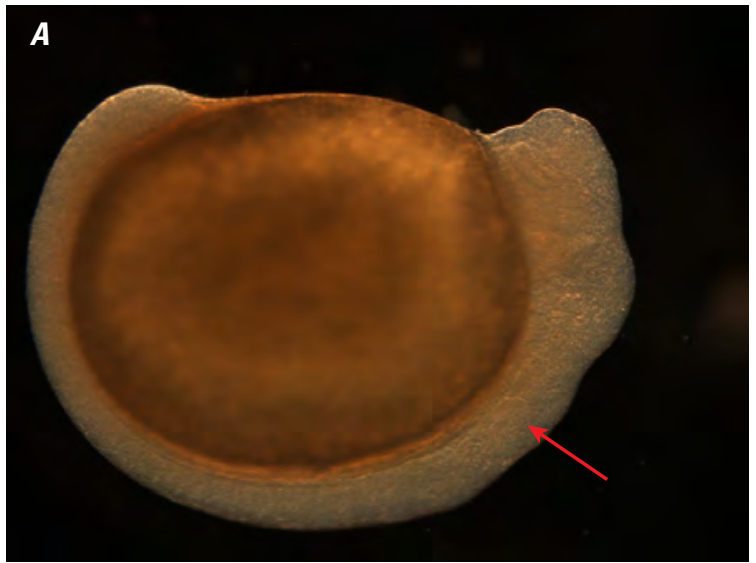

B

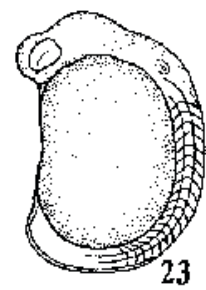

Figure 2-23. Stage 23: Otic capsule stage of silver carp development. Tail bud clearly visible, otic capsule appears, yolk elongates and the part of the yolk between the head and the tail begins to invaginate, 17-19 pairs of somites present (Yi and others, 1988). A, Preserved specimen, low temperature treatment, 26:30, picture taken with $60 \mathrm{x}$ magnification. Arrow points to the otic capsule. $B$, Line drawing of otic capsule stage from Yi and others (1988).
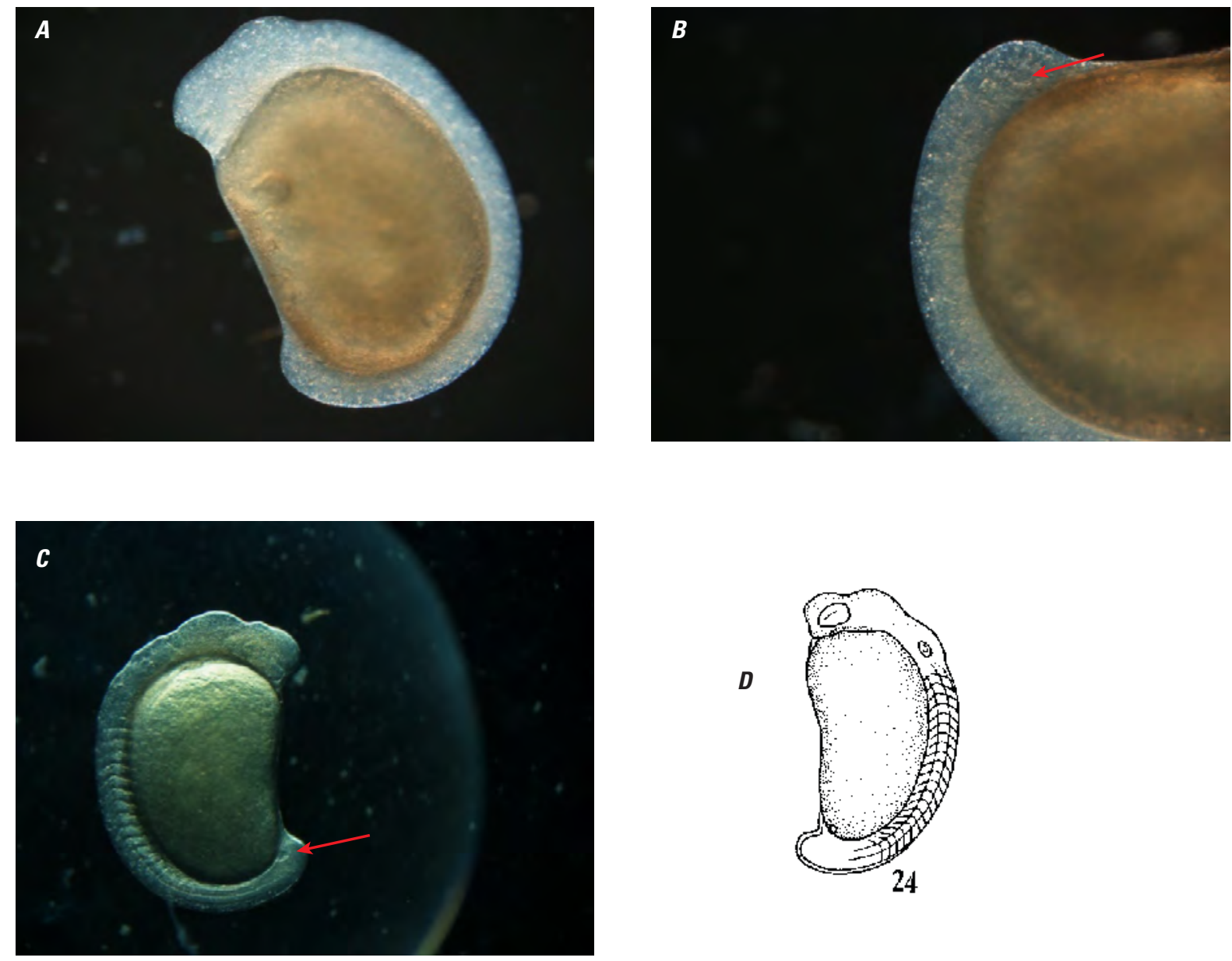

Figure 2-24. Tail vesicle stage of silver carp development. Tail bud expands outward, tail vesicle appears, bump on brain area enlarges, yolk is elongated and kidney shaped, 20-21 pairs of somites present (Yi and others, 1988). $A$, Preserved specimen, high temperature treatment, 19:13 post fertilization, picture taken with 50x magnification. $B$, Preserved specimen, high temperature treatment, 19:13 post fertilization, picture taken with 90x magnification. Arrow points to the tail vesicle. C, Live specimen, high temperature treatment, 18:05 post fertilization, picture taken with 40x magnification. Arrow points to the tail vesicle. $D$, Line drawing of tail vesicle stage from Yi and others (1988). 

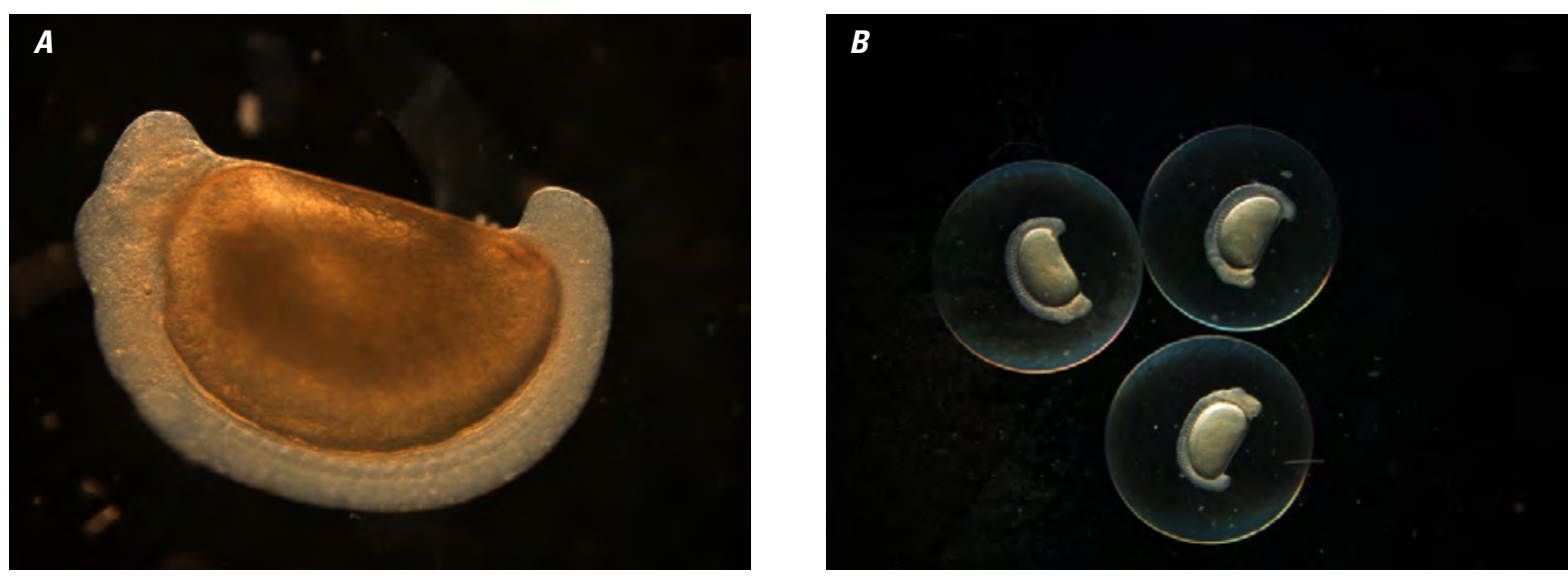

Figure 2-25. Stage 25: Caudal fin stage of silver carp development. Caudal fin expands outward, embryo and yolk elongates, 22-23 pairs of somites present (Yi and others, 1988). A, Preserved specimen, low temperature treatment, 28:10 post fertilization, picture taken with 50x magnification. $B$, Live specimen, low temperature treatment, 28:10 post fertilization, picture taken with 10x magnification.
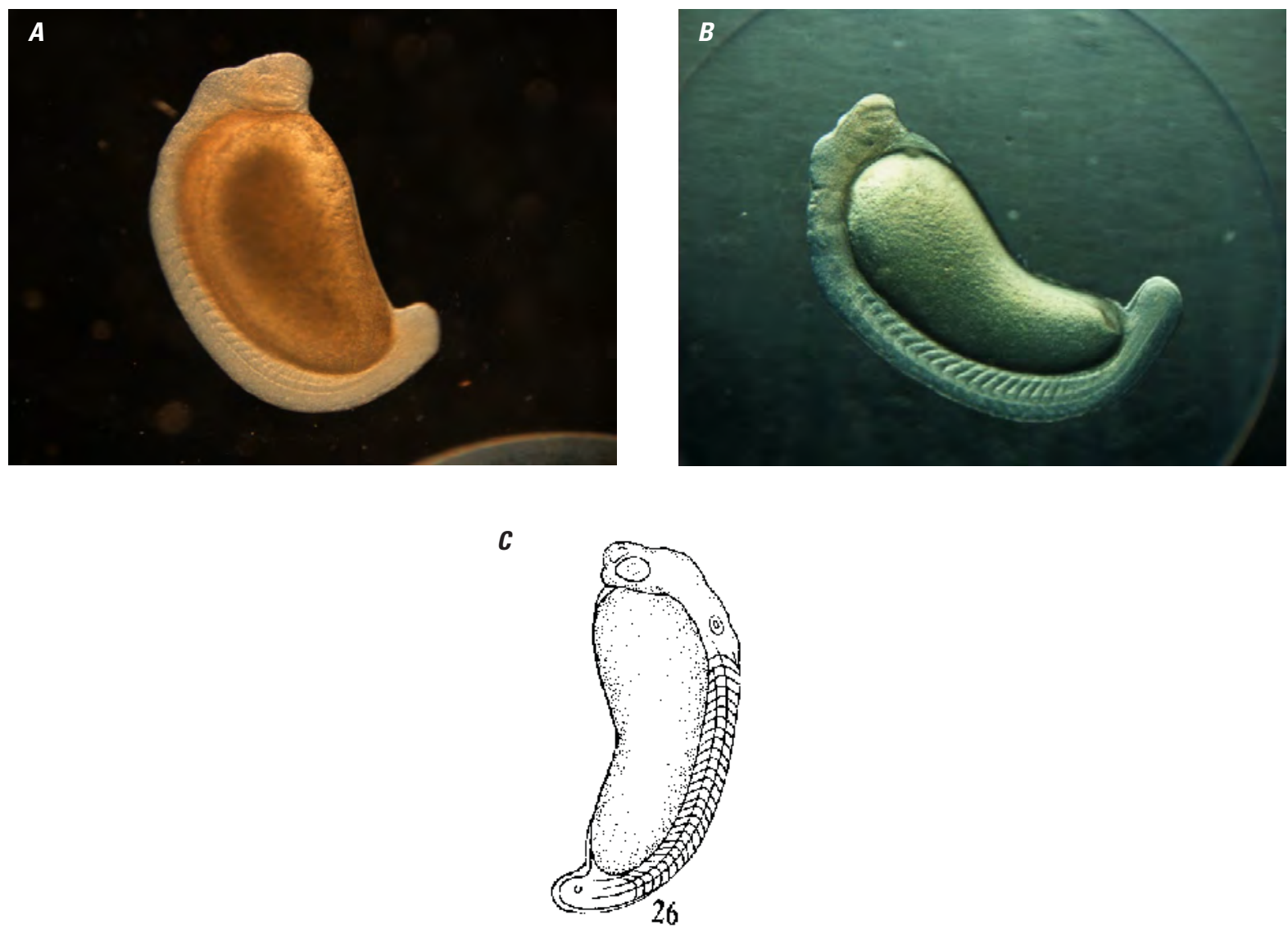

Figure 2-26. Stage 26: Lens formation stage of silver carp development. Eyes round, olfactory vesicle clearly visible. Embryo elongated, yolk further invaginated, 24-25 pairs somites present (Yi and others, 1988). A, Preserved specimen, low temperature treatment, 27:38 post fertilization, picture taken with 40x magnification. $B$, Live specimen, high temperature treatment, 20:40 post fertilization, picture taken with 40x magnification. $C$, Line drawing of lens formation stage from Yi and others (1988). 

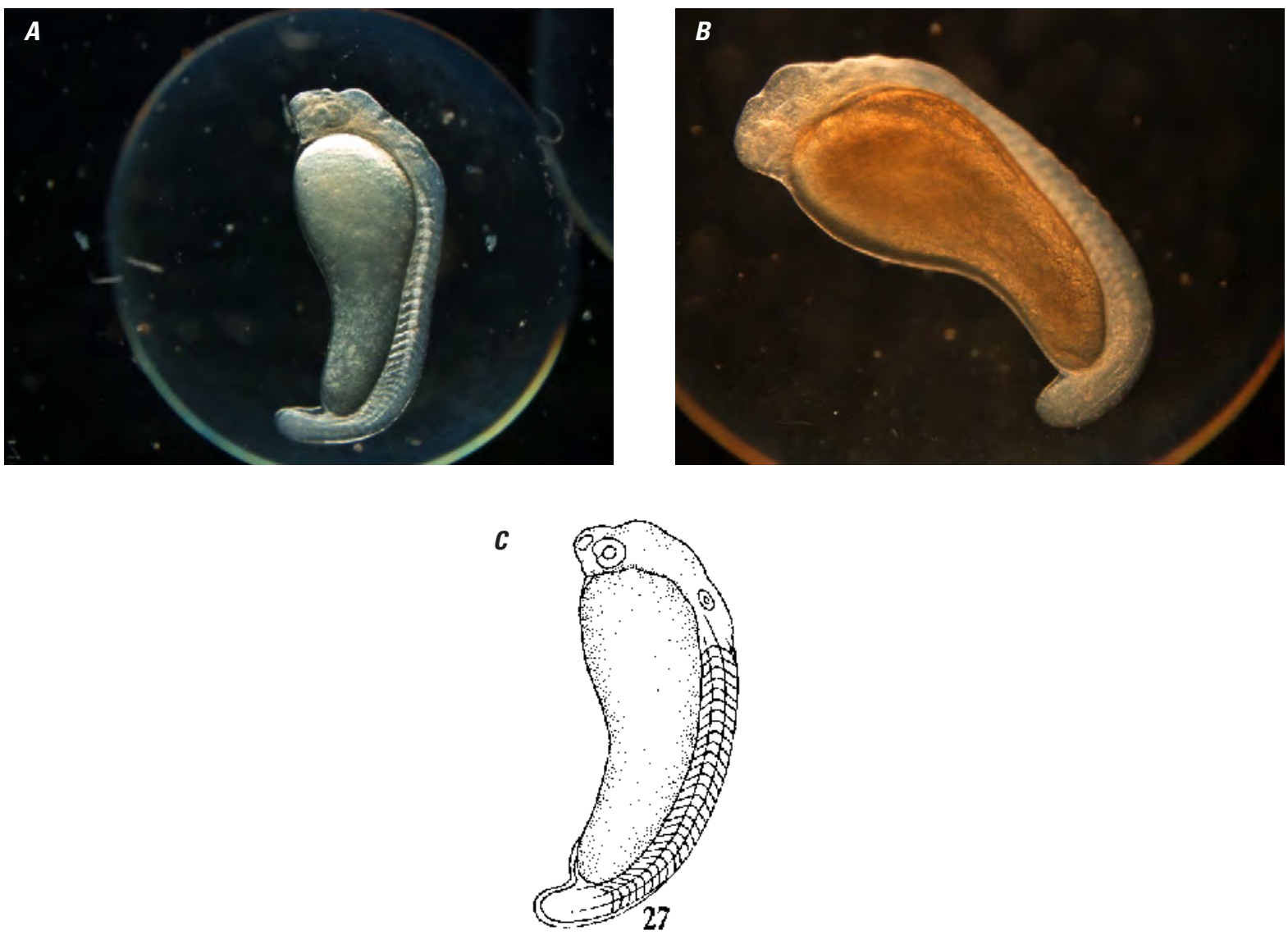

Figure 2-27. Stage 27: Muscular effect stage of silver carp development. Embryo elongating and lashing slightly. Tail vesicle disappears. Bump on brain area enlarged though not highly raised. End of yolk colorless, 26-28 pairs of somites present ( $Y i$ and others 1988). A, Live specimen, low temperature treatment, 31:03 post fertilization, picture taken with 30x magnification. $B$, Preserved specimen, high temperature treatment, 21:24 post fertilization, picture taken with 40x magnification. $C$, Line drawing of muscular effect stage from Yi and others (1988).

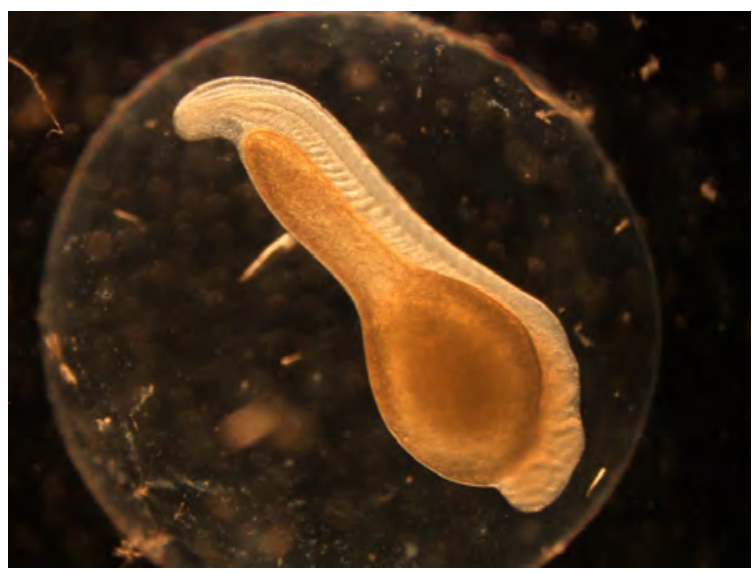

Figure 2-28. Stage 28: Heart rudiment stage of silver carp development. Heart rudiment appears. Occasional lashing, 25-30 pairs of somites present (Yi and others, 1988). Preserved specimen, high temperature treatment, 23:02 post fertilization, picture taken with $30 x$ magnification. 

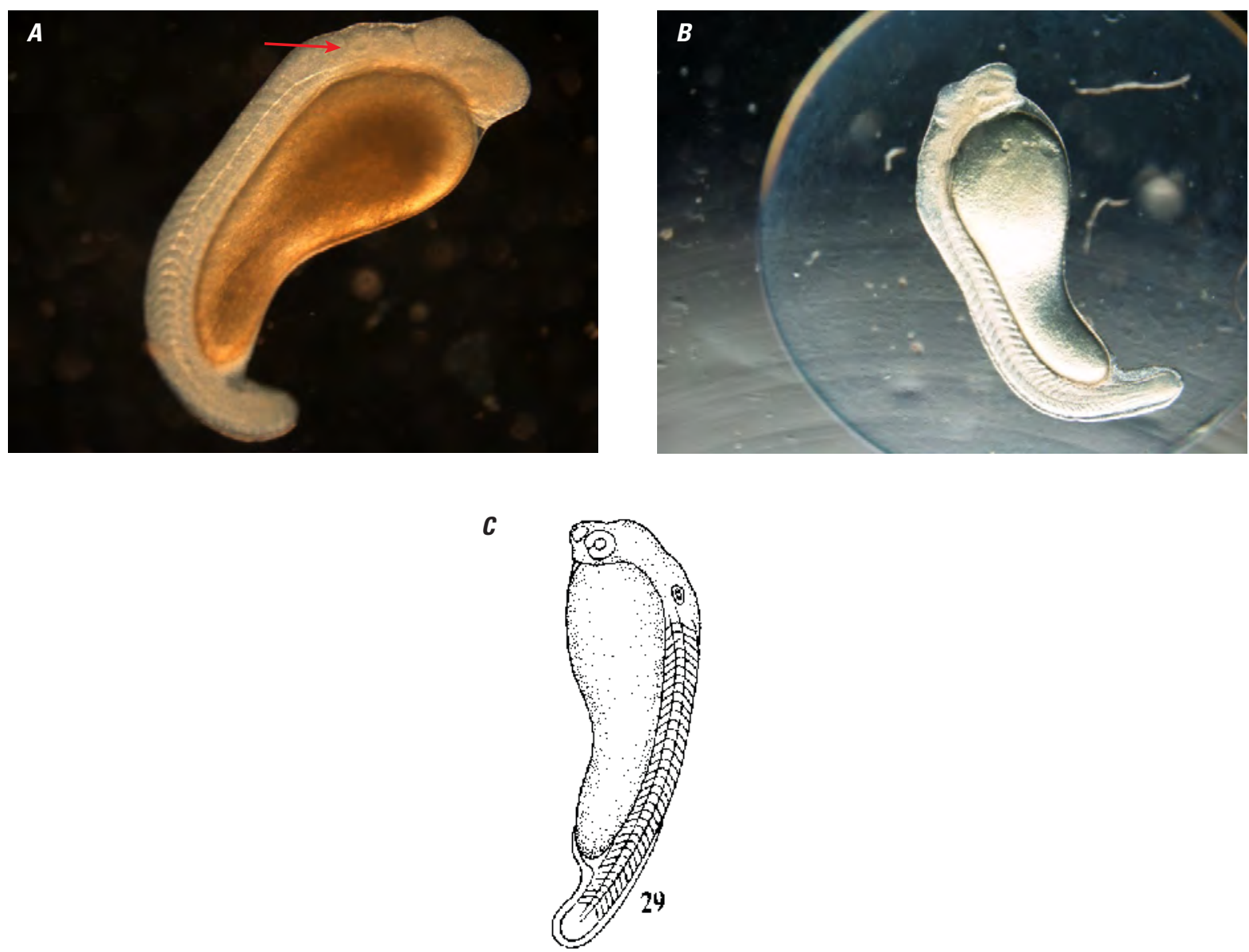

Figure 2-29. Stage 29: Otolith appearance stage of silver carp development. Embryo elongates further, moves continuously. Otolith appears, 31-35 pairs of somites present. (Yi and others, 1988). A, Preserved specimen, low temperature treatment, 31:29 post fertilization, picture taken with 40x magnification. Arrow points to otoliths. $B$, Live specimen, high temperature treatment, 23:29 post fertilization, picture taken with 30x magnification. $C$, Line drawing of otolith appearance stage from Yi and others (1988).
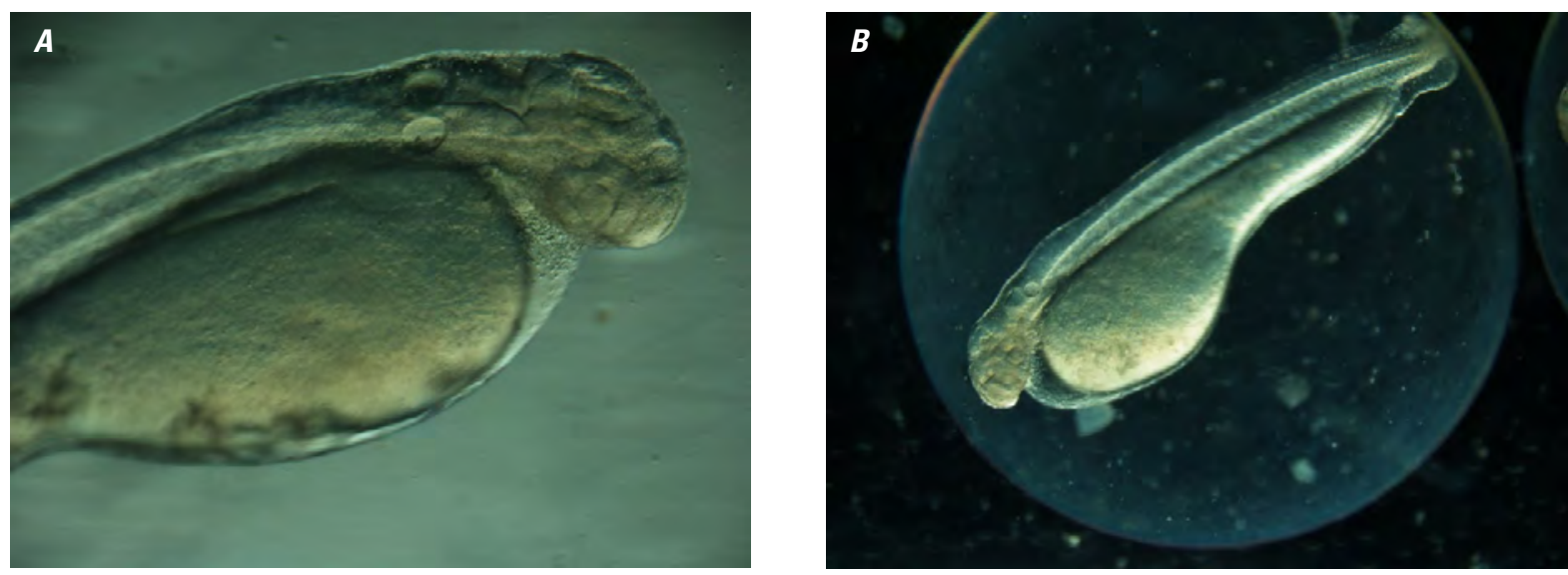

Figure 2-30. Stage 30: Heart pulsation stage of silver carp development. Heart pulsates, embryo rotates. Egg membrane softens, 36-37 pairs of somites present. Ready to hatch (Yi and others, 1988). A, Preserved specimen, low temperature treatment, 42:34 post fertilization, picture taken with $70 x$ magnification. $B$, Preserved specimen, low temperature treatment, 44:03 post fertilization, picture taken with 30x magnification. 

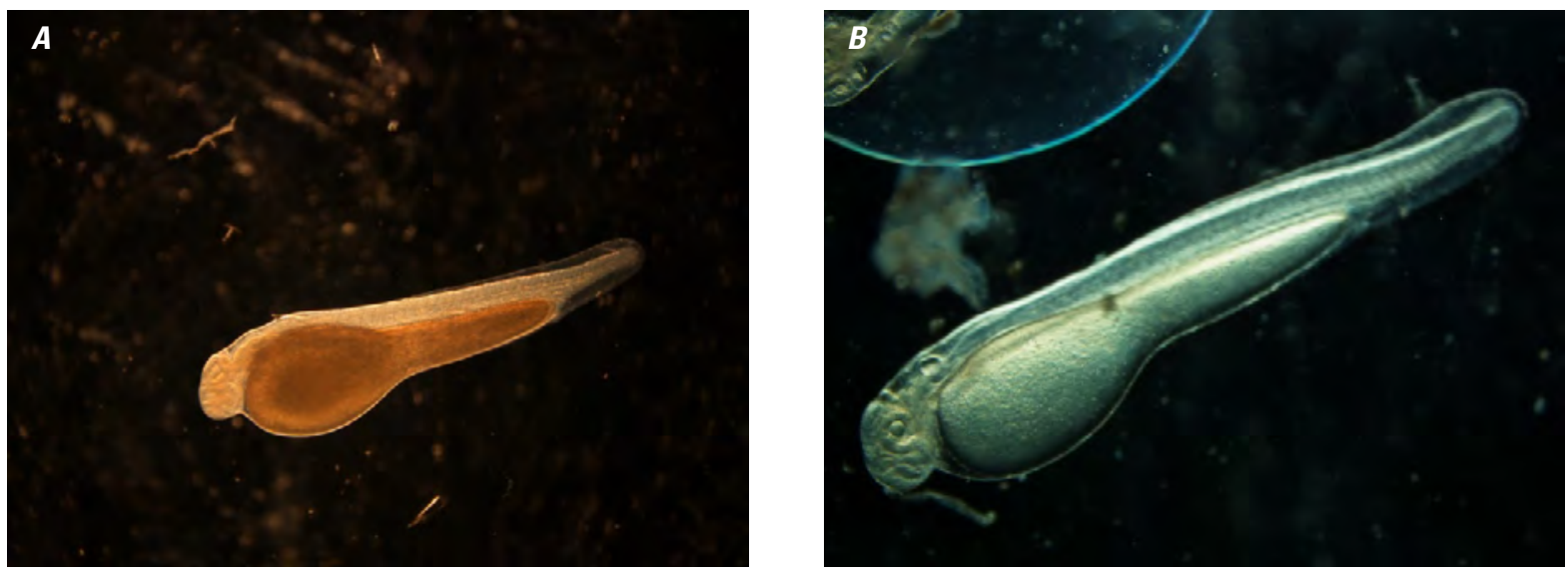

C

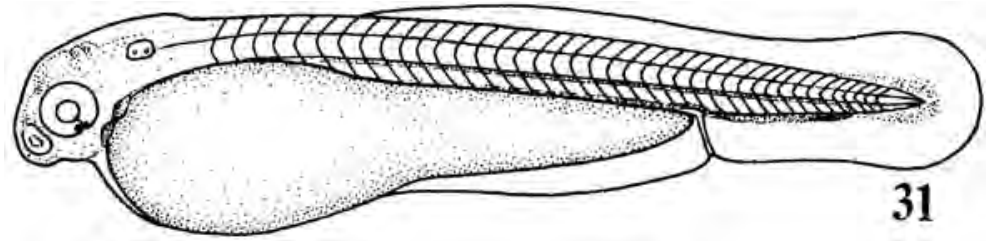

Figure 2-31. Stage 31: Hatching stage of silver carp development. The larvae is approximately 6.1 millimeters; caudal vein not obvious. Small otic capsule, 39 myomeres (Yi and others, 1988). The black spot below eye was not apparent until stage 32. $A$, Preserved specimen, high temperature treatment, 29:00 post fertilization, picture taken with 20x magnification. $B$, Live specimen, low temperature treatment, 45:17, picture taken with 30x magnification. $C$, Line drawing of hatching stage from Yi and others (1988).
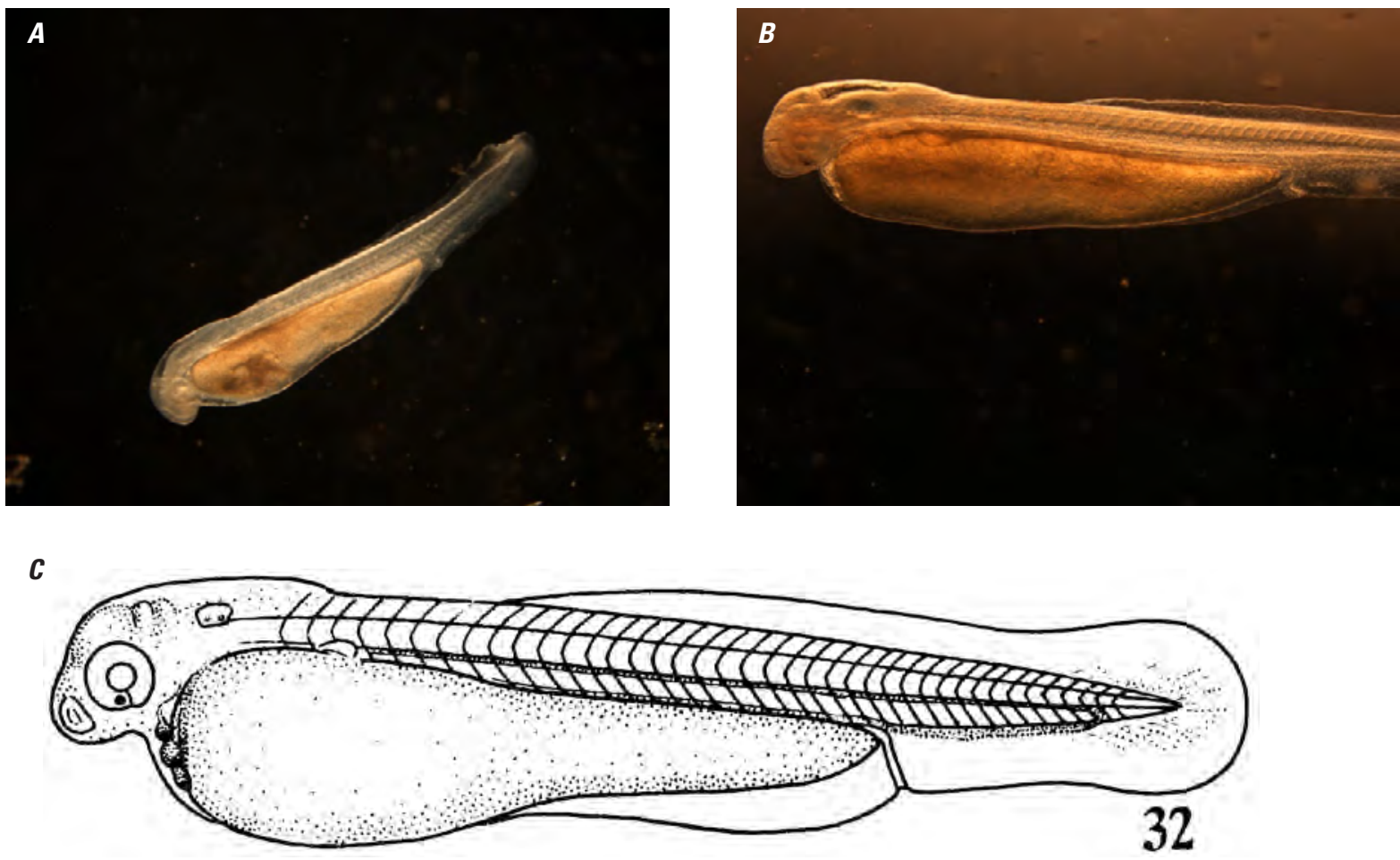

Figure 2-32. Stage 32: Rudimentary pectoral fin stage of silver carp development. The larvae are approximately 6.3 millimeters; rudimentary pectoral fin appears, 39 myomeres (Yi and others, 1988). A, Preserved specimen, high temperature treatment, 41:37 post fertilization, picture taken with 20x magnification. $B$, Preserved specimen, low temperature treatment, 60:22 post fertilization, picture taken with 30x magnification. $C$, Line drawing of rudimentary pectoral fin stage from $\mathrm{Yi}$ and others (1988). 

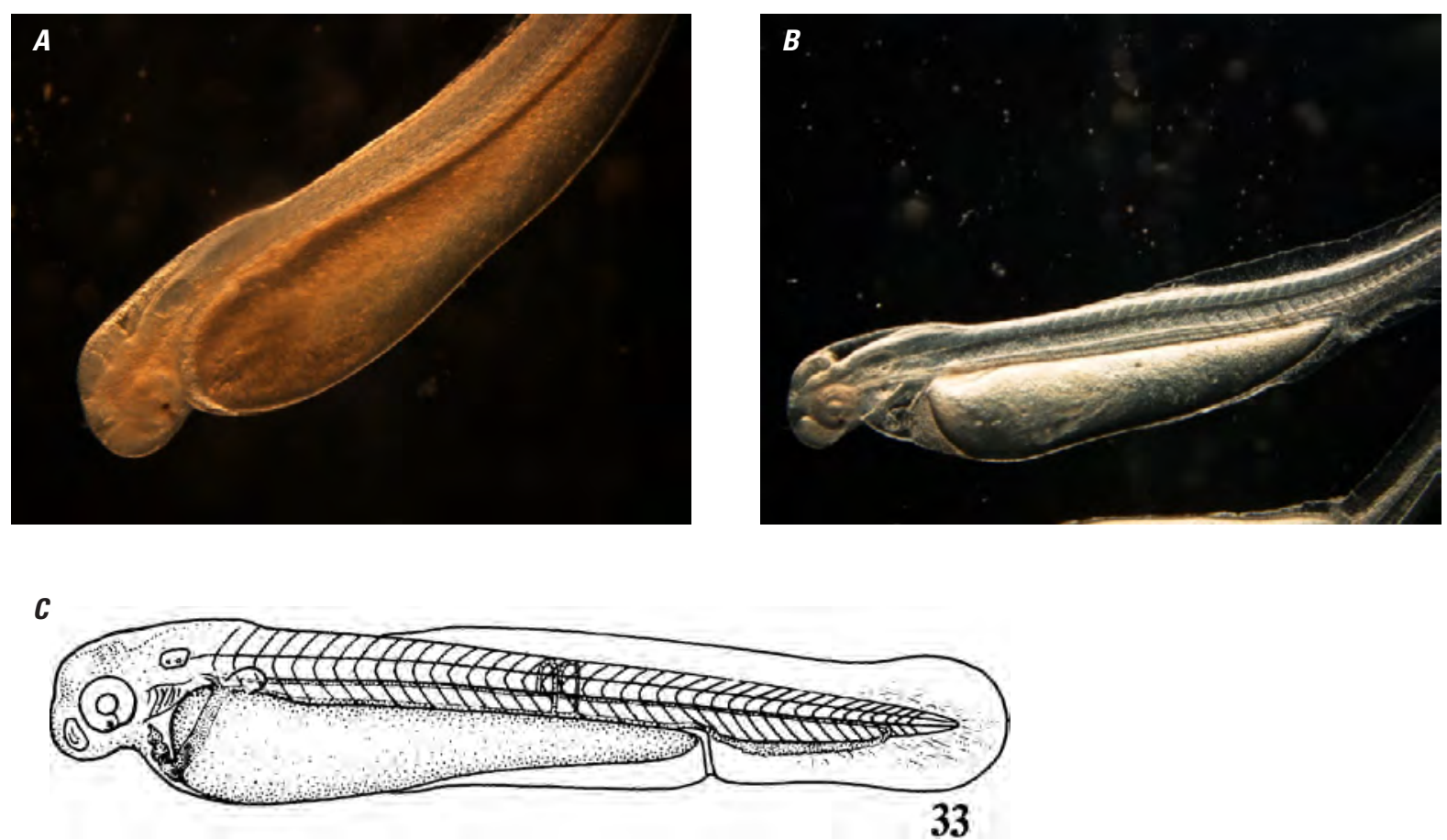

Figure 2-33. Stage 33: Gill arch stage of silver carp development. The larvae are approximately 6.83 millimeters; cuverian ducts on front side of yolk sac. Shrinking yolk sac, 40 myomeres (Yi and others, 1988). A, Preserved specimen, high temperature treatment, 45:06 post fertilization, picture taken with 40x magnification. $B$, Live specimen, high temperature treatment, 49:06 post fertilization, picture taken with 30x magnification. $C$, Line drawing of gill arch stage from Yi and others (1988).

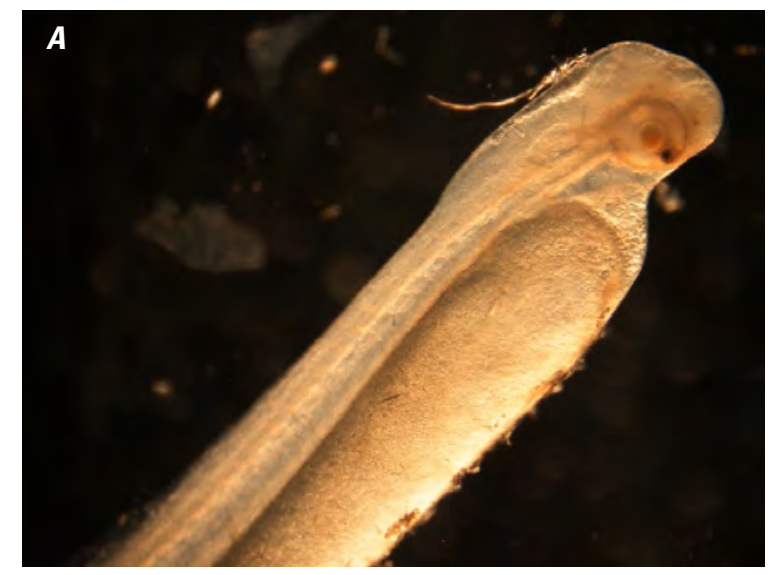

B

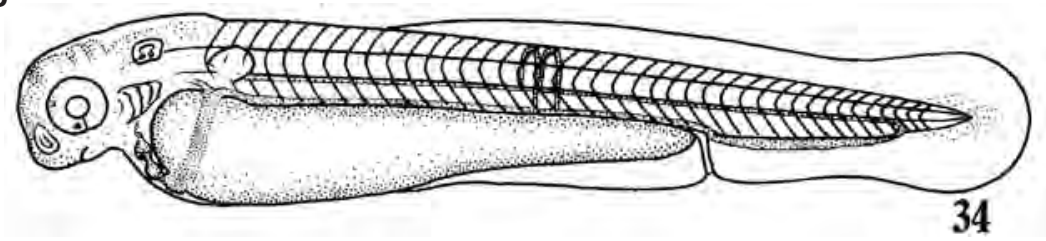

Figure 2-34. Stage 34: Xanthic eye stage of silver carp development. The larvae are approximately 7.2 millimeters; yellow pigmentation of eye appears, indentation of mouth, 40 myomeres (Yi and others, 1988). A, Preserved specimen, high temperature treatment, 53:53 post fertilization, picture taken with $40 \mathrm{x}$ magnification. $B$, Line drawing of xanthic eye stage from $Y i$ and others (1988). 

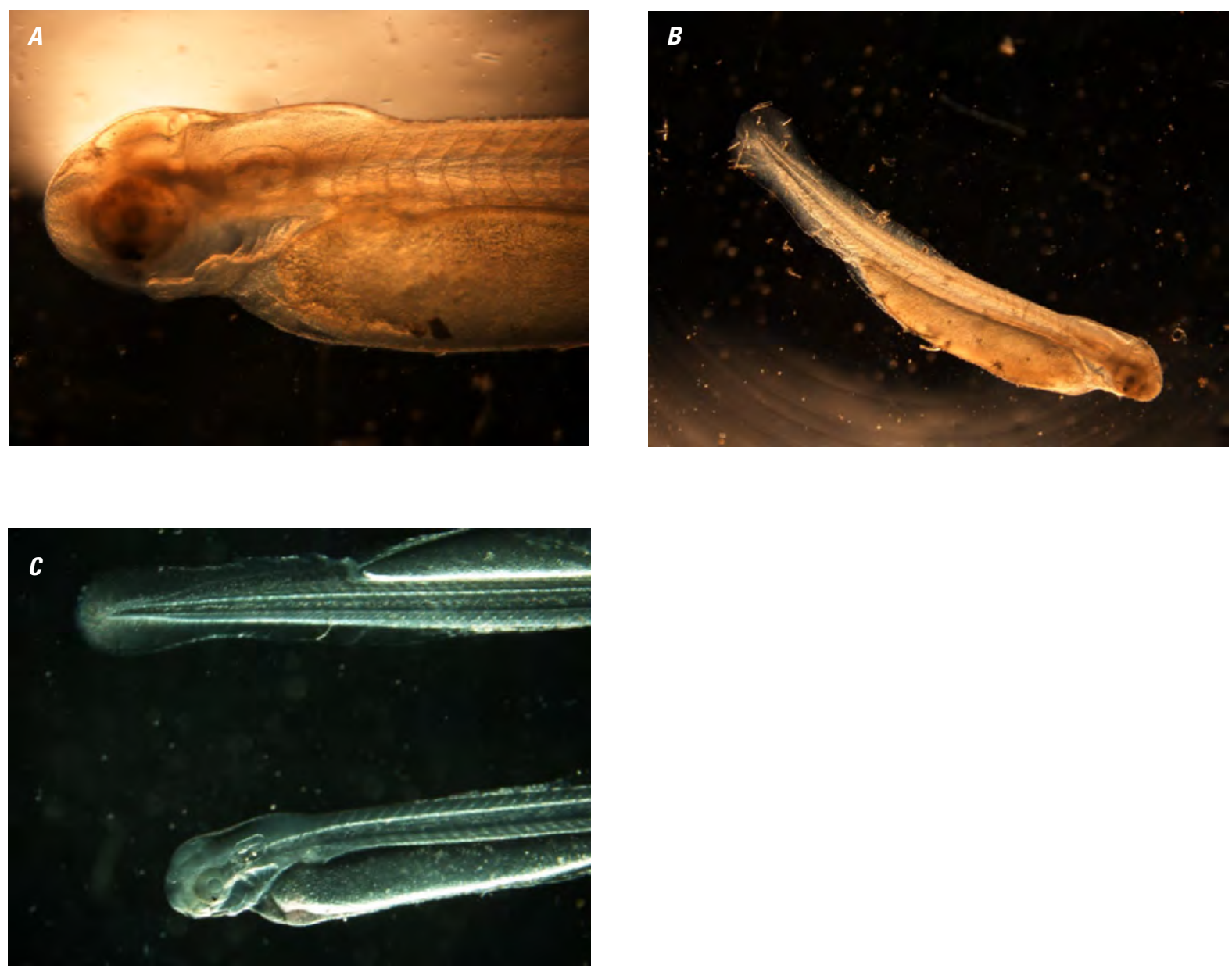

D

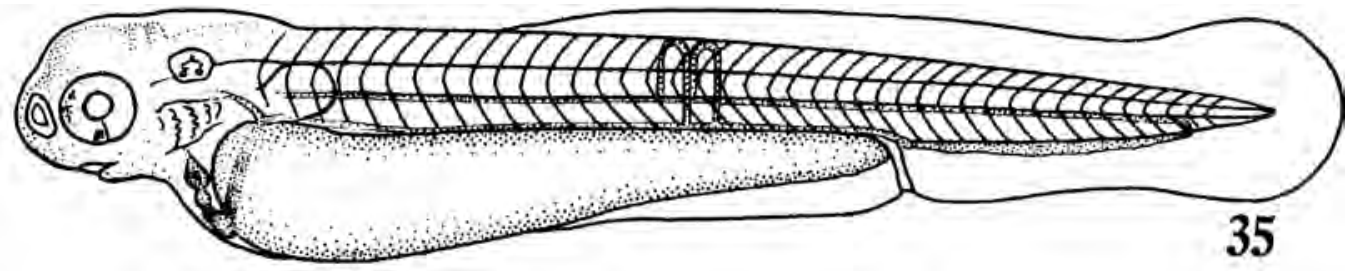

Figure 2-35. Stage 35: Gill filament stage of silver carp development. The larvae is approximately 7.5 millimeters, gill filaments extended. Melanophores increase, lower jaw movement begins ( $\mathrm{Yi}$ and others, 1988). A, Preserved specimen, high temperature treatment, 70:45 post fertilization, $6 \mathrm{x}$ magnification. $B$, Preserved specimen, low temperature treatment, 94:43 post fertilization, picture taken with 20x magnification. $C$, Live specimen, high temperature treatment, 60:31 post fertilization, picture taken with 30x magnification. $D$, Line drawing of gill filament stage from $Y i$ and others (1988). 

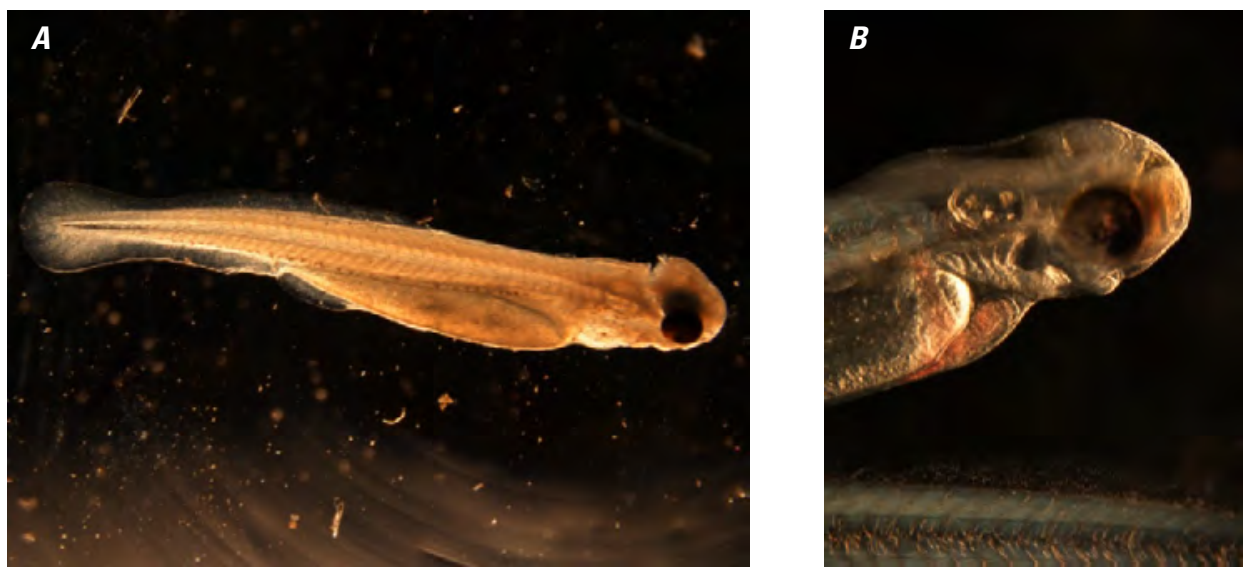

$\boldsymbol{C}$

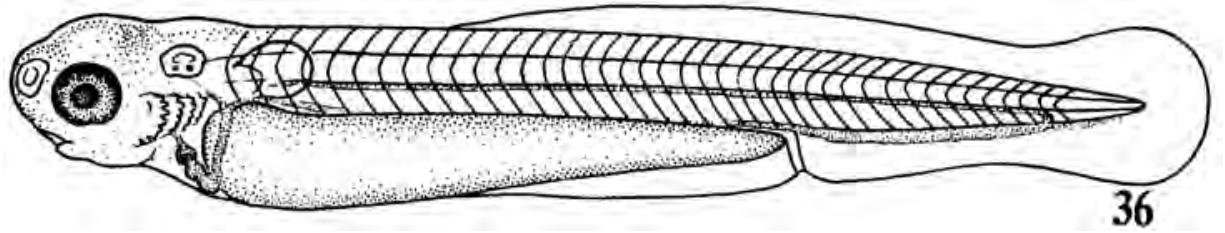

Figure 2-36. Stage 36: Melanoid eye stage of silver carp development. Melanophores all around the eye, otic capsule enlarges, mouth moves forward (Yi and others, 1988). $A$, Preserved specimen, low temperature treatment, 127:55 post fertilization, picture taken with 20x magnification. $B$, Live specimen, high temperature treatment, 70:45 post fertilization, picture taken with 60x magnification (not completely developed). $C$, Line drawing of melanoid eye stage from Yi and others (1988). 

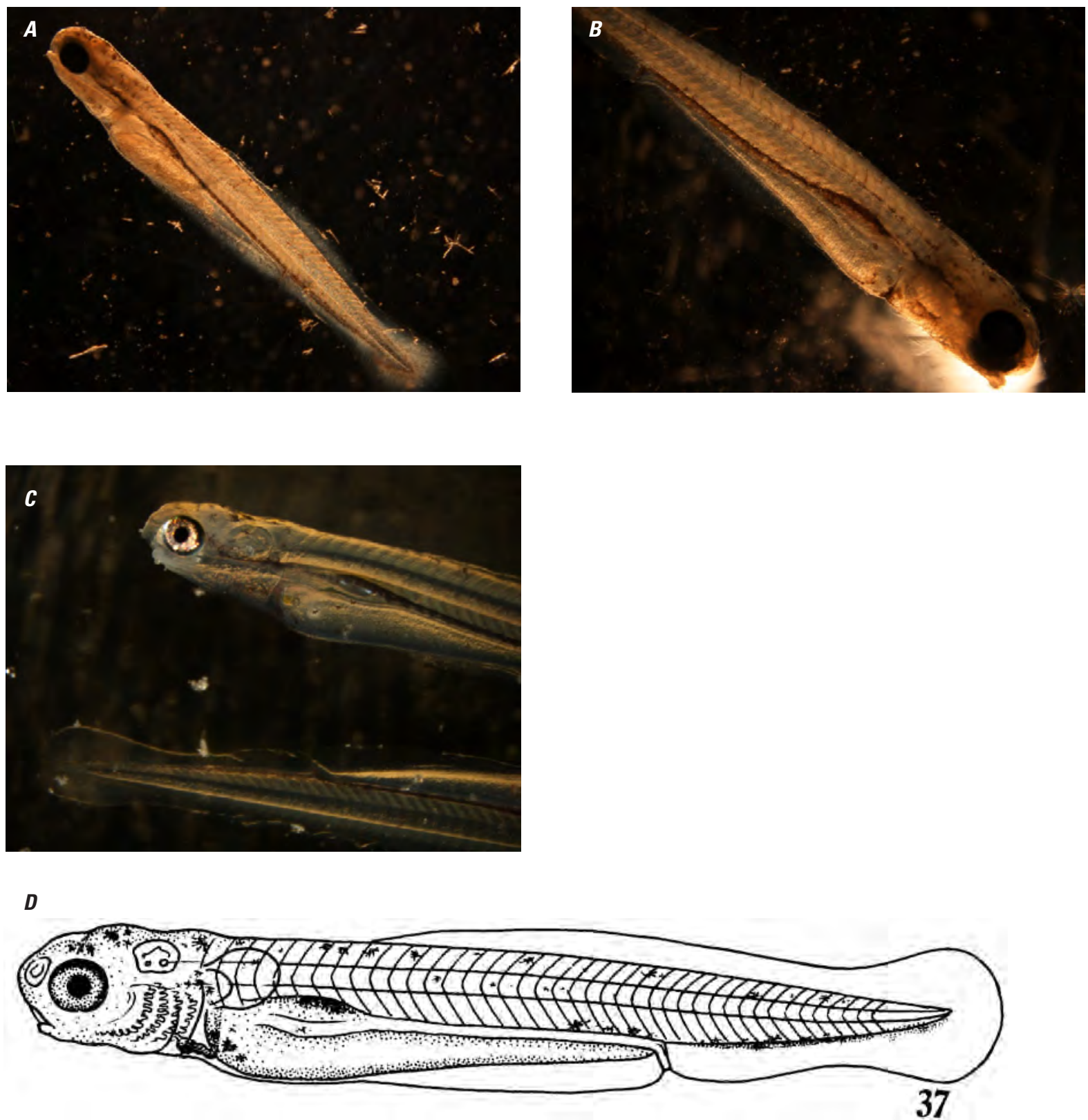

Figure 2-37. Stage 37: Gas bladder emergence stage of silver carp development. The larvae is approximately 8.2 millimeters. Gas bladder begins to appear. Melanophores on gas bladder. Gut is continuous. Yolk sac is thin strip (Yi and others, 1988). $A$, Line drawing of gas bladder emergence stage from Yi and others (1988). B, Preserved specimen, low temperature treatment, 174:30 post fertilization, picture taken with 20x magnification. $C$, Preserved specimen, high temperature treatment, 127:55 post fertilization, picture taken with 30x magnification. $D$, Live specimen, high temperature treatment, 109:00 post fertilization, picture taken with 30x magnification. 

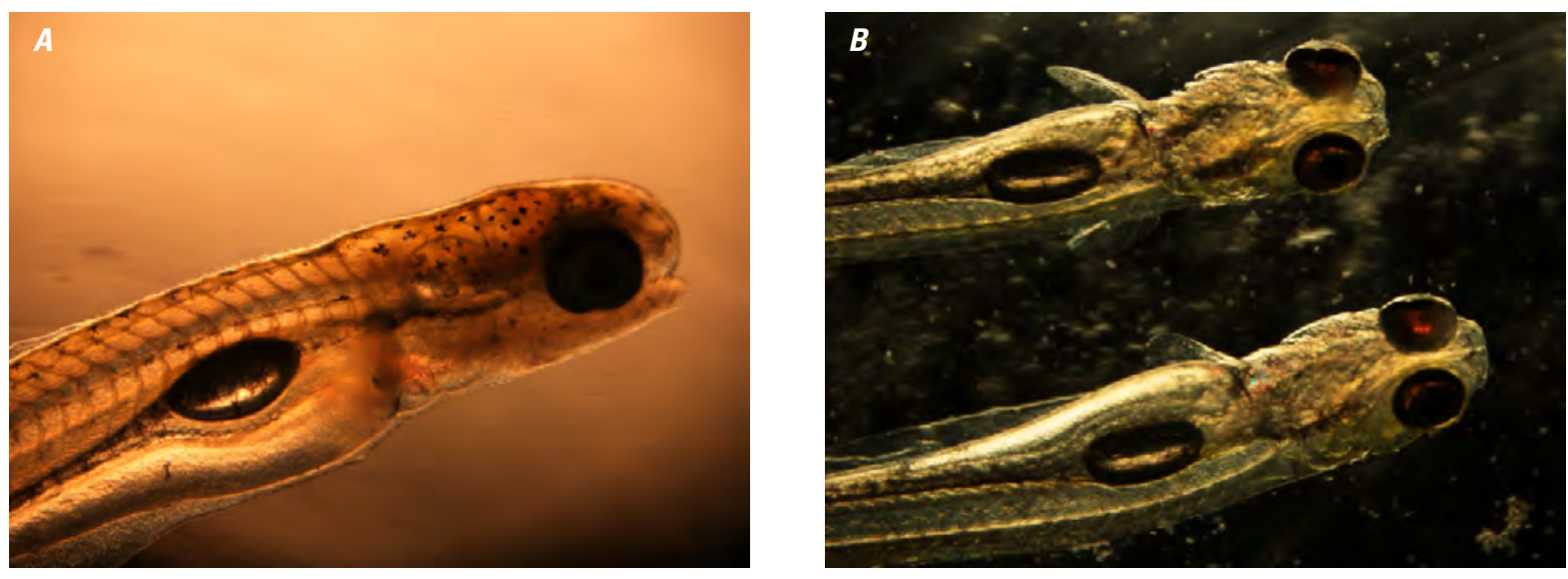

\section{C}

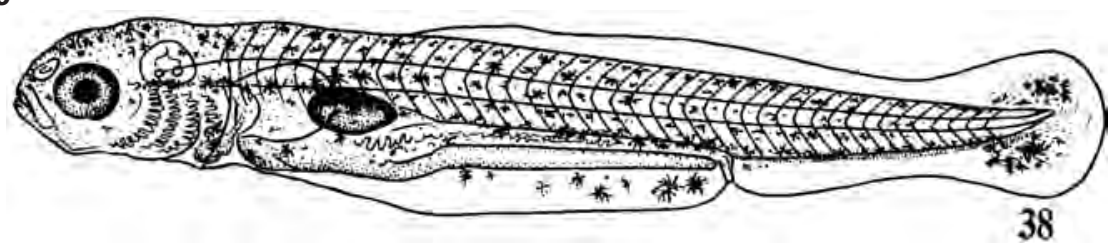

Figure 2-38. Stage 38: 1-chamber gas bladder stage of silver carp development, 40 myomeres, gas bladder oval shaped, terminal mouth, very little yolk sac remains. Greater pigment density (Yi and others, 1988). A, Preserved specimen, low temperature treatment, 191:14 post fertilization, picture taken with 40x magnification. $B$, Live specimen, high temperature treatment, $136: 40$ post fertilization, picture taken with 30x magnification. $C$, Line drawing of one chamber gas bladder stage from Yi and others (1988).
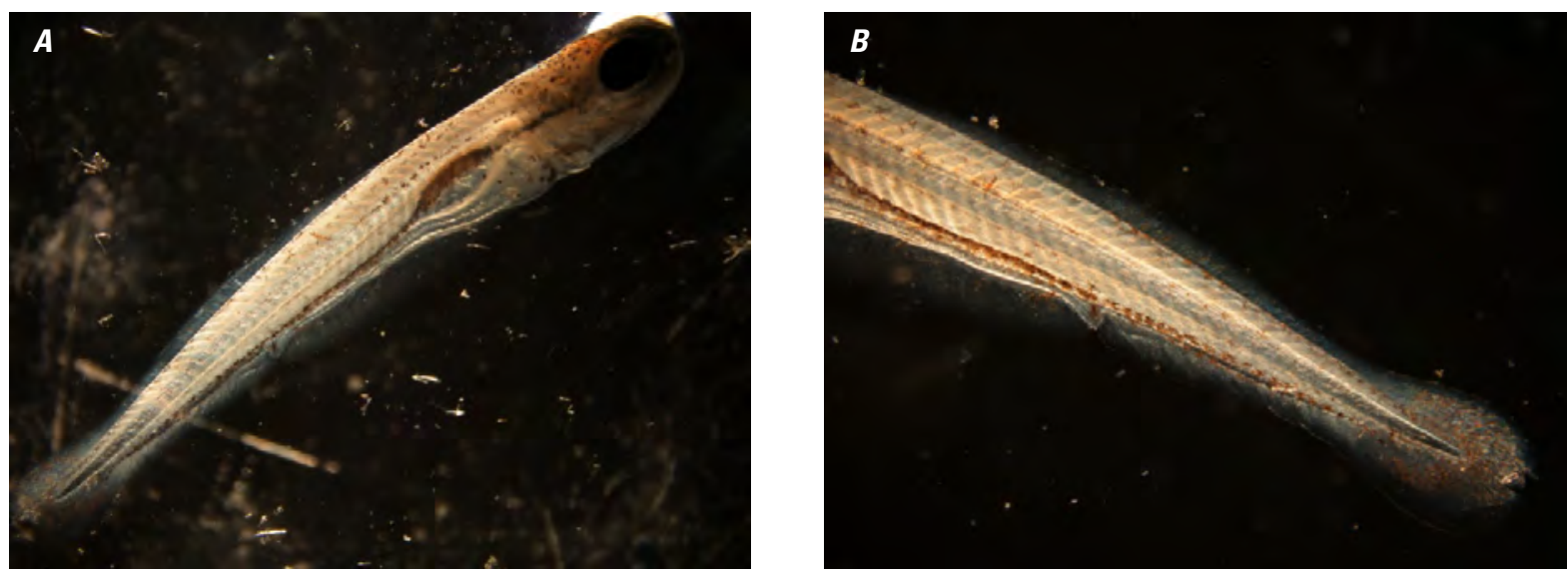

Figure 2-39. Stage 39: Yolk absorption stage of silver carp development. The larvae is approximately 8.7 millimeters; yolk sac exhausted; melanophores become darker and denser (Yi and others, 1988). A, Preserved specimen, high temperature treatment, 168:17 post fertilization, picture taken with 20x magnification. $B$, Preserved specimen, high temperature treatment, 168:17 post fertilization, picture taken with 30x magnification (melanophore detail). 


\section{Abnormalities}
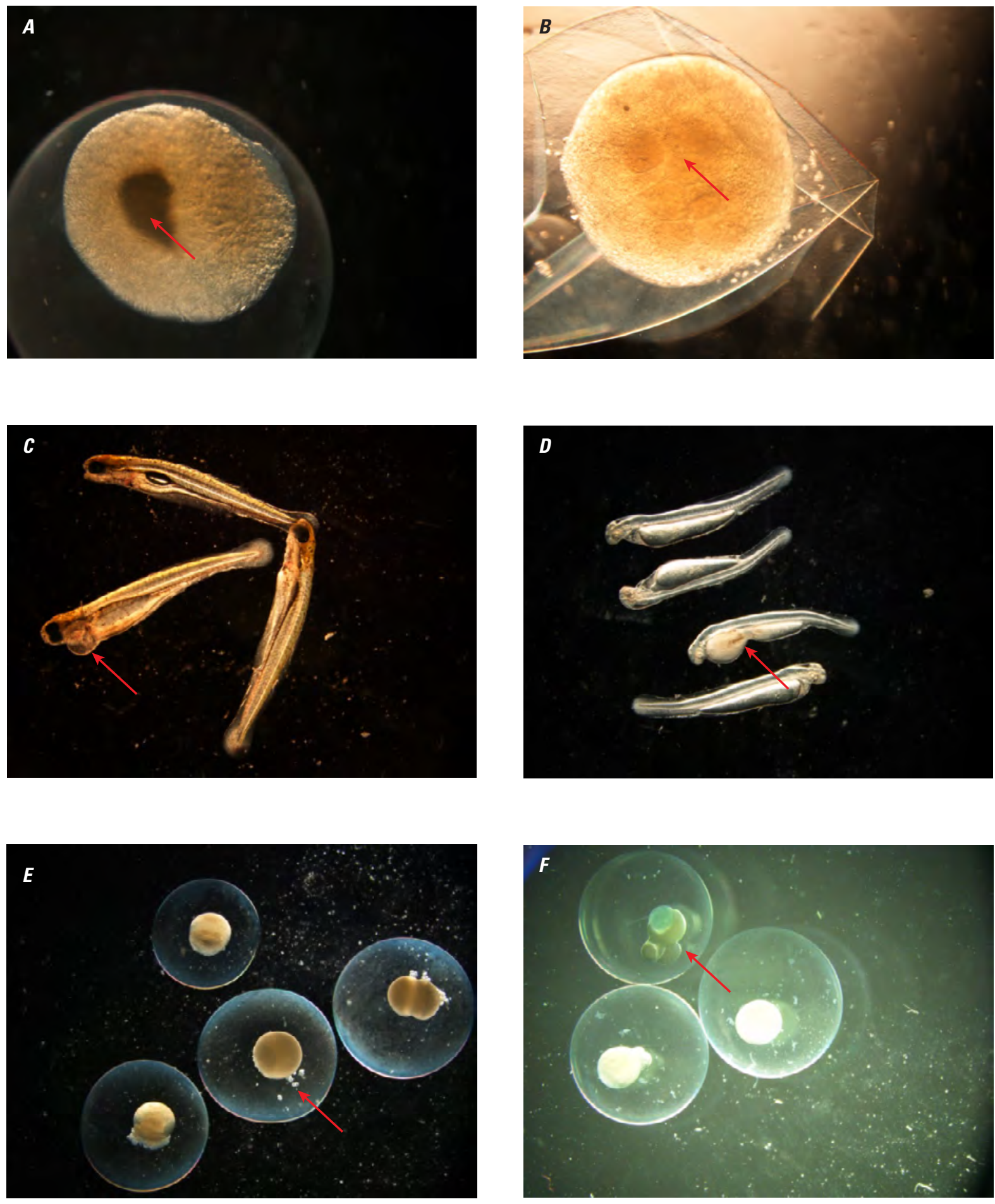

Figure 2-40. Developmental abnormalities of silver carp. $A$, Dark spots on yolk. $B$, Improper cell division (7 cell). $C$, Air bladder abnormalities. $D$, Yolk sac abonormality. $E$, Cells detached from embryo. $F$, Abnormal cell development. 
Publishing support provided by:

Rolla Publishing Service Center

For more information concerning this publication, contact:

Director, USGS Columbia Environmental Research Center

4200 New Haven Road

Columbia, MO 65201

(573) 875-5399

Or visit the Columbia Environmental Research Center Web site at: http://www.cerc.usgs.gov/ 

